\title{
Mapping the parameter space for direct-spun carbon nanotube aerogels
}

Lee Weller*, Fiona R. Smail*/**, James A. Elliott, Alan H. Windle, Adam M. Boies** and Simone Hochgreb

Advanced Nanotube Application and Manufacturing Initiative (ANAM), Department of Engineering, University of Cambridge,

Trumpington Street, Cambridge, CB2 1PZ, UK

* These authors contributed equally to this work

**Corresponding authors: Email : frs25@cam.ac.uk,amb233@cam.ac.uk

\begin{abstract}
Industrial-scale use of carbon nanotube (CNT) materials and prototype development is limited by availability of economic, high throughput production methods. Recent investigations have demonstrated the feasibility of producing direct-spun macroscopic CNT materials via floating catalyst chemical vapour deposition. However, few quantitative results have been reported regarding process yield and correlations with product quality. Validation of results is therefore challenging as identification of the key fundamental process parameters is hindered. This first meta-analysis quantifies atomic input rates and correlates them with product outputs to map the current parameter space of 55 successful conditions leading to spinnable aerogels. All mapped processes fall within a bulk residence time of $5-240 \mathrm{~s}$, operating temperature of $1100-1500{ }^{\circ} \mathrm{C}$ and an atomic $\mathrm{S}:$ Fe of 0.1-10. Low (high) S/Fe ratios favour single (multi)-wall CNTs in the direct-spun product. A high atomic carbon dilution, only $3 \%$ of the input atoms being $\mathrm{C}$, is a common feature across many systems. Furthermore, we connect the findings to known catalyst and product growth behaviour, as well as the thermodynamics of intermediates, to create an emerging picture of direct-spun CNT product formation. Elucidation of the most important factors influencing material synthesis, and the relationships between them, provides opportunities for gains in industrial-scale synthesis.
\end{abstract}

Keywords: Carbon Nanotube, CNT, Floating Catalyst Chemical Vapour Deposition, FCCVD, Aerogel, Synthesis, Macroscopic, Iron, Sulfur, Carbon

\section{Contents}

1 Introduction $\quad 2$

2 Methodology 5

$\begin{array}{lll}3 & \text { Reactor operating conditions } & 7\end{array}$

4 Catalyst nanoparticles and additives $\quad 9$

$\begin{array}{llr}5 & \text { CNT growth } & 15\end{array}$

6 Summary of process and conclusions $\quad 19$

$\begin{array}{lll}7 & \text { Challenges and opportunities } & 20\end{array}$

8 Acknowledgements and supporting information $\quad 21$

9 Appendix A : Experimental conditions 21

10 Appendix B : Fe-S and Fe-C binary phase diagrams 22 


\section{Introduction}

The desire to harness the superior qualities of carbon nanotubes (CNTs) in macroscopic materials continues to drive exploration and optimisation of assembly methods. The experimentally measured Young's modulus and tensile strength of single walled carbon nanotubes (SWCNTs) have reached $970 \mathrm{GPa}$ and $45 \mathrm{GPa}$ [1], respectively ${ }^{1}$. With electrical conductivities as high as $10^{8} \mathrm{~S} \mathrm{~m}^{-1}$ [3], coupled with densities seven times lower than copper, they are highly attractive for electrical applications in various sectors. The high individual CNT thermal conductivities, measured at over $2000 \mathrm{~W} \mathrm{~m}^{-1} \mathrm{~K}^{-1}$ [4], around five times those of copper at room temperature, also open up opportunities for low mass, high thermal conductivity applications.

The first macroscopic CNT assemblies such as buckypapers (isotropic networks of CNTs created via filtration techniques), showed potential in filtration [5, 6, 7], desalination [8], prevention of biofouling [9] as well as in applications as diverse as fire retardants [10] and field emission [11]. However, the properties of CNT assemblies proved to be poor compared to individual CNTs, with tensile strengths of only up to $95 \mathrm{MPa}$ [12], relatively low electrical conductivity (e.g. $\left.6100 \mathrm{~S} \mathrm{~m}^{-1}[13]\right)$ and thermal conductivity $\left(5-20 \mathrm{~W} \mathrm{~m}^{-1} \mathrm{~K}^{-1}\right.$ or up to $42 \mathrm{~W} \mathrm{~m}^{-1} \mathrm{~K}^{-1}$ [14] for unaligned and magneticallyaligned materials, i.e. where some anisotropy was introduced, respectively).

In the early 2000s, the discovery of four different methods for creating anisotropic assemblies of CNTs provided the first steps towards harnessing the individual CNT properties on a macroscopic scale, whereby aligning the CNTs maximises utilisation of the superior individual CNT properties along the axis of alignment. The first method, often referred to as "coagulation spinning", results in PVA-CNT composite fibres and ribbons. SWCNTs are dispersed in surfactants and the dispersion is injected through a fine capillary needle into a PVA solution. The capillary flow induces alignment of the CNTs while the PVA solution induces coagulation of the CNTs to create a condensed fibre. The fibres exhibited Young's moduli of 9-15 GPa which, while still orders of magnitude less than those of individual CNTs, demonstrated a vast improvement on the mechanical properties of buckypapers [15].

The three other innovative processes generate macroscopic, aligned, close to $100 \%$ CNT materials without the addition of polymer. Two of these processes are multi-step, starting from either the solubilisation of individual CNTs in a superacid ("wet-spun" products from solutions) or the controlled growth of a dense forest of individual CNTs on a substrate which are then drawn or twisted into film or fibre ("forest-spun" mats and yarns from arrays). Acid-solubilised individual CNTs form a liquid crystal-like phase and are

\footnotetext{
${ }^{1}$ For milimetre-long multi-wall carbon nanotubes (MWCNTs), the experimentally measured Young's modulus and tensile strength are $35 \mathrm{GPa}$ and $0.85 \mathrm{GPa}$ [2], respectively.
}

converted into aligned CNT fibres using wet-spinning techniques, such as extrusion through a spinnaret into a coagulation bath [16]. The dry-drawing and twisting of a film of individual CNTs from a forest produces uniform fibres with well-defined twist angles [17] or film materials.

The final, one-step process is the floating catalyst chemical vapour deposition (FC-CVD) driven synthesis of "direct-spun" CNT aerogels [18], drawing on earlier papers pointing to CNT aerogel formation synthesis in closed reactor tubes [19, 20, 21, 22]. The decomposition of simple iron, sulfur and carbon precursors in a high temperature tubular furnace results in catalyst nanoparticles suspended in a buffer gas (principally $\mathrm{H}_{2}$ ) from which a high concentration of individual CNTs (typically of up to $15 \mathrm{~nm}$ diameter $[18,23,24,25,26])$ grow. The individual CNTs are attracted to one another via van der Waals dispersion forces, creating bundles (typically of 30-50 nm diameter $[27,28,29,30,31,32,24,27,23,33,34])$ while at the same time forming bundles entangled with one another, creating a continuous, mechanically cohesive CNT network, commonly referred to as an "aerogel".

While early reports estimated nanotube lengths to be of the order of hundreds of microns, and up to $1 \mathrm{~mm}$ [23], in most cases the segment lengths have not been measured. Recent work by Tran et al. [35] assessed CNT minimum lengths to be of the order of a few microns by oxidising direct-spun CNT samples, followed by solubilisation them in chlorosulfonic acid. Bulmer et al. [36] determined a length of about 10 microns between CNT defects in direct-spun samples and offered that these defects could be interpreted as ends of tubes in very pure samples. These minimum values are still significantly longer than the lengths of individual CNTs found in high-purity commercial samples such as HiPco $188.3(0.29 \mu \mathrm{m})$, HiPco 183.6 $(1.51 \mu \mathrm{m})$, SWeNT CG300 $(0.71 \mu \mathrm{m})$, and UniDym OE (1.92 $\mu \mathrm{m})$ [37].

The aerogel can be extracted from the furnace system and collected on a bobbin. The aerogel can either be treated in-line with a solvent, where capillary action causes condensation to form a thin microfibre ("directspun fibre"). Alternatively multiple layers of the uncondensed aerogel can be collected on a bobbin to create a sheet of CNT material ("direct-spun mat"), which can be treated with solvent to allow some condensation if required. The FC-CVD process is illustrated in Figure 1, which shows the input flows required for the synthesis, the types of output flows which can be recorded, and a schematic of the bundling mechanism which creates the aerogel, further illustrated by an example scanning electron microscope (SEM) image of a typical aerogel material.

The methods for producing macroscopic CNT materials have been refined since their initial inceptions, producing microfibres, mats and films with increasingly superior properties. Data in Figure 2 shows the mechanical, electrical and thermal properties of directspun materials up to early 2016 for thermal properties and early 2017 for the remainder, compared to 

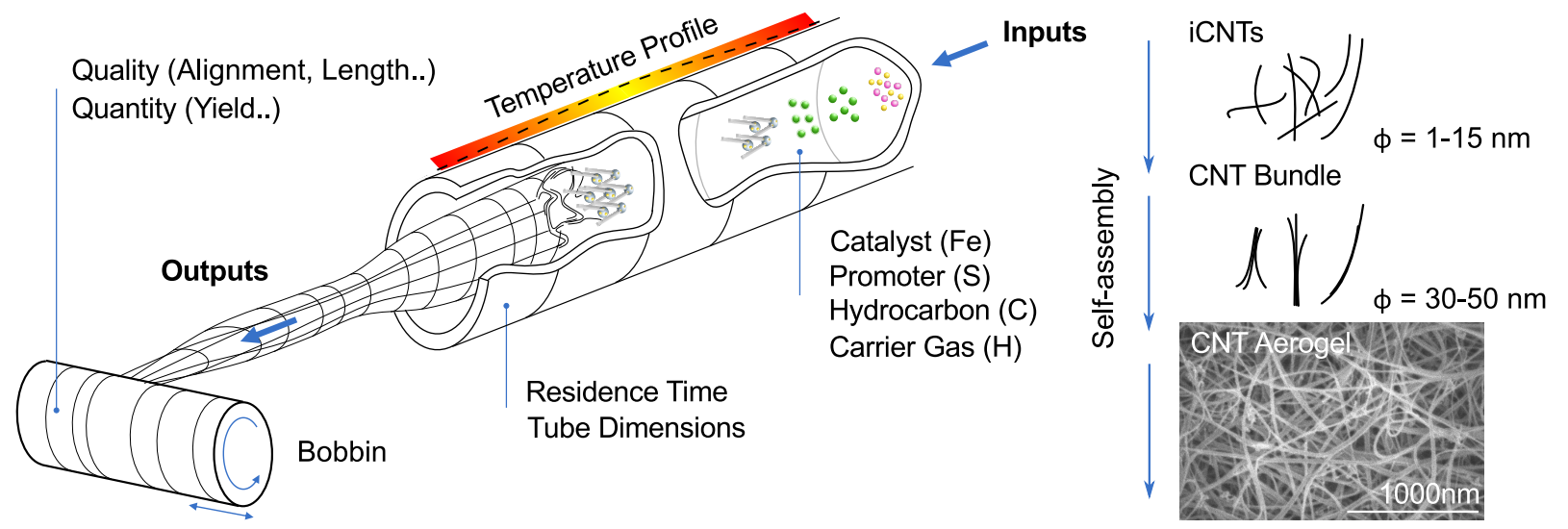

Figure 1: Schematic of the direct-spinning CNT process listing the parameters required for quantitative mapping and showing the self assembly of the macroscopic material from individual CNTs (typically 1-15 nm diameter) through bundles (typically 30-50 nm diameter) to a continuous aerogel. Input parameters required are catalyst, promoter, hydrocarbon and carrier gas and corresponding flow rates. Output parameters required are product quantity (mass, density) and quality (CNT alignment, hexagonal lattice uniformity, diameter, wall number, length of individual CNT and purity). This figure has been reproduced from [38] with permission of the corresponding authors.

other carbon materials and conventional high strength or high conductivity materials (aluminium, copper, silicon).

The properties of direct-spun materials compare very favourably to, and in some cases outperform, the established materials particularly when their low densities are considered. As shown in Figure 2, direct-spun fibres can reach Young's modulus values of $100 \mathrm{GPa}$ [39], tensile strengths of $3.75 \mathrm{GPa}$ [32], electrical conductivities of $2 \times 10^{6} \mathrm{~S} \mathrm{~m}^{-1}$ [32] and thermal conductivities of $95 \mathrm{~W} \mathrm{~m}^{-1} \mathrm{~K}^{-1}[40]^{2}$. More recent thermal conductivity data shows values up to $900 \mathrm{~W} \mathrm{~m}^{-1} \mathrm{~K}^{-1}$ for macroscopic direct-spun fibre samples $[42]^{3}$.

The combination of the current direct-spun product properties, combined with the relative simplicity of the direct-spun production method and the potential to improve properties further towards those of individual CNTs has, therefore, attracted significant industrial interest $[44,45]$ due to the wide range of fields where application of these materials might induce step changes in technologies. Various reviews and publications provide excellent summaries of applications of macroscopic CNT materials, including those from direct-spun production methods, covering areas such as electrical applications [46, 47, 48], composites [49, 50, 51, 52], synthesis [53], smart textiles [54, 55, 56] and improvement in strength [57].

Despite the relative maturity of the direct-spun process, reflected by the number of publications and research groups in the field, the numerous parameters of the process and different equipment setups means that reproducibility of results between research groups is challenging. Many of the publications offer empirical findings, and provide few quantitative relationships between all four important categories, namely reactant

\footnotetext{
${ }^{2} \mathrm{~A}$ value of $760 \mathrm{~W} \mathrm{~m}^{-1} \mathrm{~K}^{-1}$ has been measured for a directspun mat [41]

${ }^{3}$ Values as high as $1250 \mathrm{~W} \mathrm{~m}^{-1} \mathrm{~K}^{-1}$ have been measured on a sample of tens of microns in length [43]
}

inputs, output product characterisation, product yield and macroscopic product performance metrics. A few papers do provide more systematic data, linking reaction parameters with either a measured change in a product performance metric or with a change in product characterisation. For example, Li et al. [58] reported an increase in overall tensile strength for an increase in furnace temperature, which also correlated with an increase in the number of produced multiwall carbon nanotubes (MWCNTs) in comparison to SWCNTs. Likewise, Hou et al. [59] investigated the effect of temperature increase in direct-spun synthesis (1150$1500{ }^{\circ} \mathrm{C}$ ), and found a transition from majority SWCNTs, through to mainly MWCNTs in the CNT fibre, coupled with an increase in the rate of thermal pyrolysis and soot formation in the final product. Furthermore, the authors measured a two-fold increase in carbon yield (defined as in Section 5.3) from the lowest to highest temperatures. Finally, the authors tracked the change in electrical conductivity of the direct-spun product across the $1150-1500{ }^{\circ} \mathrm{C}$ temperature range, measuring the highest conductivity at $1400{ }^{\circ} \mathrm{C}$. The higher conductivity correlated with the change in CNT quality, as measured by the $I_{\mathrm{G}} / I_{\mathrm{D}}$ ratio in the Raman spectrum (see Section 2.2), in spite of the detrimental increase in impurities.

Macroscopic product qualities are characterised by performance metrics such as tensile strength, stiffness, electrical conductivity and thermal conductivity. For comparative purposes, these metrics need to be consistently normalised with respect to product density. In the case of $2 \mathrm{D}$ mat products, this requires use of areal density (in $\mathrm{g} \mathrm{m}^{-2}$ ) while the properties of direct-spun microfibres, which often show significant axial variation in their cross sectional area, are best described using units of $\mathrm{N}$ tex ${ }^{-1}$ [60] $\left(=10^{6} \mathrm{~N} \mathrm{~m} \mathrm{~kg}^{-1}\right.$, or numerically equivalent to a stress in GPa divided by bulk density in $\mathrm{g} \mathrm{cm}^{-3}$ ). In the case that all material dimensions are consistent and can be accurately measured then conventional bulk density values $\left(\mathrm{kg} \mathrm{m}^{-3}\right)$ can be used. 

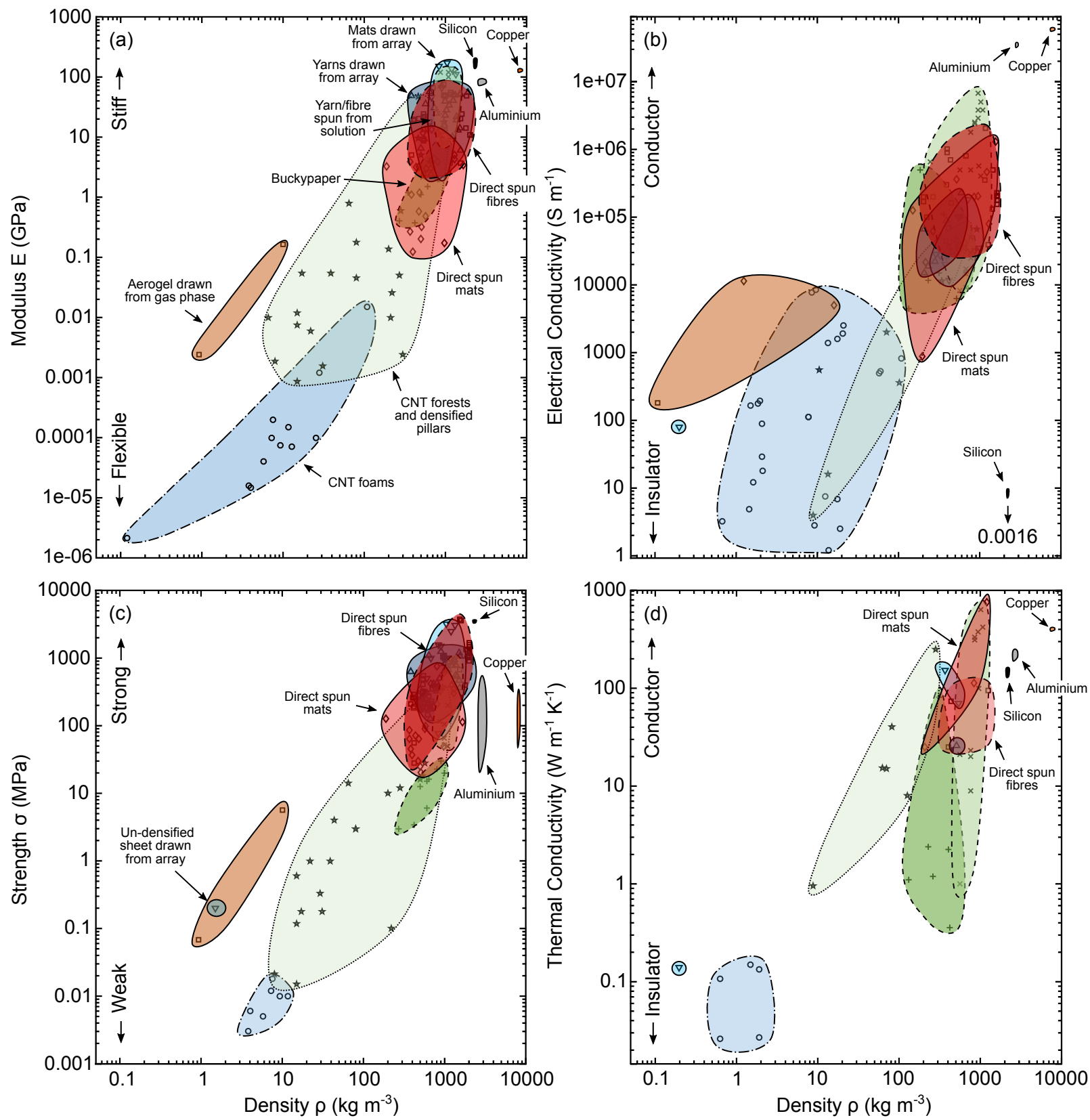

Figure 2: Macroscopic properties of various CNT materials compared with those of silicon, copper and aluminium plotted as a function of density. The properties highlighted are (a) Modulus, (b) electrical conductivity, (c) tensile strength and (d) thermal conductivity and are reproduced from [38] with permission of the corresponding authors. References for the experimental data used in these figures are included in the supplementary material of [38].

In this work, we collect all quantitative data available from the published literature in the field of directspun production via FC-CVD and simplify these down to molar input rates of the required elements to facilitate a direction comparison between them. By correlating the processed data with the main type of individual CNT that makes up the associated direct-spun product (correlation of reaction inputs with product characterisation) and, where possible, the direct-spun yield, we produce comprehensive maps of the current direct-spun synthesis parameter space.

By quantifying and comparing the limiting behaviour and parameter trends from the literature, we provide a broader understanding of factors affecting catalyst particle generation and activity, as well as carbon utilisation in the process and reaction yield. These findings provide a platform from which future research can quantitatively and systematically advance the state-of-the-art in a reproducible manner. We begin with a description of our methodology, followed by an analysis of critical features common to all directspun production experiments, before mapping parameters that principally influence catalyst nanoparticle formation and activity, followed by mapping parameters affecting CNT nucleation and growth. The analysis concludes with an overall process summary and by setting out challenges and opportunities for future research and large-scale CNT production. 


\section{Methodology}

\subsection{Data selection criteria}

The field of direct-spun literature contains upwards of 261 journal publications (as of July 2018) consisting principally of the following categories of paper: reviews (15), post processing and applications (140), material characterisation (66) and synthesis (40). The distribution of publications across the different categories is shown in Figure 3 (a), with the associated references list found in the supplementary information associated with Hoecker et al. [61] for papers through to late 2016 and in the caption for papers since then. Our analysis focuses on investigations which contained sufficient detail about the experimental data to allow quantitative analysis, consisting of 32 out of the 40 publications available. In cases where process data were incomplete, authors were directly contacted, or quantities were estimated by cross-referencing with other publications from the same author group.

The 32 publications were selected based on the availability of the following quantities: (a) reactant flow rates, (b) total bulk residence times, (c) direct-spun product type (SWCNT, DWCNT or MWCNT) associated with a given set of conditions, (d) additional details such as reactor material, reactor dimensions and product yield where available. Figure 3 (b) shows the distribution of publications according to the outlined criteria. An example analysis is given in Table 2 of Appendix 9 along with the common parameters defined across all studies.

The map of limiting conditions for the process of direct spinning is inherently composed of conditions which produce a stable aerogel that can be continuously extracted from a furnace and collected on a bobbin. Figure 4 shows the family tree of synthesis publications in the direct-spun field since 2004. Since there is clearly a great degree of heritability between groups, it is important to note that there may be other possible unexplored regions in the operating space that allow aerogel formation. The fact that negative results are rarely, if ever, published is a limitation to advancement of knowledge in the field.

The 32 publications generated a total of 55 discrete sets of experimental conditions and corresponding products. Where publications instead referred to a range of conditions rather than a discrete value for a given parameter, a mid-value has been selected as the data point, with the span of conditions indicated as range (not error) bars. The direct-spun product type (predominantly SWCNT, DWCNT or MWCNT) is associated with the mid-value. It is unclear from the literature whether the product associated with this mid-value can be made across the entire width of associated range conditions i.e. an alternative product type may be possible under conditions at the end of any particular range bar.

\subsection{Parameter measurement and characterisation}

Reactant inputs are usually quantified using volume or mass flow control methods, often coupled with vapour-pressure curve calculations in cases where reactants are being supplied as a vapour in a carrier gas from a heated or cooled source. At present, there are no reports of in-line, real time measurements of reactant supplies to support the vapour pressure data, and only occasionally are the calculations supported by a measurement of the total mass of a reactant supplied over the duration of the reaction. This means that, at best, the reactant input data for vaporised sources is an average value, and it assumes full vapour pressure equilibrium within the supply equipment at all times. In this paper, we have used the nominal mass flow rates where quoted, and calculated flow rates from material properties where needed. Further details on how inputs were processed are detailed in Appendix 9.

A wide portfolio of techniques are required to characterise the solid product, as no single method supplies sufficient information. Measurements of product purity (i.e. quantity of non-carbonaceous materials in the product), uniformity of the hexagonal lattices comprising the CNT walls (sometimes referred to as "crystallinity"), CNT type and the degree of anisotropy (i.e. orientational order of tubes) within the product are typical characterisation metrics.

Analyses of Scanning and Transmission Electron microscopy (SEM, TEM) images are used to determine relative proportions of SWCNTs, double-wall CNTs (DWCNTs) and MWCNTs in a sample. Fouriertransformed SEM images can be used to quantify the degree of anisotropy [79]. X-ray scattering techniques (Small Angle and Wide Angle scattering) can offer data on anisotropy and the purity of the constituent CNTs [172]. Raman spectroscopy is often used as a measure of quality, where the ratio of the Defect (D) and Graphitic $(\mathrm{G})$ peak heights or areas $\left(I_{\mathrm{G}} / I_{\mathrm{D}}\right.$ ratio $)$ is a commonly used metric. Raman scattering of samples shows the presence of SWCNTs in a sample, indicated by Radial Breathing Mode (RBM) peaks, which can also be used to determine SWCNT diameters and, with the use of Kataura plots, whether CNTs of a particular diameter are metallic or semiconducting as well as their chirality. EDX/XPS (Energy Dispersive X-ray / X-ray photoelectron spectroscopy) has been used to confirm the CNT composition, surface chemistry and other similar properties for the catalyst nanoparticles. In addition, specific surface area and micropore size distributions can also be measured using a gas sorption analyzer. A number of reports in the direct-spun field give empirical relationships between reactant supply rates and trends in product characteristics, for example various empirical studies $[170,160]$ have shown how product quality and CNT type can be changed by altering process parameters and reactant stoichiometry.

Process yield and carbon conversion are measured via a combination of simple mass calculations (mass of reactants supplied per unit time divided by mass of product collected per unit time) and thermogravimetric analysis (TGA). The method quantifies amorphous (i.e. non-CNT) carbon mass, total CNT mass and metals content but must be treated with caution when 
(a)

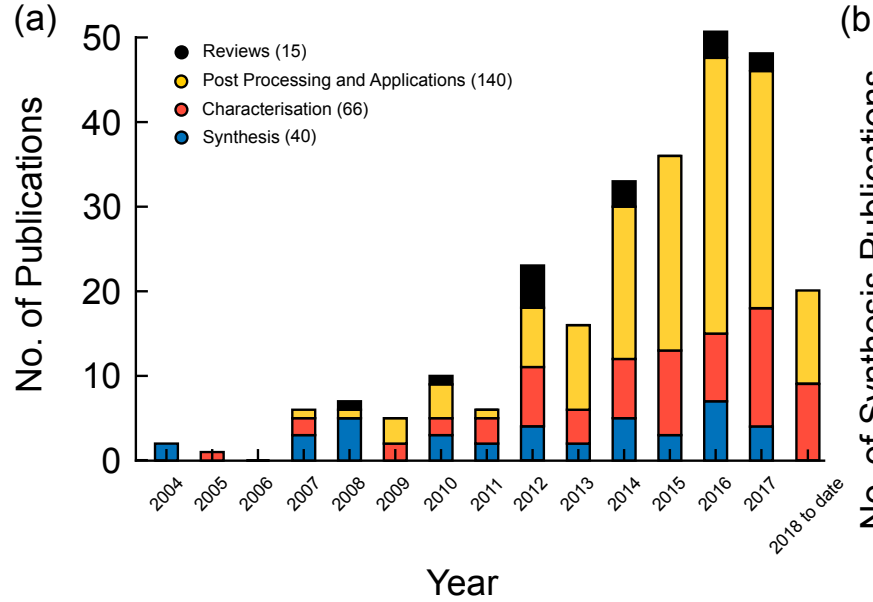

(b)

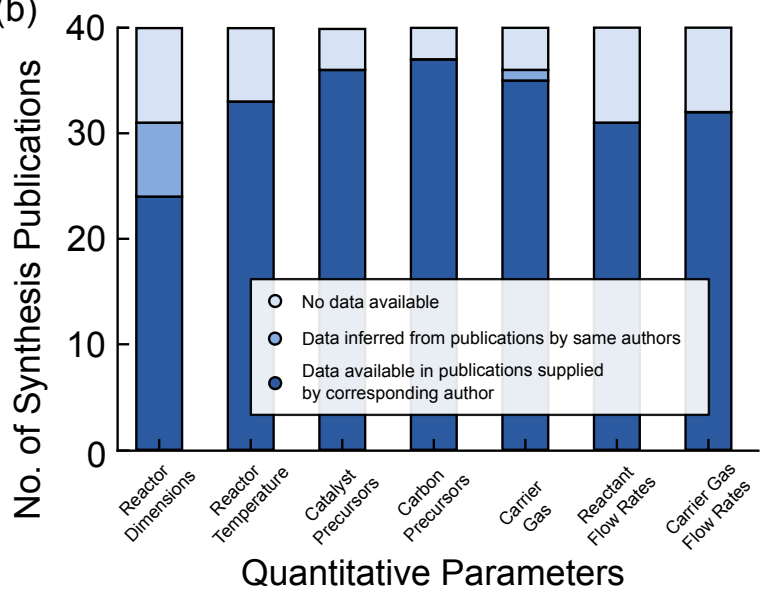

Figure 3: (a) Bar chart showing publications on the direct-spinning process and categorised as reviews, post processing and applications, characterisation and synthesis papers between 2004 and 2018 (July), with the number of publications of each type shown in parentheses. The majority of the papers contributing to the chart between 2004-2016 are summarised in Hoecker et al. [61], with additional papers from that period added as follows Review papers: 2014 [62, 63], 2016 [47], 2017 [64, 51]. Post-processing and application papers: $2015[65,66], 2016[67,68,69,70,71,72,73,74,75,76,63,77,78,41,79,80,81,82,83,84,85,86,87,88$, 89, 90, 91, 92, 93, 94, 95, 96], 2017 [97, 98, 99, 100, 101, 102, 103, 104, 105, 106, 107, 108, 109, 110, 111, 112, 113, 114, 115, 116, 117, $118,119,120,106,121], 2018$ to date [122, 123, 124, 125, 126, 127, 128, 129, 122, 130, 123]. Material characterisation: 2015 [131], 2016 [132, 133, 134, 42, 135, 136, 137, 138], 2017 [36, 43, 139, 60, 101, 140, 141, 142, 143, 144, 145, 146, 147, 148, 149], 2018 to date [38, 150, 151, 152, 153, 154]. Synthesis papers: 2012 [155, 156], 2013 [157], 2014 [158], 2016 [159, 160, 34, 161, 162, 163, 61], 2017 [59, 164, 165, 166], 2018 to date [167]. (b) Bar chart showing quantitative parameter availability from publications focusing on synthesis of direct-spun materials (40 publications). The abscissa shows the categories of quantitative data necessary for the calculations involved in this article. The ordinate indicates the number of synthesis publications with quantitative data categories shown in the legend. Quantitative data for all categories was obtained for 32/40 synthesis publications.

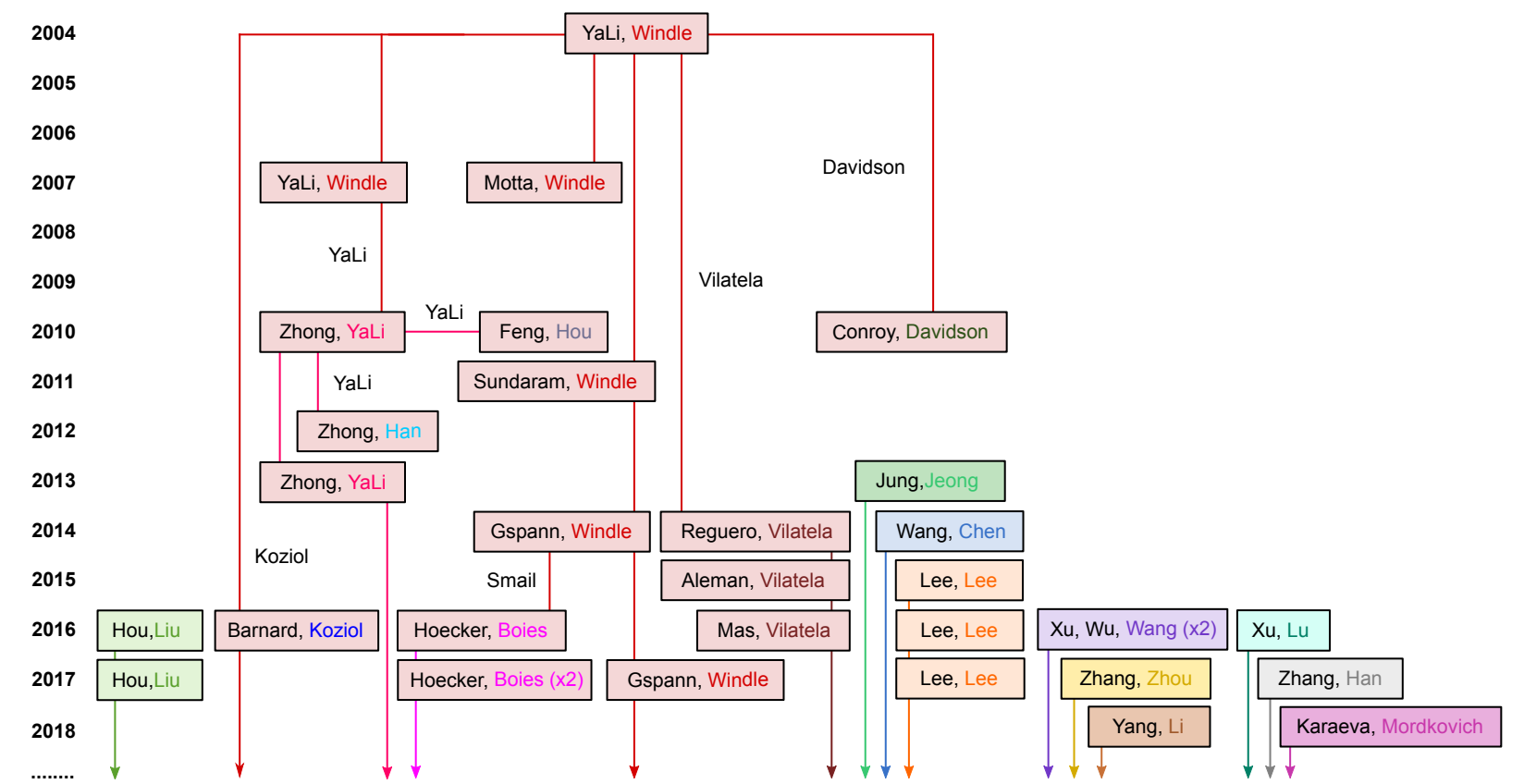

Figure 4: Family tree for the 32 publications concerning direct-spun CNT synthesis containing sufficient quantitative data to qualify for inclusion in our meta-analysis. The papers span a timeline from 2004-2018, shown on the left. In a given box, a name in black text is the first author of a publication while coloured text represents the corresponding author. Changes in line-colours connecting the boxes indicates the establishing of a new, but related (11 different families shown by different box colours), research group. The 32 publications represented herein are: 2004 [18], 2007 [28, 168], 2010 [26, 30, 23], 2011 [31], 2012 [24], 2013 [169, 157], 2014 [33, 32, 170], 2015 [25, 171], 2016 [34, 159, 160, 70, 69, 161, 162, 163], 2017 [61, 42, 164, 165, 166, 59, 106] and 2018 [167, 124].

comparing data across publications, as variation in technique parameters may alter measured results [173]. While TGA analyses are often available, a lack of yield data, provided by only a handful of publications means that the analyses can only be used as part of the characterisation portfolio. Perhaps even more fundamentally, the concepts of product quality or yield are not used consistently across studies, which makes it even more challenging to apply scientific rigour to scale up and optimisation processes (see Section 5.3).

\subsection{Common parameters}

The surveyed synthesis processes all share the following common features: 


\section{- Reactors}

Reactor materials are typically ceramic (usually alumina or mullite) or quartz. Quartz has a lower maximum operating temperature. Reactors are tubular in dimension with different radius and length.

\section{- Temperature profile}

Maximum furnace set points of $1100{ }^{\circ} \mathrm{C}$ up to $1300{ }^{\circ} \mathrm{C}$ are typical, with the hottest zone symmetrically bounding the central point of the reactor axis, stretching to between one-third and half of the heated length and returning to approximately 200-300 ${ }^{\circ} \mathrm{C}$ at each end of the reactor.

\section{- Residence times}

Residence times covering a range of values with a median of $20 \mathrm{~s}$ are typically required to produce direct-spun product.

\section{- Carrier gas}

Mixtures of ( $\left.\mathrm{He}, \mathrm{N}_{2}, \mathrm{Ar}\right)-\mathrm{H}_{2}$, as well as pure $\mathrm{H}_{2}$, $\mathrm{N}_{2}$ and Ar have been used. Depending on the process configuration, these may additionally be used to carry vaporised precursors into the reactor.

The impact of tubular reactors, high temperatures, residence times and carrier gases are discussed further in Section 3.

\section{- Catalyst}

Catalysts are typically transition metals (Fe, Co, $\mathrm{Ni}$ ). These are introduced via sublimation or vaporisation of an organometallic precursor.

\section{- Promoter}

Elements of group 16, such as S, Se or Te are considered essential to the direct-spun process. Sulfur is supplied via sublimation, or in precursors such as thiophene (selenophene or tellurophene for Se and $\mathrm{Te}$ ) or carbon disulfide via vaporisation. Thiophene is preferred in most cases.

The role and impact of catalyst and promoter sources are discussed further in Section 4.

\section{- Carbon source}

A variety of aliphatic (e.g. methane and hexane), aromatic (e.g. toluene), and oxygen-containing hydrocarbons (e.g. alcohols, ketones) are used, in gaseous or liquid form.

The impact of different carbon sources on directspun product formation is discussed further in Section 5. While impacts of reactor materials, injection methods and reactor temperature profiles can be discussed more generally, characterising chemistry in a continuous flow reactor is challenging because as one parameter is altered (e.g. reducing residence time by increasing carrier gas flow rate) it simultaneously impacts other variables (e.g. increasing in the overall dilution of the reaction system). Therefore, to study the process in a systematic fashion, only elemental ratios are used in this paper.

\section{Reactor operating conditions}

\subsection{Reactors}

All direct-spun processes investigated use vertical or horizontal furnace tubes made of glass or ceramic materials such as quartz $\left(\mathrm{SiO}_{2}\right)$, mullite $\left(3 \mathrm{Al}_{2} \mathrm{O}_{3} 2 \mathrm{SiO}_{2}\right.$ or $\left.2 \mathrm{Al}_{2} \mathrm{O}_{3} \mathrm{SiO}_{2}\right)$ or alumina $\left(\mathrm{Al}_{2} \mathrm{O}_{3}\right)$. These materials play no part in the CNT growth mechanisms; however, empirical observations reported in [174] describe the detection of $\mathrm{Si}$ and $\mathrm{Al}$ in the direct spun product. This is the result of $\mathrm{H}_{2}$ etching of silica in mullite and quartz as shown in $[175,176,177]$. In addition these materials are (relatively) inexpensive and are able to withstand the elevated temperatures required for directspun production. However, their brittleness (particularly with respect to the ceramics) makes them prone to temperature-gradient stress fractures which, without careful control of heating (or cooling) temperature rates pre- (or post-) reaction, can limit tube lifetimes. A range of cylindrical dimensions have been used for direct-spun reactors, varying between 25 and $320 \mathrm{~mm}$ in diameter and 0.7 and $2.4 \mathrm{~m}$ in length.

The use of a horizontal configuration results in a strong vertical convection current at the furnace exit, compared to a more symmetric flow pattern at the exit of a vertically orientated tube [159]. There are currently only two examples in the literature where multiple reactors in series have been used for directspun synthesis. Zhang et al. [164] achieved continuous spinning out of a first reactor tube and used a second reactor to reactivate carbon-encapsulated catalyst particles for further direct-spun synthesis via the addition of water vapour. Hoecker et al. [166] used a tworeactor system to show that catalyst particle synthesis in the first reactor could be successfully decoupled from direct-spun synthesis in the second.

The use of tubular reactors has been dictated by common laboratory furnace configurations; to our knowledge, exploration of other geometries has not yet been carried out. Alternate geometries may offer different avenues to scale up the process or research. Similarly, only use of ceramic or quartz reactors have been reported, and these have inherent lifetime issues [174] and limitations regarding machining adaptations as the tubes are cast in one piece.

One seemingly possible way to improve reactor temperature robustness and adaptability (e.g. by the addition of ports along the entire reactor axis rather than only at tube ends) is by incorporating high temperature-resistance metals (e.g. Kanthal, a FeCrAl alloy). However, in cases where a Kanthal reactor tube (ID $40 \mathrm{~mm}$, L $700 \mathrm{~mm}$ ) was used, in conjunction with successful direct-spun reaction parameters similar to those described in [166] by the same authors, the resulting product was predominantly soot rather than CNTs. There are two hypotheses for the unsuitability of such metal surfaces: a) metallic nanoparticles can be emitted from the walls, interfering with the reaction chemistry and limiting their availability, or b) metals serving as growth surfaces for carbon species, reacting with carbon from the feedstocks [178, 179, 180, 181], 
and thus reducing the amount of carbon available to create direct-spun products.

With the current reactor tubes, catalyst materials are lost to the walls, evidenced by deposition zones observed post-synthesis during equipment cleaning. Losses are dependent on catalyst nanoparticle diameter, with much greater percentages of smaller particles $(<10 \mathrm{~nm}$ diameter) lost compared to larger ones (see [174] and supplementary information associated with [161]). Prevention of these losses and, therefore, maintaining supplied ratio of reactants into the key reaction zones (see Section 4.1.2) would also offer better process replication and control.

\subsection{Injector arrays}

Numerous research groups have used different injector arrays (single tubes, concentric tubes, multiple tubes) in efforts to control the mixing of reactants relative to their decomposition temperatures. Single injectors typically consist of a narrow diameter metal tube (outer diameters $<6 \mathrm{~mm}$ ), designed to mix the reactants rapidly while creating a short jet stream flow into a selected temperature region. The jet then alters to a fully developed Poiseuille flow within a length of approximately three reactor-tube radii from the injector [23]. Alternatively, single shower-head injectors can be used, occupying most of the reactor cross-section. In these cases, the lower flow velocity creates a laminar flow immediately after the injection.

There are opportunities to improve the directspun process via development of novel injector techniques and changes in total reactor flow rates to alter mixing and reactor flow patterns. At present, direct-spun reactors are characterised by low (typically $<10$ ) Reynolds numbers $(R e)$ running in laminar flow regimes. While this has proved advantageous in synthesising anisotropic direct-spun CNT materials, the potential benefits of improved mixing associated with turbulence have not been explored. Under normal conditions, flow patterns are always laminar for $R e<2000$, with $R e>4000$ indicating the onset of turbulence and flow instabilities beginning in the $R e=2200-2300$ range [182]. Therefore lab-scale systems are unlikely to explore direct-spun CNT synthesis in high Re ranges, but such conditions are desirable for exploitation of the process at large scale by industry.

\subsection{Temperature profile}

The temperature profile measured along the reactor axis is one of the key parameters associated with directspun CNT material production. The steepness of the temperature gradients is determined by furnace design and heat transfer to exposed lengths of reactor tubes. The direct-spun process requires higher temperatures than substrate-based CVD synthesis. The wall temperature profile in a FC-CVD reactor furnace starts around $100-250{ }^{\circ} \mathrm{C}$, steeply rising to peak temperatures of $1100-1500{ }^{\circ} \mathrm{C}$ [59], plateauing through the mid section of the reactor and cooling towards $100-250{ }^{\circ} \mathrm{C}$ at the reactor exit. Temperature ranges and gradients of temperature profiles are clearly limited by current equipment capabilities but extending the range beyond $1600{ }^{\circ} \mathrm{C}$ and having better control over the gradients may increase reaction control.

\subsection{Residence times}

The residence time is another key parameter associated with direct-spun production. Figure 5(a) shows a histogram of bulk residence times used in the observed direct-spun experiments, with values ranging between 5 and $240 \mathrm{~s}^{4}$. These distributions can be further categorised according to their stated direct-spun product type (SWCNTs, DWCNTs, MWCNTs). Bulk residence times of $60-80 \mathrm{~s}$ are a crossover range, with SWCNT synthesis dominating at lower time values and MWCNTs generally dominating from this point on. Synthesis of all three types (SWCNTs, DWCNTs, MWCNTs) are possible across all of the reported residence times by adjusting other parameters. Increases in carrier gas flow rate, leading to decreased residence time, have been correlated with smaller diameter CNTs, due to a smaller catalyst particle size [23, 168]. Short residence times also suppress the decomposition of hydrocarbons and the formation of amorphous carbon [18], resulting in products with a lower amount of non-CNT additives. High quality SWCNTs are obtained for systems with $>20 \%$ hydrogen gases and short residence times (typically on the order of $10 \mathrm{~s}$ ). Liu et al. [183] suggest this is due to the highly reactive nature of hydrogen, which removes surface carbon from the metallic particles, and delays the onset of catalyst particle encapsulation for larger diameter nanoparticles.

Based on a $40 \mathrm{~mm}$ ID reactor of $700 \mathrm{~mm}$ length with a typical temperature profile of maximum temperature $1300{ }^{\circ} \mathrm{C}$, the bulk residence time is typically around $20 \mathrm{~s}$. In the $600-1000{ }^{\circ} \mathrm{C}$ temperature zone the residence time is calculated to be $2.5 \mathrm{~s}$ (based on a mean temperature of $800{ }^{\circ} \mathrm{C}$ ) whereas the gases only spend $1.6 \mathrm{~s}$ in the hottest zone of the reactor. While calculating the bulk residence time we know the individual CNT growth occurs on a faster time scale than this, as the majority of this growth, sufficient for bundling and aerogelation to take place, occurs in the downward temperature profile zone (see Section 4.1.2). Once the time-scales for formation of individual CNTs are fully understood in the direct-spun system, the time-scales for CNT bundling and bundle assembly into a macroscopic aerogel can then be determined. Knowing this type of kinetic data would then inform reactor design for scale-up purposes.

\subsection{Carrier gas}

Figure 5(b) categorises the residence times according to the carrier gas used for the reaction (inert, hydrogen, inert + hydrogen). The carrier gas serves as the main means of heat transfer from the furnace walls to the reactants, and its flow rate controls the overall

\footnotetext{
${ }^{4}$ One inert experiment has been reported with a residence time of $500 \mathrm{~s}$ [26].
} 

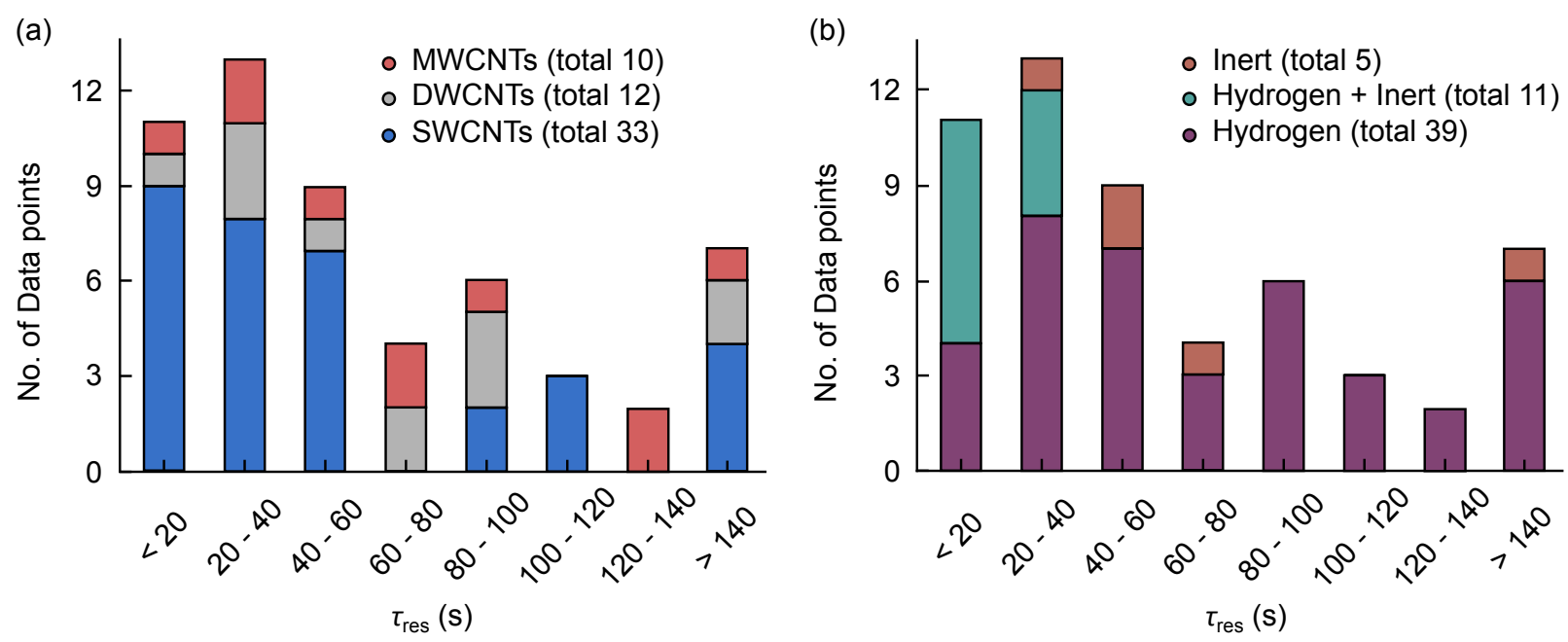

Figure 5: Bar charts showing (a) the influence of total bulk residence time on the main CNT type present in the direct-spun product; SWCNTs, DWCNTs or MWCNTs and (b) the use of different carrier gas combinations distributed across the residence time range. Carrier gas categories are inert gas (meaning Ar or $\mathrm{N}_{2}$ ), hydrogen + inert (meaning a mixed carrier gas system of $\mathrm{H}_{2}$ with either $\mathrm{N}_{2}$ or Ar) or hydrogen. The total number of data points associated with each CNT product type and carrier gas are shown in parentheses in the legends.

residence time. $\mathrm{H}_{2}$ is the most common gas used in direct-spun synthesis systems and is present at mass concentrations from $0.02 \%$ [106] to $98 \%$ [33]. From the literature, $\mathrm{H}_{2}$ 's leading roles are thought to be in preserving catalyst lifetime via etching of amorphous carbon [184] and controlling breakdown of the hydrocarbon precursors [58]. The first impetus driving the use of inert gases was a response to safety concerns with regards to using large amounts of $\mathrm{H}_{2}$. As a result several groups have explored the use of $100 \% \operatorname{Ar}[26,106,142]$ or $100 \% \mathrm{~N}_{2}[32,34,70]$.

However, the products of the hydrocarbon pyrolysis in inert gases can be different to those in $\mathrm{H}_{2}$ [185] or, where the products are the same, different in proportion in $\mathrm{H}_{2}$ [186]. Different pyrolysis products, or greater abundances of particular pyrolysis products caused by the use of inert gases may produce a reaction mixture more suitable for CNT production. This supports the observation that reactors operated with $100 \%$ inert gases or containing some percentage of inert gas generally run with shorter bulk residence times compared to those running $100 \% \mathrm{H}_{2}$ (as shown in Figure $5(\mathrm{~b}))$.

The ideal composition of carrier gas remains to be defined as the importance of hydrogen's role as a carbon etchant and suppressor of precursor decomposition rate in the direct-spun process needs to be confirmed. If etching and precursor decomposition suppressant roles are crucial, then a recent paper [159] studying the process using a $3 \% \mathrm{H}_{2}$ to $97 \%$ Ar mixture potentially indicates a minimum $\mathrm{H}_{2}$ requirement while maintaining some degree of continuous spinning. An interesting effect was observed whilst varying the molar ratio of $\mathrm{Ar}: \mathrm{H}_{2}$ carrier gas in a high temperature $\left(900-1200{ }^{\circ} \mathrm{C}\right) \mathrm{FC}-\mathrm{CVD}$ system with a low $\mathrm{C}$ to $\mathrm{H}$ molar input $(\mathrm{C}: \mathrm{H}=1: 5)$. We note that on average a pure $\mathrm{H}_{2}$ direct-spun system requires a much higher $\mathrm{C}$ to $\mathrm{H}$ molar input (see Section 5, between $\mathrm{C}: \mathrm{H}=$ 1:1 and 100:1) to produce direct-spun products. Liu et al. [183] showed that for the same argon and hydrogen carrier gas flow rates, they measured $7.2 \pm 2 \mathrm{~nm}$ and $10.1 \pm 5 \mathrm{~nm}$ mean CNT diameters, respectively. The authors observed a decrease in the SWCNT diameter distribution of the catalytic nanoparticles with increasing argon content.

If experiments in inert gases can be successfully reproduced, this points to other reactant species (such as oxygen content, see Section 4.4) compensating for hydrogen's chemical role. While on a laboratory scale using hydrogen in a one-pass reactor is the norm, the costs of hydrogen on scale up would make recycling a necessity if it proves to be crucial to the reaction.

\section{Catalyst nanoparticles and additives}

\subsection{Catalyst nanoparticle : metal and nucleation sources}

\subsubsection{Metal source}

A wide range of catalyst materials have been used in CVD synthesis of CNTs including metals, bimetallic or trimetallic alloys and non-metals such as silicon and germanium [187, 188, 189], although $\mathrm{Fe}, \mathrm{Ni}$ and Co are often favoured due to their high solubility in liquid hydrocarbons and carbons high diffusion rate through the metals at the requisite growth temperatures. In directspun synthesis systems, catalyst precursors are usually supplied as organometallic compounds (e.g. nickelocene, cobaltocene and ferrocene $[190,191,192])$. Ferrocene was the choice in all 32 publications (see Figure 4) due to its lower toxicity, stability under ambient conditions and low cost. Some examples within the field of direct-spun literature have used cobaltocene but nickelocene was not successful [166]

The metallocenes all have very similar decomposition temperatures $\left(\approx 450{ }^{\circ} \mathrm{C}\right.$, measured via pyrolysis techniques in vacuum or inert conditions) but slightly 
different decomposition mechanisms. Ferrocene initially decomposes via loss of a H-atom from the cyclopentadiene $(C p)$ ring followed by the scission of both remaining carbon rings from the Fe atom [193, 194], whereas the corresponding $\mathrm{Ni}$ and Co metallocenes decompose via scission of the complete $C p$ ring through $C p$-metal bond breakage. The differences in their decompositon mechanisms means that the presence of $\mathrm{H}_{2}$ as a carrier gas may impact the kinetics of ferrocene decomposition, but not that of cobaltocene. Compared to ferrocene and cobaltocene, nickelocene is much less stable and decomposes so rapidly in $\mathrm{H}_{2}$ environments (and at $50{ }^{\circ} \mathrm{C}$, vastly below its pyrolysis temperature [195]) that the reduction to $\mathrm{Ni}$ occurs in the injector system, preventing delivery of the metallocene to the reactor.

Homogeneous formation of nanoparticles initially occurs in the reactor upon decomposition of the metallocenes, once local vapour saturation levels are reached. These can then grow into larger clusters. Evidence from plasma and flame studies [196, 197] at temperatures similar to direct-spun systems suggests that in the case of Fe, a critical cluster size of 9-12 atoms is required for further growth to occur by coalescence and agglomeration. Below the critical cluster size the reduction in bulk free energy due to clustering does not compensate for the increase in surface free energy at the liquid-vapour interface and vaporisation occurs [198]. Particle size distribution studies [166] along the axis of a direct-spun reactor have shown that upstream-nucleated nanoparticles of iron were not detected below $1050^{\circ} \mathrm{C}$ (see Section 4.1.2). This indicates that insufficient Fe atoms were present below $1050{ }^{\circ} \mathrm{C}$ for particle nuclei of the critical cluster size to form. One may note, however, as described In section 3.1, that if mullite or quartz are used as reactor materials, the $\mathrm{H}_{2}$ etching of particles from the walls creates a potential source for heterogeneous nucleation of catalyst particles. In addition, any CNTs formed in the first stage of the reactor do not disappear or evaporate in the middle section of the reactor, and so can also be a surface for heterogeneous renucleation of iron nanoparticles [161].

\subsubsection{Nucleation source}

The control of active catalyst nanoparticle generation and composition is not dependent on the metal source alone. The inclusion of an element from group 16 ( $\mathrm{S}, \mathrm{Se}, \mathrm{Te})$ is also crucial to the direct-spun process. These elements play two important roles: as a promoter of CNT growth, as well as a promoter of catalyst nanoparticle nucleation. CNT growth promotion by group 16 elements is discussed in Section 5.4 while here we discuss its role of nucleation. Sulfur is the most commonly used group 16 promoter, delivered via thiophene for 45 of the 55 data points $[18,28,168,26,30$, $23,31,24,169,157,33,32,170,25,34,171,159,70,69$, $161,163,59,61,166,164,167,42,124]$, either through vaporisation of thiophene or co-supplied with a liquid phase carbon source. Supply via sublimation of elemental S generated 7 data points [25, 160, 106, 165] and vaporisation of carbon disulfide, one datapoint [31].
The remaining two data points [162] used selenium supplied via selenophene (its thiophene analogue). One particular set of investigations [199, 163] claimed the ability to generate direct-spun product without the addition of sulfur. However, attempts to replicate the experiment using the same equipment have proven unsuccessful [33].

Figure 6 shows the effect of sulfur on catalyst particle nucleation along the reactor axis, described based on results measured using a particular reactor geometry and reactant input rates [166]. In the absence of sulfur (Figure 6(a)), catalyst nanoparticles only form once sufficient Fe has been released via ferrocene decomposition to create a saturated Fe-vapour-concentration such that atom-clusters with a radius exceeding the critical radius can form (first orange zone, Figure 6(a)). Diffusion losses of the catalyst nanoparticles to the reactor walls occurs $[161,174]$, lowering the Fe concentration in the system. Catalyst nanoparticle evaporation then occurs as the remaining particles are advected downstream by the carrier gases to the hottest section of the reactor. Renucleation from the iron vapour occurs on the downward temperature profile as the gas phase reaches Fe-supersaturation.

In the presence of sulfur (Figure 6(b)), catalyst nanoparticles nucleate and renucleate farther downstream at lower and higher temperatures, respectively, than without sulfur. S is thought to lower the energy required for critical cluster formation, analagously to its role in increasing nucleation in atmospheric and diesel emissions aerosol systems [200, 201, 202]. The role of $\mathrm{S}$ as a nucleating agent does not influence the size of the final catalyst nanoparticles, and thus does not make up a large mass fraction of the final particles. A small fraction of $\mathrm{S}$ lowers the nucleation threshold, allowing the Fe growth and coagulation which are the dominant mechanisms once particles have nucleated. This is shown in [166] where the mean diameter of the resulting particle size distribution is $15 \mathrm{~nm}$, both with and without $\mathrm{S}$, albeit with a larger geometric standard deviation when $\mathrm{S}$ is present.

The experiments described in [166] were conducted in the presence of only the small amount of $\mathrm{C}$ released during the decomposition of the ferrocene and thiophene. However, earlier experimental work by the same group showed that nucleation, evaporation and renucleation of the catalyst nanoparticles persisted under conditions in which carbon for growing CNTs was sufficient [161]. SEM analysis showed deposition of catalyst nanoparticles on a small amount of CNT formed in the nucleation zone, followed by evaporation of these catalyst nanoparticles from the scant CNT bundles in the hottest part of the reactor. Furthermore, considering the lowering of the surface tension of a ternary system as an analogy for a lowering of the boiling point, a cessile-drop study on the surface tensions of Fe-C-S systems by Lee et al. [203] showed that addition of $\mathrm{C}$ to an $\mathrm{Fe}-\mathrm{S}$ system increased the chemical activity of $\mathrm{S}$, resulting in a drop in the surface tension of the ternary system.

The difference in the decomposition temperatures of 


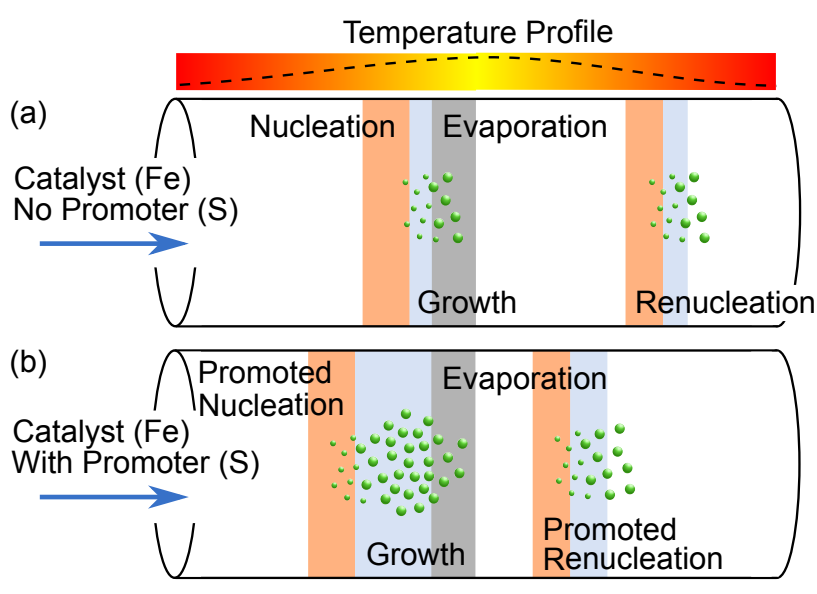

Figure 6: Schematic showing the effect on catalyst nanoparticle nucleation, growth, evaporation and renucleation in (a) absence and (b) presence of sulfur along a reactor axis in relation to a typical temperature profile associated with a tubular reactor (hottest zone in the centre region, with a positive(negative) temperature gradient in the first(last) portion of the reactor tube).

different S-sources and therefore the S-availability for catalyst particle generation and CNT growth promotion can lead to differences in the types of CNTs making up the direct-spun products. This will be discussed in sections 4.2 and 5.4 in relation to $\mathrm{Fe}$ and $\mathrm{C}$ sources, respectively.

\subsection{Effect of $S / F e$ ratio on $C N T$ product morphology}

Figure 7 shows the sulfur to iron molar input rates for all of the direct-spun reaction studies discussed, overlaid with colour shading indicating the resulting CNT morphology (SWCNTs, DWCNTs and MWCNTs) in the direct-spun product. Successful reactions have been established for $\mathrm{S} / \mathrm{Fe}$ molar ratios between 0.1 and 10 as indicated by the dashed (blue and red) trend lines in Figure 7 corresponding to the minimum (0.1) and maximum (10) molar ratios. The minimum ratio correlates most closely with studies where elemental S was sublimed whereas the maximum ratio corresponds to studies where thiophene was vaporised.

Below the dashed blue line is the current experimentally determined S/Fe molar lower boundary for successful direct-spun processes, beyond which if the molar ratio is decreased, a spinnable product has not been reported. The lower boundary may indicate that enough sulfur must be present to lower the nucleation barrier sufficiently to create enough suitable catalytic nanoparticles for CNT growth. Similarly, the dashed red line describes the current experimentally determined upper boundary, beyond which product yield is too low to be successfully collected.

Between the blue and red boundaries, as the molar ratio is increased, the corresponding product moves from being predominately SWCNTs (blue) to DWCNTs (grey) to MWCNTs (red) in the direct-spun material. The upper and lower $\mathrm{S} / \mathrm{Fe}$ boundaries shown on Figure 7 both coincide with the use of $\mathrm{CH}_{4}$ as the carbon source while the liquid injection experiments, typically using alcohols or higher molecular weight hydrocarbons, are spread between these boundaries, and

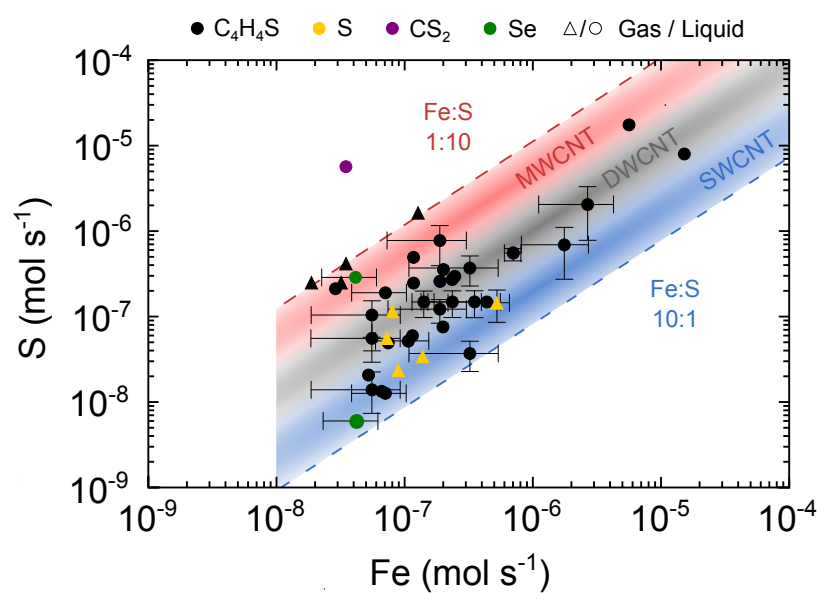

Figure 7: The total promoter (ordinate) and iron (abcissa) molar flow rates for all successful direct-spinning experiments in the dataset with the predominant CNT type present in the product. The triangles (circles) represent gas (liquid) injection experiments. The colours of the data points indicate the promoter source used in each experiment. Black, yellow, purple and green correspond to thiophene, sulfur, carbon disulfide and selenophene, respectively. The shaded red, grey and blue regions correspond to MWCNTs, DWCNTs and SWCNTs respectively.

all use thiophene as their S-source. The fact that the data for non- $\mathrm{CH}_{4}$ sources consists of widely distributed points to their being multiple factors (for example iron availability with respect to carbon availability from different feed-stocks) controlling the type of CNT synthesised and the complexity of the parameter space. Although there are not many studies associated with the use of elemental sulfur (yellow triangles), the trend does appear to be comparable to that of thiophene (black triangles). The use of elemental sulfur allows less $\mathrm{S}$ for a given amount of $\mathrm{Fe}$, and the resulting directspun product tends to consist mainly of SWCNTs.

The two main effects linked to the nature of the nucleation sources are: (a) the $\mathrm{S}$ availability relative to Fe due to decomposition temperature (thiophene) or vapour pressure (elemental sulfur) of the source and (b) the contribution of any $\mathrm{C}$ from the metal and nucleation source towards CNT growth. The thermal breakdown of thiophene begins at $800{ }^{\circ} \mathrm{C}$ [204] and therefore occurs further along the reactor temperature profile, compared with elemental sulfur which is available immediately for participation in catalyst nanoparticle nucleation processes. The presence of Fe species as potential catalysts does not lower the temperature of $\mathrm{S}$ availability [61]. An overview of the nucleation process will be summarised in Section 6 .

\subsection{Effect of $S / F e$ ratio on catalyst composition}

Studies using high resolution TEM and EELS (Electron Energy Loss Spectroscopy) of ex situ, catalyst nanoparticles used in direct-spun production showed that sulfur was located only at the catalyst surface $[205,170,25]$. Motta et al. highlighted that Sseparation to the surface in Fe-rich systems is a widely known effect exploited in the cast iron and steel production industries [206, 207, 208, 209]. Additional evidence (see references within [205]) shows S-segregation 
to the surface of molten macroscopic Fe droplets and to the interface between the Fe droplets and their support.

Sections 4.3.1 and 4.3.2 use ternary phase diagrams to indicate the active catalyst compositions, which are composed of two immiscible liquid phases, a carbonrich liquid $\left(\mathrm{L}_{1}\right)$ and sulfur-rich liquid $\left(\mathrm{L}_{2}\right)$. The use of equilibrium, bulk phase ternary phase diagrams to describe finite time nanoscale systems is justified as follows. The typical timescales for ferrocene to fully decompose in carbon-rich flame regions of comparable temperatures is a maximum of $0.1 \mathrm{~s}$, based on calculations using data contained in [210, 211]. This compares to total bulk residence times in the reported dataset of an average of $20 \mathrm{~s}$. Even if the residence time of reactants in the hottest parts of a reactor is lower than one fifth of the total residence time (due to expansion of the total gas volume with temperature), the duration far exceeds the necessary time scales for equilibrium to be reached.

While initial phase diagrams only covered temperature ranges down to $1400{ }^{\circ} \mathrm{C}$ (a temperature above the set reactor temperatures of the majority of the studied dataset), it is important to remember that there is a lowering of melting points for nanoscale objects when compared to the equivalent bulk phases due to the Gibbs-Thomson effect [212]. This effect has been quantified by Ding et al. [213] who calculated the size dependence of pure Fe clusters on temperature through a molecular dynamics approach. They found that the coalescence (and hence the melting temperatures) of nanoscale clusters decrease linearly with decreasing cluster diameter, so that $6 \mathrm{~nm}$ diameter Fe nanoparticles are expected to melt at $1167^{\circ} \mathrm{C}$ compared to a bulk melting point for $\mathrm{Fe}$ of $1538{ }^{\circ} \mathrm{C}$. Experimental work by Benissad et al. [214] found that the melting point of $15 \mathrm{~nm}$ Fe nanoparticles was decreased to $1100{ }^{\circ} \mathrm{C}$. Therefore, phase changes described at higher temperatures in the bulk phase can be used to consider their analogues in nanoparticles at somewhat lower temperatures.

In Section 4.3.1 links are made between the alteration of $\mathrm{L}_{1} / \mathrm{L}_{2}$ ratio and the resulting CNT product morphology. In Section 4.3.2 new information on the temperature evolution of the immiscible boundaries indicates a minimum critical operating temperature for direct-spun product will exist.

\subsubsection{Fe-S-C ternary phase diagram : effect of $S$}

Information from the binary phase diagrams (see Appendix 10) can be used to construct ternary $\mathrm{Fe}-\mathrm{S}-\mathrm{C}$ phase diagrams (Figure 8 and Figure 9). The phases shown along the horizontal $\mathrm{S}$ axis of Figure 8(a) correspond to the $1400{ }^{\circ} \mathrm{C}$ line marked on the binary $\mathrm{Fe}-\mathrm{S}$ diagram (Figure 15(a)) and those along the $60^{\circ}$ angle Fe axis correspond to the $1400{ }^{\circ} \mathrm{C}$ line in the binary $\mathrm{Fe}-$ $\mathrm{C}$ diagram (Figure 15(b)). Recent work by Tafwidli et al. [215] has allowed a more accurate determination of the isothermal sections at $1400{ }^{\circ} \mathrm{C}$ to construct the boundaries in Figure 8(a). The positions of the catalyst compositions calculated from the study of inactive (a)

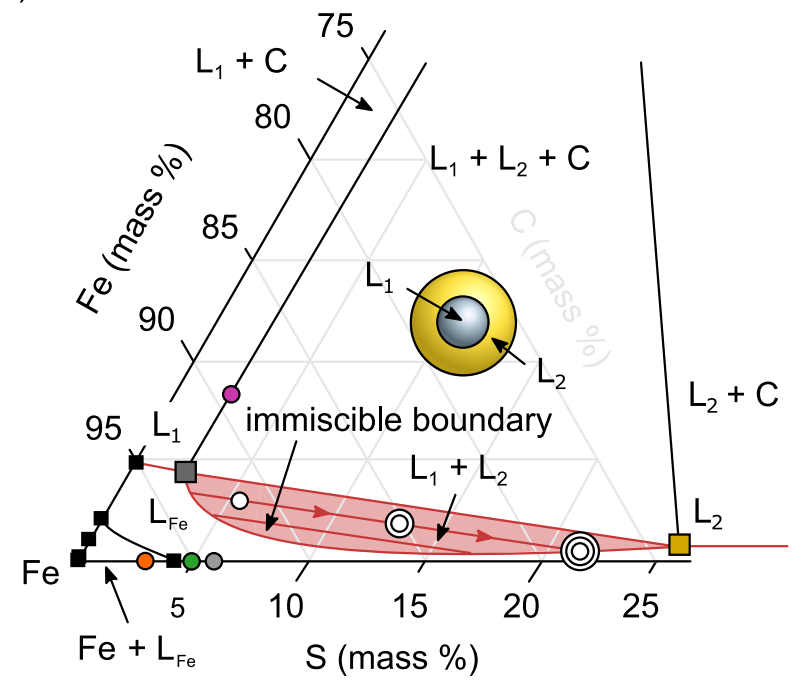

(b)

(i) 0
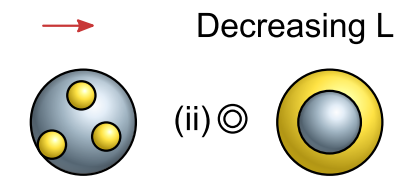

(iii)@

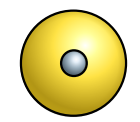

Figure 8: (a) Bulk equilibrium section (mass percentages) of the $\mathrm{Fe}-\mathrm{C}-\mathrm{S}$ ternary phase diagram at $1400^{\circ} \mathrm{C}$. Black squares on the $\mathrm{Fe}(\mathrm{S})$ axis mark phase changes on the related $\mathrm{Fe}-\mathrm{C}(\mathrm{Fe}-\mathrm{S})$ binary phase diagrams (see Appendix 10). The schematic within (a) shows the two immiscible carbon and sulfur-rich liquids $\mathrm{L}_{1}$ and $\mathrm{L}_{2}$ that comprise an active catalyst nanoparticle. The orange, green and grey (purple) circles indicate an active (inactive) catalyst mass composition in the absence of carbon. Single, double and triple-circled points indicate catalyst nanoparticles of decreasing $\mathrm{L}_{1} / \mathrm{L}_{2}$ ratios of 3,1 and 0.25 , respectively with (b) illustrating the impact of this on the catalyst composition.

(purple circle [170]) and active particles (orange circle, ignoring the carbon content [170] and green circle [25]) are also plotted.

The composition of the immiscible carbon-rich liquid ( $\mathrm{L}_{1}$-grey solid square) and sulfur-rich liquid $\left(\mathrm{L}_{2}-\right.$ yellow solid square) contain up to $93 \% \mathrm{Fe}, 2.5 \% \mathrm{~S}, 4.5 \% \mathrm{C}$ and $73.5 \% \mathrm{Fe}, 26 \% \mathrm{~S}, 0.5 \% \mathrm{C}$, by mass respectively, at $1400{ }^{\circ} \mathrm{C}[215]^{5}$. The surfactant role of sulfur in liquid iron (the addition of sulfur lowers the surface tension of liquid iron [216]), coupled with the evidence from high resolution TEM and EELS indicates that the $\mathrm{L}_{2}$ liquid forms the outer shell as illustrated by the catalyst nanoparticle sketch embedded in Figure 8(a).

Following the hypothesis [170] stating that the catalyst composition of active particles needs to be in the $\mathrm{L}_{1}+\mathrm{L}_{2}$ (red) region for successful direct-spun processes, we now relate this to the $\mathrm{S} / \mathrm{Fe}$ molar ratio range found in our dataset. From the experimental dataset (Figure 7) it can be seen that the minimum input molar ratio $(\mathrm{S} / \mathrm{Fe})$ is one sulfur atom for every ten iron atoms, corresponding to a mass ratio of $94.6 \% \mathrm{Fe}: 5.4 \% \mathrm{~S}$ (grey circle on the $\mathrm{S}$ axis in Figure $8(\mathrm{a})$ ). The maxi-

\footnotetext{
${ }^{5}$ In Tafwidli's work [215], $\mathrm{L}_{1}$ and $\mathrm{L}_{2}$ are modelled as having the same elemental composition as cementite $\left(\mathrm{Fe}_{3} \mathrm{C}\right)$ and pyrrhotite $\left(\mathrm{Fe}_{1-x} \mathrm{~S}(\mathrm{x}=0-0.2)\right)$, respectively.
} 
mum ratio used in experiments is ten sulfur atoms for every one iron atom, corresponding to a mass ratio of $14.8 \% \mathrm{Fe}: 85.2 \% \mathrm{~S}$ (this would occur at the far right hand corner of Figure 8(a)). This implies that the reaction system can tolerate the presence of an excess of S, but if the hypothesis holds true [170], the excess must not be present in the catalyst. In Section 5.4, we discuss the consequence of excess sulfur further with respect to CNT growth in the system.

For the minimum $\mathrm{S} / \mathrm{Fe}$ ratio, only one carbon atom for every $10 \mathrm{Fe}$ and $1 \mathrm{~S}$ is required to create an active catalyst composition (shifting the mass\% composition from the grey circle to a single white circled point within the red region of Figure 8(a)). A particle of this composition would contain $75 \%$ mass $\mathrm{L}_{1}$ and $25 \%$ mass $\mathrm{L}_{2}$. Increasing $\mathrm{L}_{2}$ content moves the total catalyst composition to the bottom right of the red region (following the direction of travel indicated in Figure 8 (a) from 1 to 2 to 3 white circles). Particles of $\mathrm{L}_{1} / \mathrm{L}_{2}$ ratios of $1(50 \% / 50 \%)$ and $0.25(20 \% / 80 \%)$ correspond to the double-circled and triple-circled points, respectively.

In Figure 7, we can see that predominately SWCNT and MWCNT products are synthesised using low and high $\mathrm{S} / \mathrm{Fe}$ ratios, respectively. These ratios correlate with low and high $\mathrm{L}_{1} / \mathrm{L}_{2}$ ratios, respectively and have consequences for the catalyst nanoparticle structure as sketched in Figure 8(b). The single, double and triple white circled points in Figure 8(b) correspond to the $\mathrm{L}_{1} / \mathrm{L}_{2}$ ratios 3, 1 and 0.25 . Nanoparticles of a low $\mathrm{L}_{2}$ composition (Figure 8(b)(i)) consist of $\operatorname{droplet}(\mathrm{s})$ which form a nucleation site, or sites, for a small diameter (and therefore single-wall) nanotube(s) to grow. This theory is supported by evidence found in a number of papers where SWCNTs of significantly smaller diameter than their active catalyst nanoparticle ${ }^{6}$ have been observed with $\mathrm{S} / \mathrm{Fe}$ ratios between $0.002^{7}$ and 0.4 being used [217, 218, 25, 165].

For the maximum $\mathrm{S} / \mathrm{Fe}$ molar ratio systems we hypothesise that the CNTs grow from catalyst nanoparticles that exist in the bottom right $\left(\mathrm{L}_{2}\right.$ dominated) part of the active $L_{1}+L_{2}$ zone (represented by Figure 8(b)(ii) and (iii)). In this case, the entire surface of the catalyst nanoparticle will be dominated by $\mathrm{L}_{2}$ and the CNT diameter will be determined by the diameter of the catalyst nanoparticle, with MWCNTs dominating the resulting product.

\subsection{2. $F e-S-C$ ternary phase diagram : effect of $T$}

Recent work [215] on the Fe-S-C ternary phase diagrams has allowed a more accurate determination of the phase boundaries from 1600 to $1200{ }^{\circ} \mathrm{C}$ as shown in Figure 9(a). This new information highlights that the coexistence of the carbon-rich liquid $\left(\mathrm{L}_{1}\right)$ and sulfurrich liquid $\left(\mathrm{L}_{2}\right)$ phases, for a given $\mathrm{Fe}: \mathrm{C}: \mathrm{S}$ ratio, only occurs above $1400{ }^{\circ} \mathrm{C}$ (indicated by the red immis-

\footnotetext{
${ }^{6}$ The diameters of the CNTs were of the order of 3 times smaller than the corresponding nanoparticle from which they grew [25, 165].

${ }^{7}$ The ratios used in this work do not produce a truly spinnable aerogel.
}
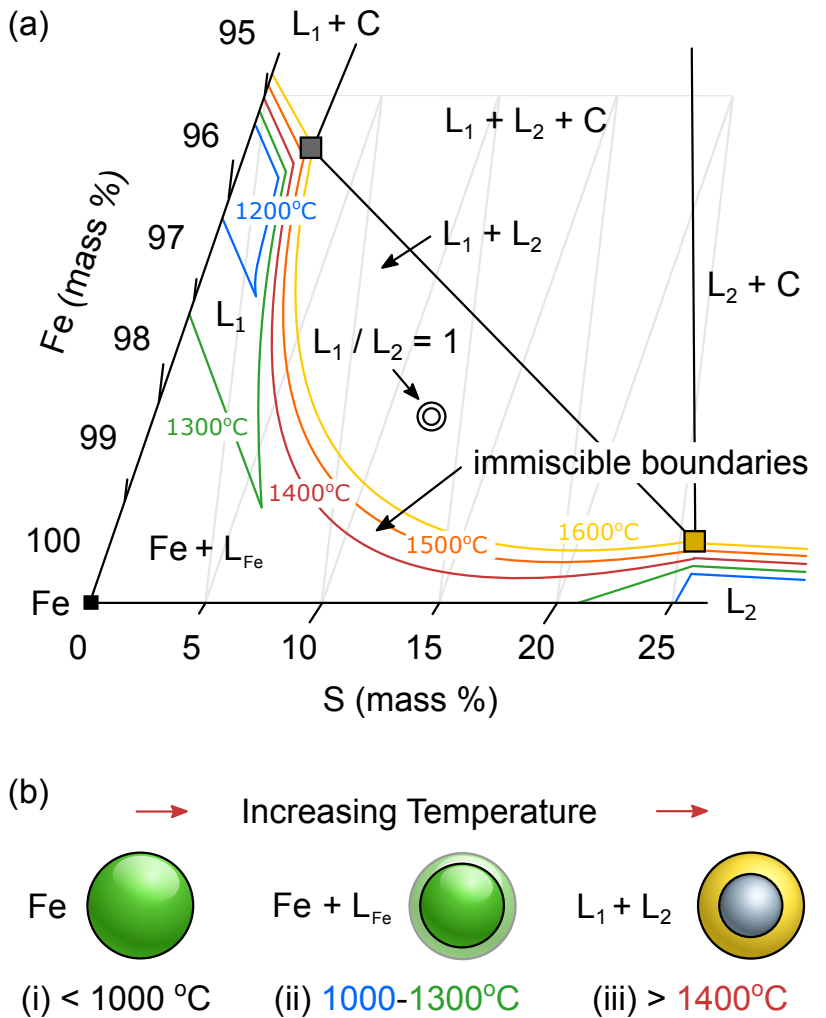

Figure 9: (a) Bulk equilibrium section (mass percentages) of the Fe-C-S ternary phase diagram at various temperatures between $1200{ }^{\circ} \mathrm{C}$ and $1600{ }^{\circ} \mathrm{C}$. The carbon and sulfur-rich liquids phases $\mathrm{L}_{1}$ and $\mathrm{L}_{2}$ exist above $1200{ }^{\circ} \mathrm{C}$ with the immiscible boundaries occuring for a range of $\mathrm{Fe}: \mathrm{C}: \mathrm{S}$ compositions at temperatures above $1300{ }^{\circ} \mathrm{C}$. The double-circled point is located in (a) where the Fe : C : S composition corresponds to $\mathrm{L}_{1} / \mathrm{L}_{2}=1$ with (b) showing the impact of increasing temperature on the phases of this catalyst nanoparticle.

cible boundary line) in Figure 9(a). Between $1200{ }^{\circ} \mathrm{C}$ and $1300{ }^{\circ} \mathrm{C}$, both phases can exist, but only at high $\mathrm{C}$ (mass\%) and high S (mass\%), respectively, represented by the areas bounded by the blue and green isothermal phase boundaries, respectively.

We use Figure 9 to study the evolution of the active catalyst particles as they experience the temperature gradients present in a direct-spinning reactor. Note that as described in Section 4.3 we are extrapolating from the higher temperatures based on bulk phase diagrams to predict the behaviour of nanoparticles at the temperatures associated with the direct-spun process. Consider a particle of composition $85.4 \%$ Fe, $12.8 \% \mathrm{~S}$, $1.8 \% \mathrm{C}$, indicated by the 2 white circles in Figure 9 (a). Up to $1000{ }^{\circ} \mathrm{C}$ it will be a solid particle as shown in Figure $9(\mathrm{~b})(\mathrm{i})$. It contains no $\mathrm{L}_{1}$ or $\mathrm{L}_{2}$ phases and so will not be active for rapid CNT growth ${ }^{8}$. Between 1000 and $1300{ }^{\circ} \mathrm{C}$ the same particle contains Fe and liquid Fe $\left(\mathrm{L}_{\mathrm{Fe}}\right)$ dominated phases Figure 9 (b)(ii). Only once the particle reaches $1400{ }^{\circ} \mathrm{C}$ does it split to a twophase $\left(50 \% \mathrm{~L}_{1}\right.$ and $\left.50 \% \mathrm{~L}_{2}\right)$ system represented by Fig-

${ }^{8} \mathrm{CNT}$ growth rates measured without sulfur addition have diffusion-limited values of $0.2-17 \mu \mathrm{m} \mathrm{s}^{-1} \quad[219,220,221,222]$. Growth rates of CNTs in direct-spinning systems are not diffusion-limited and a recent paper has shown that $\mathrm{S}$ increases the growth rate [223]. 
ure 9 (b)(iii). Only in this situation can the sulfur-rich liquid phase facilitate rapid CNT growth.

We discussed in Section 4.1.2 how catalyst particles can evaporate at high temperatures in the direct spinning process. Therefore the presence of active catalyst nanoparticles in the positive temperature gradient region is decreased due to their evaporation. Where catalyst particles renucleate due to negative temperature gradients, their renucleation as particles of mixed $\mathrm{L}_{1}+$ $\mathrm{L}_{2}$ phases will drive rapid CNT growth. While an absolute temperature for the presence of active catalyst nanoparticles cannot be determined due to the uncertainties inherent in applying bulk data to nanoscale systems, the information suggests that there will be a minimum temperature on the positive temperature gradient (maximum temperature on the negative temperature gradient) where active particles will exist.

\subsubsection{Achieving CNT selectivity by catalyst control?}

A degree of selectivity over CNT chiral indices can be achieved via catalyst nanoparticle diameter or choice of metallic catalyst. For example, a bias towards CNTs with armchair configurations can be achieved when SWCNTs are synthesised in iron-catalyst based FC-CVD processes due to the CNTs growing from small liquid-like catalyst nanoparticles [31, 132, 224]. Conversely, a recent publication has shown that small cobalt-tungsten based solid catalyst nanoparticles favour semiconducting CNT synthesis [225].

At present, the approach to identifying combinations of catalysts and synthesis methods offering chiral selectivity is essentially empirical. However, to create customised catalyst nanoparticles tuned towards synthesis of a particular CNT type will require the control of catalyst chemistry and size in accordance with guidance offered by ternary phase diagrams that account for nanoscale thermodynamic properties.

With reference specifically to reactions for synthesising directly spun product, catalyst control is limited by the kinetics and thermodynamics of catalyst precursor decomposition in the gas phase and by an overall dilution of the system. Separation of the catalyst nanoparticle synthesis and CNT growth steps potentially offers an opportunity for a much higher level of control, allowing for a wider range of catalyst materials to be explored. Providing a mono-sized supply of catalysts with controlled chemistry into the reaction zone may offer optimisation of individual CNT properties, an in turn enhance the performance of direct-spun product. While potential for such systems has been demonstrated at the laboratory scale (e.g. by means of catalyst mobility size selection), future work is required to scale these techniques for high throughput.

\subsection{Effect of O-containing species}

Next we discuss the relevance of different additives to the reaction system and their roles in maintaining the catalyst activity (as only a tiny percentage of catalyst nanoparticles promote CNT growth [170]), preventing graphitic encapsulation of the nanoparticles and therefore facilitating CNT growth. The group 16 elements
$\mathrm{O}$ and $\mathrm{S}$ have distinct but different roles in this regard. Unlike S, O is not essential for a successful aerogel formation in the direct-spun process. However, some publications have indicated that oxygen may improve selectivity in CNT growth (e.g. semiconductor vs metallic CNTs) [226], increase CNT growth kinetics [227, 228], length of CNTs [229], and minimise amorphous carbon by-products [230] while additionally reducing the overall concentration of hydrogen required in the reactor [231]. Oxygen can be introduced into the reactor as a constituent of the hydrocarbon, (in alcohols, acetone etc.) which is the most common method employed in direct-spun systems. Alternatively, it could be added separately, e.g. as water vapour (as found for three data points $[24,169,25])$. No publications have introduced pure oxygen into the reactor as a gas due to the explosion risks associated with mixtures of hydrogen and oxygen at high temperature.

Figure 10(a) shows the total iron and oxygen molar flow rates for the subset of relevant aerogel data (39 of 55 data points). The dashed (black) trend line in Figure 10(a) corresponds to a molar ratio of $250 \mathrm{O}: 1 \mathrm{Fe}$. Three data points, circled in red, correspond to studies where there was an injection of water rather than supply of oxygen as a constituent of the hydrocarbon. Two of these data points, where water was injected as a vapour separately from the other reactants [24, 25] do not follow the trend line while the third, where water was injected with other liquid reactants [169] falls on it. In experiments where water is injected as a vapour, significantly more iron can be injected compared with experiments where oxygen is supplied as a constituent of the hydrocarbon. This suggests that oxygen from water vapour plays an important role as it becomes available. Zhang et al. [164] showed using the directspun process in two coupled FC-CVD furnaces that deactivated (carbon-encapsulated) iron nanoparticles could be reactivated after reacting with hydrogen and water vapour. The authors showed that in the absence of water vapour CNTs could not be spun out of a second furnace and claimed that the water vapour reactivated catalyst activity by etching away amorphous carbon at high temperatures. Note that as the molar input of Fe is increased, the corresponding amount of $\mathrm{C}$ in the reactor can also be increased (see Figure 11). Therefore when a carbon source contains an $\mathrm{O}$ atom, it can be seen that the $\mathrm{Fe}$ : O ratio follows a similar trend to the $\mathrm{Fe}: \mathrm{C}$ ratio.

Figure 10(b) shows the total carrier gas $\left(\mathrm{H}_{2}+\mathrm{N}_{2}+\right.$ $\mathrm{Ar}$ ) and oxygen molar fractions for the oxygen containing data subset, with the dashed (black) line describing the corresponding trend. All experiments in the data set without oxygen require a carrier gas molar fraction greater than 0.95. Alternatively, when oxygen is present, the carrier gas mole fraction can be as low as 0.65. The four data points with the lowest mole fractions of carrier gas all correspond to experiments where no $\mathrm{H}_{2}$ was used $[26,106,142,32,34,70]$. Additionally these experiments have the highest $\mathrm{O}$ mole fractions (up to 0.11). It can therefore be presumed that $\mathrm{O} / \mathrm{S}$ etchant role is in helping to preserve catalyst activity 

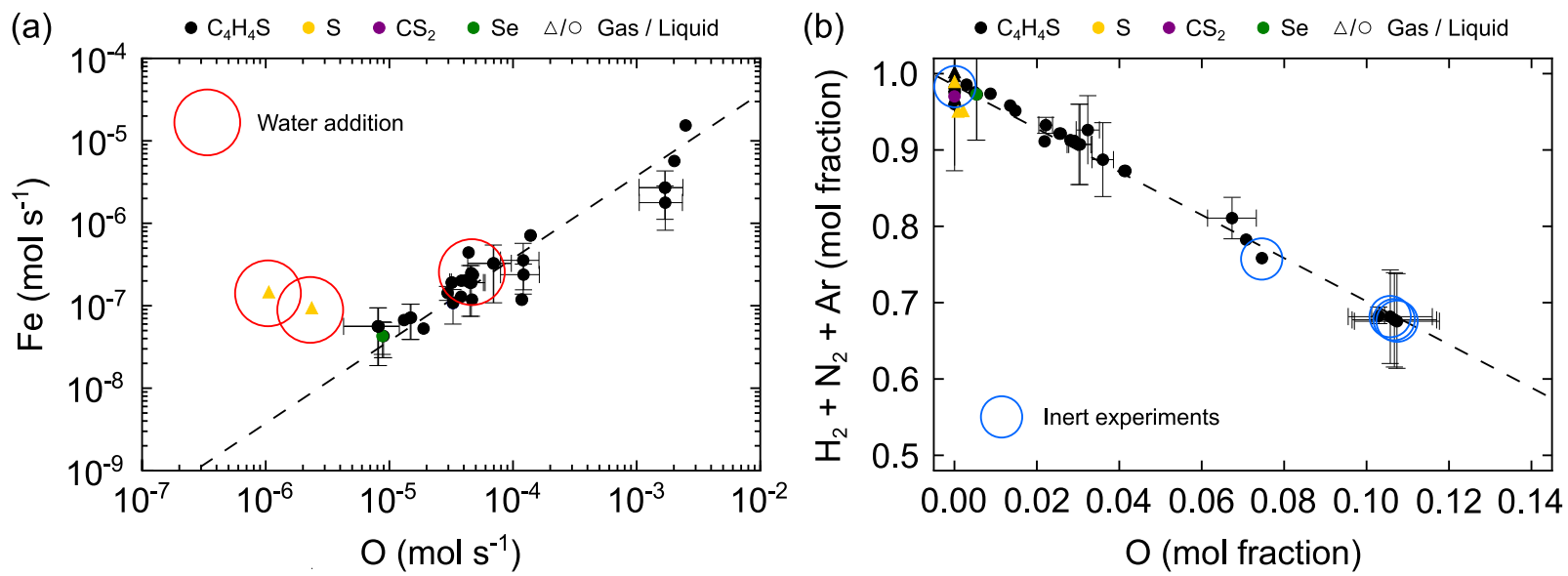

Figure 10: (a) The total iron (ordinate) and oxygen (abcissa) molar flow rates and (b) total carrier gas $\left(\mathrm{H}_{2}+\mathrm{N}_{2}+\mathrm{Ar}\right.$, ordinate) and oxygen (abcissa) mole fractions are plotted for all successful direct-spinning experiments in the dataset. The red circles in (a) indicate experiments where $\mathrm{O}$ was added as water, whereas for other data points $\mathrm{O}$ is a constituent atom in the hydrocarbon source. The blue circles in (b) indicate experiments carried out using either $\mathrm{Ar}$ or $\mathrm{N}_{2}$ as the carrier gas (inert experiments). For (a) and (b) the triangles (circles) represent gas (liquid) injection experiments. The colours of the data points indicate the promoter source used in each experiment. Black, yellow, purple and green correspond to thiophene, sulfur, carbon disulfide and selenophene, respectively.

in the absence of $\mathrm{H}_{2}$ suppressing hydrocarbon pyrolysis (see Section 5.1 for an explanation of links between $\mathrm{H}_{2}$ and pyrolysis).

Therefore, for experiments using inert carrier gases that include $\mathrm{O}$ in their reaction systems (highlighted by blue circles) the overall volume of carrier gas required is reduced. The monetary and safety benefits of running without $\mathrm{H}_{2}$ on scale-up of the reaction are considerable, if factors such as product yield and bulk properties are not adversely impacted. Much more work is required in this area to confirm results from the inert gas experiments and identify the differences in chemistries between systems using or not using $\mathrm{H}_{2}$ as a significant component of reaction mixtures.

Up until this point, the article has focused on the factors influencing nanoparticle formation and how the formed nanoparticles can impact the nature of the CNT product. The next section discusses the growth of CNTs in relation to the breakdown of the carbon precursor and their carbon availability, using the correlations of iron to carbon to quantify observable reaction trends and discuss the other main function of $\mathrm{S}$ in promotion of CNT growth.

\section{CNT growth}

\subsection{Carbon precursor}

Direct-spun formation has been demonstrated using a wide range of single hydrocarbon sources and combinations of two hydrocarbon sources. Single hydrocarbons include methane $\left[\mathrm{CH}_{4}\right]$ (13 studies [31, 33, $25,160,161,106,61,166,165,42])$, acetylene $\left[\mathrm{C}_{2} \mathrm{H}_{2}\right]$ (one study [165]), ethylene $\left[\mathrm{C}_{2} \mathrm{H}_{4}\right]$ (one study [165]) and toluene $\left[\mathrm{C}_{7} \mathrm{H}_{10}\right]$ (3 studies $\left.[33,61,42]\right)^{9}$. Oxygenated species include ethanol $\left[\mathrm{C}_{2} \mathrm{H}_{5} \mathrm{OH}\right]$ (22 stud-

\footnotetext{
${ }^{9}$ Note Gspann et al. [33] use $\mathrm{mg} \mathrm{min}^{-1}$ instead of $\mathrm{g} \mathrm{h}^{-1}$ for their carbon precursor input rate.
}

ies $[18,28,168,23,24,169,157,32,34,70,69,163,61$, 164, 124]), n-butanol [ $\left.\mathrm{CH}_{3} \mathrm{CH}_{2} \mathrm{CH}_{2} \mathrm{CH}_{2} \mathrm{OH}\right]$ (9 studies $[170,171,162,42])$ and acetone $\left[\mathrm{CH}_{3} \mathrm{OCH}_{3}\right]$ (3 studies $[26,30,25])$. Combinations of hydrocarbon sources which have also proved successful, include methanol $\left[\mathrm{CH}_{3} \mathrm{OH}\right]$ with $n$-hexane $\left[\mathrm{C}_{6} \mathrm{H}_{14}\right]$ (2 studies $\left.[159,59]\right)$, and ethanol with acetone (one study [167]). A direct-spun reaction has also been reported using 1propanol $\left[\mathrm{CH}_{3} \mathrm{CH}_{2} \mathrm{CH}_{2} \mathrm{OH}\right]$, diethylether $\left[\left(\mathrm{C}_{2} \mathrm{H}_{5}\right)_{2} \mathrm{O}\right]$, ethylene glycol $\left[-\left(\mathrm{CH}_{2}-\mathrm{CH}_{2}-\mathrm{O}\right)_{9}\right]$ [232] and ethylformate $\left[\mathrm{CH}_{3} \mathrm{CH}_{2} \mathrm{COOH}\right]$. Attempts at direct-spun production using methanol, $n$-hexane, benzene $\left[\mathrm{C}_{6} \mathrm{H}_{6}\right]$ and mesitylene $\left[\mathrm{C}_{6} \mathrm{H}_{3}\left(\mathrm{CH}_{3}\right)_{3}\right]$ on their own have been unsuccessful [18, 28]; however, the addition of methanol to the hydrocarbons (hexane, benzene and mesitylene) made it possible [18, 159].

In direct-spun processes, there are two routes to the release of $\mathrm{C}$ from the hydrocarbon for CNT growth. The first is catalytic breakdown of the precursor molecule on the Fe-based nanoparticle. The second is the thermal pyrolysis of the precursor molecule, resulting in the formation of a range of pyrolytic carbon products, followed by a further catalytic breakdown of these pyrolysis products. The supply of pyrolysis products concurrently drive the formation of generally unwanted carbon species (for example carbonencapsulated catalyst nanoparticles, amorphous carbon deposits, wide diameter, badly deformed carbon tubules and soot [33]). Information on decomposition temperatures and bond dissociation energies are available for all of the hydrocarbon sources commonly used in direct-spun systems [233, 234, 235, 236, 237]. This information provides a simple explanation of i) the expected temperature at which carbon should start to become available via pyrolysis and ii) by considering which bonds have the lowest dissociation energy, the types of pyrolysis products which might emerge. However, often pyrolysis data is collected under vacuum conditions or uses inert gases as buffers to keep systems 
oxygen-free. Therefore care must be taken in extrapolating information related to the reported decomposition products (particularly solid carbon) to direct-spun systems. Direct-spun systems often contain high concentrations of $\mathrm{H}_{2}$ which can participate in the pyrolysis processes, leading to a different balance of decomposition products than that derived in hydrogen-free systems [185].

\subsubsection{Loss of carbon as $C O$}

When considering selection of a carbon source with respect to the maximum amount of carbon available for CNT growth per mole of species, the pyrolytic breakdown pathways are particularly pertinent. Being isostoichiometric, in optimised reaction conditions, both methane and methanol should release the same amount of C per unit molecule for CNT growth. However, direct-spun processes can be run with methane but not with methanol alone [238]. This is because $90 \%$ of carbon released via methanol pyrolysis forms carbon monoxide (CO) [236] via a multistage mechanism initiated by the breaking of the $\mathrm{H}-\mathrm{CH}_{2} \mathrm{OH}$ bond, the weakest in the molecule, that then proceeds via the formation of formaldehyde $\left(\mathrm{H}_{2} \mathrm{C}=\mathrm{O}\right)$ to $\mathrm{CO}$ while the remainder converts to $\mathrm{CH}_{4}$ [239]. Given the strength of the carbon-oxygen bond, $\mathrm{CO}$ remains stable in the reactor, leaving with the exhaust gases, and removing the carbon from CNT growth mechanisms. This possibility of $\mathrm{CO}$ acting as a carbon sink needs to be considered for all alcohols.

Ethanol decomposition via the beta-scission mechanism [240] also results in the formation of $\mathrm{CH}_{4}$, ethane, ethylene, small amounts of $\mathrm{CO}_{2}$ and $\mathrm{H}_{2} \mathrm{O}$ [236, 241]. The utilisation of only the beta-scission carbon from ethanol molecules for CNT growth has more recently been supported by experiments with isotopically labelled ethanol $\left({ }^{12} \mathrm{CH}_{3}-{ }^{13} \mathrm{CH}_{2}-\mathrm{OH}\right)$ which found that no ${ }^{13} \mathrm{C}$ was incorporated into the CNT structures [242]. The hydrocarbons released from ethanol decomposition continue on high temperature reaction paths through to acetylene [236]. Any small amounts of $\mathrm{CO}_{2}$ in the presence of trace $\mathrm{H}_{2} \mathrm{O}$ may react with $\mathrm{H}_{2}$, undergoing a high-temperature water-gas shift reaction, catalysed by Fe-based catalysts resulting in the presence of $\mathrm{CO}$ in the exhaust gas. Both $\mathrm{CO}$ and $\mathrm{CO}_{2}$ ultimately act as carbon sinks with respect to the directspun growth. For example Zhang et al. [164] detected $\mathrm{CO}$ and $\mathrm{CO}_{2}$ in the gases exiting a $\mathrm{FC}-\mathrm{CVD}$ reactor when using ethanol. Their exit gas analysis showed $12.78 \mathrm{~mol} \%$ methane, $8.53 \mathrm{~mol} \%$ carbon monoxide, $0.08 \mathrm{~mol} \%$ carbon dioxide, and $78.60 \mathrm{~mol} \%$ hydrogen. Ethylene and hydrogen sulphide were also detected in negligible quantities.

Multiple decomposition routes and intermediates available through $n$-butanol make calculation of the absolute losses to CO much more complicated [243], particularly as the first stage of the decomposition seems to split equally between two routes: a dehydrogenation route which ultimately leads through to the formaldehyde decompostion previously described for methanol, and a dehydration route, where $\mathrm{H}_{2} \mathrm{O}$ is the first small molecule eliminated. Acetone, which is also used in direct spinning [30] loses up to $43 \%$ of its carbon to $\mathrm{CO}$ and proceeds via initial scission of the $\mathrm{H}_{3} \mathrm{C}-\mathrm{C}(\mathrm{O}) \mathrm{CH}_{3}$ bond [239].

\subsubsection{Pyrolysis products including acetylene}

There is evidence that acetylene is the main precursor molecule for CNT synthesis, despite the wide range of carbon precursors used [244, 245]. Eres et al. [244] carried out CNT growth experiments under vacuum via impinging a molecular beam of hydrocarbon molecules onto a heated catalyst target. The technique prevents secondary collisions of the precursor molecule (or any of its pyrolysis products) with the catalyst, hence allowing quantification of the amount of CNT growth from a particular carbon source. Acetylene pyrolysis produced an order of magnitude more CNT growth than propylene, while methane, ethylene, benzene and xylene produced no CNTs. The authors concluded that CNT growth from most of the commonly used carbon sources is via their secondary, decomposition products. Zhong et al. [245] used a mixture of $10 \%$ by volume $\mathrm{CH}_{4}$ diluted in $\mathrm{H}_{2}$ in a plasma-enhanced CVD reactor to grow a SWCNT carpet on a heated substrate. They showed that the carbon precursor leading to SWCNT growth was not $\mathrm{CH}_{4}$, as the SWCNTs did not grow when the plasma (which would crack the $\mathrm{CH}_{4}$ ) was switched off. Analysis by mass spectroscopy identified conversion of the $\mathrm{CH}_{4}$ to acetylene and the researchers further confirmed acetylene as the active species by carrying out a successful SWCNT growth experiment without the plasma, under otherwise comparable conditions using $5 \%$ acetylene in $\mathrm{H}_{2}$.

These experimental results agree with the modelling work of Kuwana et al. [246] who carried out a numerical analysis for the pyrolysis of xylene and toluene in the presence of $10 \% \mathrm{H}_{2}$. They showed that considerable quantities of acetylene can be generated above $700{ }^{\circ} \mathrm{C}$. $\mathrm{CH}_{4}$ pyrolysis begins at $1000{ }^{\circ} \mathrm{C}$ [247] and is very slow as shown in [248] where in a $\mathrm{H}_{2}$ environment, $\mathrm{CH}_{4}$ only cracks catalytically, producing no amorphous carbon deposits over a period of 10 minutes. However, once $\mathrm{CH}_{4}$ pyrolysis occurs, it also produces acetylene as a tertiary decomposition product [249]. Thermodynamic calculations show that most hydrocarbons become unstable as the temperature of the system is increased whereas acetylene becomes more stable as temperature increases [250]. While acetylene remains unstable relative to both hydrogen and carbon in these circumstances, it can be assumed that, due to Le Chatelier's principle $\left(\mathrm{C}_{2} \mathrm{H}_{2} \rightleftharpoons 2 \mathrm{C}+\mathrm{H}_{2}+227 \mathrm{~kJ} \mathrm{~mol}^{-1}\right.$ [251]), the presence of an excess of $\mathrm{H}_{2}$ in direct-spun systems would shift the position of equilibrium towards acetylene [251].

Lee et al. [165] have successfully showed direct-spun production using three different hydrocarbon sources (methane, acetylene and ethylene) injected at different locations of the reactor (using independent injection tubes) relative to the catalyst source. The authors showed that product can be successfully spun from methane, with a high decomposition temperature, 
for injectors at a wide range of locations. However, for acetylene and ethylene, spinning was only possible within very narrow ranges of injector locations. The hypothesis for this was that the catalyst particles were deactivated due to the excess carbon released before a critical catalyst nanoparticle size could be reached.

Within a critical temperature window the authors were able to use almost two orders of magnitude less moles of carbon for acetylene and ethylene compared with methane, for the same conditions. In addition, measured $I_{\mathrm{G}} / I_{\mathrm{D}}$ ratios were 70,19 and 4 for acetylene, ethylene and methane, respectively, therefore acetylene produced CNTs with higher purity. Note that unlike the conventional injection of precursors at the upstream end of the reactor, different injection locations resulted in complete separation of catalyst growth and CNT synthesis.

\subsubsection{What is the ideal carbon source?}

In future, to make a fair comparison in terms of ideal hydrocarbon sources for direct-spun processes, hydrocarbon sources need to be supplied at rates where their carbon availabilities (based on their pyrolysis mechanisms) are comparable. At the same time,the dilution of the hydrocarbon source and the concentrations of the $\mathrm{Fe}$ and $\mathrm{S}$ precursors must be held constant. At present, studies controlled to this level of detail do not exist in the literature.

Despite the evidence pointing towards pyrolysis products including acetylene, identification of the active carbon building blocks for CNT growth in the direct-spun system is still an open question. Data need to be supported by a quantitative analysis of decomposition routes of common carbon sources in hydrogen environments.

A route to achieve direct-spun product selectivity with respect to SWCNTs, DWCNTs and MWCNTs, while maximising reaction yield, could be through use of a mixture of carbon precursors (rather than individual hydrocarbon species) leading to an idealised pyrolytic carbon mixture. This requires detailed knowledge of the pyrolysis processes in the system and definition of what the ideal pyrolysis mixture is. A lack of literature covering these pyrolysis routes means thermodynamic and kinetic modelling are unavailable to inform researchers about the reaction intermediates. In examples where authors have used binary mixtures of carbon precursors $[167,159,59]$ there is no direct link made between their choices and pyrolysis chemistry or overall yield.

\subsection{Effect of $\mathrm{Fe} / \mathrm{C}$ ratio on catalyst nanoparticle effi- ciency}

While the experiments studied in this analysis have successfully synthesised CNTs using different reactors, mixtures, temperatures, and flow rates, the proportions of iron to carbon molar ratios leading to successful CNT aerogel formation fall into a relatively narrow band. Figure 11 highlights this fact, showing the iron to carbon molar input for the studies reviewed. There is a clear correlation between the required amounts of

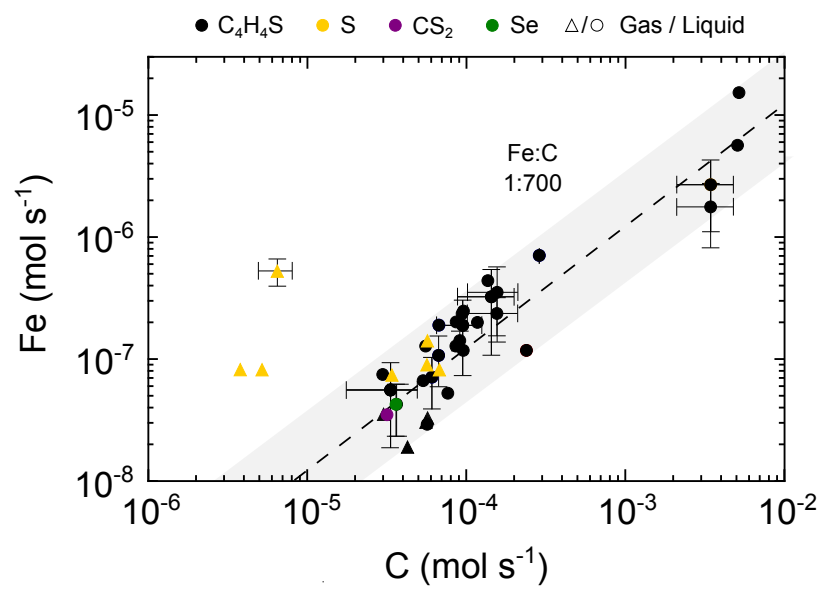

Figure 11: The total iron (ordinate) and carbon (abcissa) molar flow rates for all successful direct-spinning experiments in the dataset. The triangles (circles) represent gas (liquid) injection experiments. The colours of the data points indicate the promoter source used in each experiment. Black, yellow, purple and green correspond to thiophene, sulfur, carbon disulfide and selenophene. The dataset is bounded by high and low Fe : $\mathrm{C}$ ratios of $1: 300$ and $1: 2500$ shown as the grey shaded area and a trend line at $\mathrm{Fe}: \mathrm{C}=1: 700$ is shown.

Fe and $\mathrm{C}$ for a successful direct-spun formation, presented by the dashed (black) trend line in the shaded grey box of Figure 11. The trend line corresponds to a molar $\mathrm{Fe}: \mathrm{C}$ ratio of 0.0014 , this ratio corresponds to approximately $1 \mathrm{Fe}: 700 \mathrm{C}$. The shaded grey area encompasses the majority of the $\mathrm{Fe}$ : $\mathrm{C}$ ratios from 0.0004 to 0.003 which correspond to molar ratios of $1 \mathrm{Fe}: 2500 \mathrm{C}$ and $1 \mathrm{Fe}: 300 \mathrm{C}$, respectively.

The direct-spun process does not currently make efficient use of the iron catalyst with respect to CNT growth. Reguero et al. [170] calculated that less than $0.1 \%$ of the Fe-based nanoparticles formed contributed to CNT aerogel formation. The final CNT products tend to include from 5 to $10 \mathrm{wt} \%$ iron residue which can be readily removed by acid washing $[252,253,74,104]$. Such metal catalyst impurities can significantly affect to the bulk properties of the direct-spun products. Therefore keeping these catalytic nanoparticles unencapsulated such that they have a higher chance of acting as a catalyst site for growth is very important. If the carbon to iron input is too high $(\mathrm{C}: \mathrm{Fe}>2500: 1$ bottom right of Figure 11), an oversupply of carbon leads to soot production dominating over CNT synthesis. If the carbon to iron input is too low $(\mathrm{C}: \mathrm{Fe}$ $<300$ : 1 top left of Figure 11) there are insufficient CNTs to form bundles and create an aerogel. Combing the findings of Section 4.2 and Section 5.2 we conclude that for sulfur and thiophene experiments the range of corresponding molar ratios $(\mathrm{C}: \mathrm{Fe}: \mathrm{S})$ for optimal aerogelation are $70000: 100: 10$ to $700: 1: 10$, respectively.

In addition, a minimum catalyst mass concentration $\left([\mathrm{Fe}]=0.2 \mathrm{~g} \mathrm{~m}^{-3}\right)^{10}$ has been identified [166] which is complementary to the window of successful molar ra-

\footnotetext{
${ }^{10}$ The amount of $\mathrm{S}$ is a negligible contributor to the minimum
} Fe mass concentration. 
tios for aerogel formation. The majority of the data points in Figure 11 fall above this minimum value by orders of magnitude, even with losses ${ }^{11}$. A calculation using simplified conditions at a temperature of $1000{ }^{\circ} \mathrm{C}$ showed that approximately $40 \%$ of $10 \mathrm{~nm}$ diameter catalyst particles would be lost to the reactor walls and that the proportion lost would increase dramatically with increasing particle diameter [166]. In addition to this, losses to the walls are further evidenced by deposition bands observed on the reactor walls, which are located at specific temperature related positions (see supplementary information associated with Hoecker et al. [161]).

\subsection{Carbon efficiency and process yield}

Figure 12 shows the process yield $\eta_{\mathrm{p}}(\%)$ as a function of carbon efficiency $\eta_{\mathrm{c}}(\%)$. The process yield is defined here as the molar production rate of directspun product $\dot{n}_{\mathrm{CNT}}$ per total molar input rate of all reactants $\dot{n}$ (see Appendix 9, note that the values of $\dot{n}$ are dominated by the carrier gases). The carbon efficiency $\eta_{\mathrm{c}}$ is defined as the molar production of carbon in the direct-spun product divided by the rate of total molar carbon supplied into the system (represented by $\dot{n}_{\mathrm{CNT}} / \dot{n}_{\mathrm{c}}$, note that $\dot{n}_{\mathrm{c}}$ is dominated by carbon from the hydrocarbon source, with negligible amounts supplied by catalyst and promoter precursors).

$$
\eta_{\mathrm{p}}=\frac{\dot{n}_{\mathrm{CNT}}}{\dot{n}}=\frac{\dot{n}_{\mathrm{c}}}{\dot{n}} \frac{\dot{n}_{\mathrm{CNT}}}{\dot{n}_{\mathrm{c}}}=X_{\mathrm{c}} \eta_{\mathrm{c}}
$$

In Equation 1, multiplication of numerator and denominator by $\dot{n}_{\mathrm{c}}$ allows rearrangement to show that the mole fraction of carbon $\left(X_{\mathrm{c}}=\dot{n}_{\mathrm{c}} / \dot{n}\right)$ is the scalar linking $\eta_{\mathrm{p}}$ and $\eta_{\mathrm{c}}$. Figure 12 draws data from only the eight publications in our survey of the literature that have reported yield figures, providing a total of 15 data points [30, 169, 33, 170, 171, 161, 167, 124]). They cover a range of different hydrocarbon sources and carrier gas types.

Section 5.1.1 indicates that the maximum carbon efficiencies that might be achieved from ethanol and $n$ butanol are $50 \%$ and $63 \%$, respectively. The lower carbon efficiencies shown in Figure 12 highlight the improvement required from these hydrocarbon sources. Figure 12 shows that, although processes vary greatly in scale, type of hydrocarbon and carrier gases, the common feature in the direct-spun process is the low mole fraction of carbon in the reactor systems, typically $X_{\mathrm{c}}=0.03$. This means that systems are run very dilute with respect to carbon. At lower dilution values (higher carbon mole fractions), the increased carbon concentration would cause excess soot production. At higher dilution values (lower carbon mole fractions), there would be insufficient carbon present to synthesise sufficient CNTs (either with respect to length or number concentration) to form a spinnable aerogel.

\footnotetext{
${ }^{11}$ Minimum input does not include losses to the reactor walls, with diffusion accounting for up to half of the mass being lost.
}

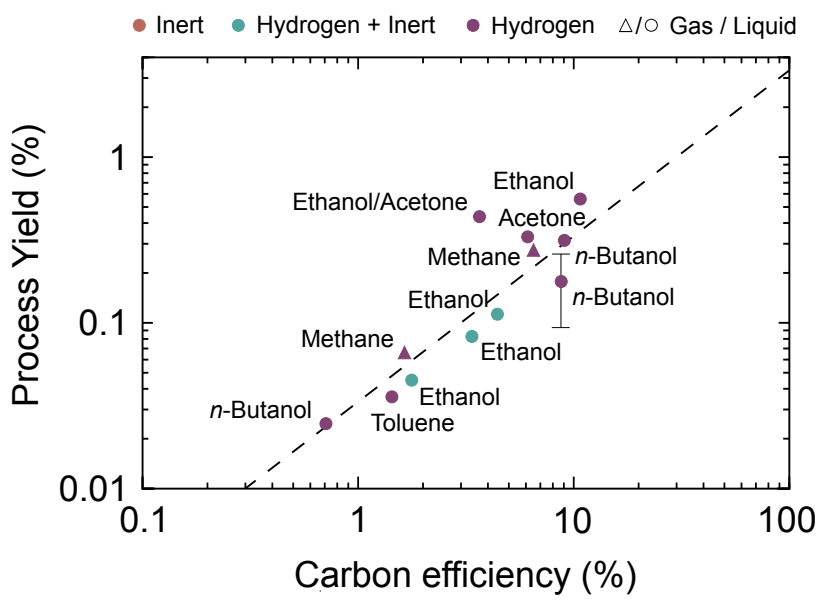

Figure 12: Process yield (\%, ordinate) and carbon efficiency $(\%$, abcissa) for all successful direct spinning experiments in the dataset. The triangles (circles) represent gas (liquid) injection experiments. Red, green and purple data points represent inert gas (meaning $\mathrm{Ar}$ or $\mathrm{N}_{2}$ ), hydrogen + inert (meaning a mixed carrier gas system of $\mathrm{H}_{2}$ with either $\mathrm{N}_{2}$ or $\mathrm{Ar}$ ) and hydrogen, respectively.

The availability of only 15 data points for this study shows that quantitative relations with respect to carbon efficiency and process yield are lacking in the literature. While studies have not linked carbon efficiency or processes yields to macroscopic product properties (strength, conductivity, etc.) these correlations are crucial process intensification metrics. Measuring them will increase the ability of researchers to compare and contrast their quantitative results with greater confidence. Based on the current data, the direct-spun synthesis process is not efficient and researchers need to increase the carbon conversion and minimise the quantities of the non-CNT components of their materials, for example iron residue and amorphous carbon by products.

\subsection{Role of sulfur in CNT growth promotion}

Having discussed how the interaction of $\mathrm{S}$ with $\mathrm{Fe}$ influences nanoparticle formation in Section 4.1.2, it is important to discuss the role $\mathrm{S}$ plays in CNT growth. Sulfur has been identified as a growth promoter in vapour-grown carbon fibre systems [254]. The role of S as a promoter was shown in individual CNT synthesis via electric arc, where it increased CNT yields [255] and diameters [256]. The same effects were identified in early CVD synthesis of CNTs, where addition of different amounts of $\mathrm{S}$ controlled product type, and ratio (SWCNTs vs. MWCNTs), and also improved yield [19]. A recent publication by Suzuki and Mori [223] has quantified the increase in the rate of areal coverage of individual CNTs during carpet growth when including $\mathrm{S}$ in their reaction system, providing the first kinetic information on the impact of $S$ in CNT growth. Similar qualitative effects have been observed in the direct-spinning process with increasing S promoting the production of MWCNTs [157, 170].

Figure 13 shows $\mathrm{S} / \mathrm{Fe}$ molar ratios versus $\mathrm{C} / \mathrm{H}$ molar ratios. The minimum and maximum $\mathrm{S} / \mathrm{Fe}$ ratios (see 


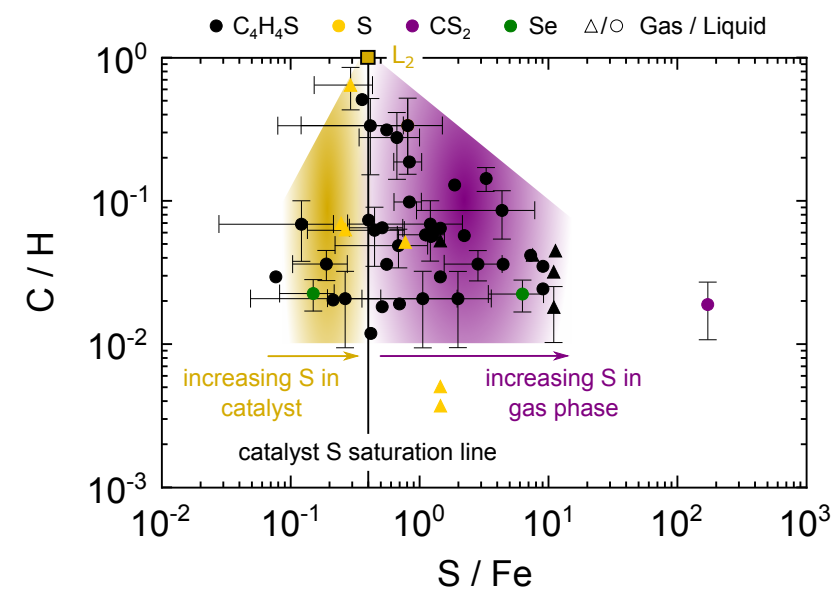

Figure 13: Total carbon to hydrogen molar ratio (ordinate) versus sulfur to iron molar ratio (abcissa) for all successful direct spinning experiments in the dataset. The yellow square at the apex of data represents the $\mathrm{L}_{2}$ composition with respect to $\mathrm{Fe}$ and $\mathrm{S}$ from Figure 8. This is the maximum amount of sulfur that can be present in a catalyst nanoparticle composed solely of $\mathrm{L}_{2}$. All the $\mathrm{S} / \mathrm{Fe}$ ratios in the yellow shaded area fall within the $\mathrm{L}_{1}+\mathrm{L}_{2}$ zone in Figure 8 while those in the purple shaded area have higher S contents. Black, yellow, purple and green correspond to thiophene, sulfur, carbon disulfide and selenophene.

Section 4.2) are 0.1 and 10 , respectively. The minimum and maximum $\mathrm{C} / \mathrm{H}$ ratios are 0.01 and 1 , respectively. The data shows that $\mathrm{C} / \mathrm{H}$ ratios from 0.01 to 0.1 are successful across all $\mathrm{S} / \mathrm{Fe}$ ratios. The data above $\mathrm{C} / \mathrm{H}>0.1$ reaches a maximum at $\mathrm{C} / \mathrm{H}=1$ and $\mathrm{S} / \mathrm{Fe}=$ 0.6 . This $\mathrm{S} / \mathrm{Fe}$ value is equivalent to a $\mathrm{S}: \mathrm{Fe}$ mass ratio of $74 \%: 26 \%$, matching very closely the composition of the sulfur-rich liquid, $\mathrm{L}_{2}$, in Figure 8.

We observe that higher $\mathrm{S} / \mathrm{Fe}$ ratios require decreasing $\mathrm{C} / \mathrm{H}$ ratios. We know from our dataset that decreases in the $\mathrm{C} / \mathrm{H}$ ratio are mainly caused by increased amounts of $\mathrm{H}$ (principally via carrier gas) for successful production of direct-spun product. We hypothesise that increasing $\mathrm{S} / \mathrm{Fe}$ ratio beyond the catalyst $\mathrm{S}$ saturation line (indicated by the solid black line on Figure 13) requires an increase in $\mathrm{H}$ to deal with the excess $\mathrm{S}$ in the gas phase, resulting in a dropping $\mathrm{C} / \mathrm{H}$ ratio. Thermodynamic calculations show that $\mathrm{H}_{2} \mathrm{~S}$ is the likely sink for $\mathrm{S}$ in the gas phase [186].

Having identified that additives are important for catalyst nanoparticle nucleation and CNT growth, the following question remains: is a group 16 element the most appropriate choice for these roles. The body of evidence supporting sulfur is strong, with exploration of other group 16 elements limited by their lack of availability due to their expense. However there maybe other elements more suitable to these roles, for example iodine is known to lower the nucleation barrier of aerosol particles in a variety of systems [257]. Furthermore, $\mathrm{Mn}$ and $\mathrm{Ni}$ are known to lower the melting points of $\mathrm{Fe}-\mathrm{C}-(\mathrm{Mn} / \mathrm{Ni})$ eutectics and lower their resulting carbon content [258, 259], analogous to the role sulfur plays in CNT growth promotion.

\section{Summary of process and conclusions}

The trends observed from mapping the experimental data and the associated conclusions regarding the roles of the key elements $(\mathrm{Fe}, \mathrm{S}, \mathrm{C}, \mathrm{H})$ in the directspinning process facilitate a much richer description of their roles. The schematic in Figure 14 summarises the role of each element in the various process steps.

The first step in the reaction pathway in Figure 14 represents the decomposition of iron and sulfur precursors, releasing the corresponding Fe (pink) and S (yellow) atoms for catalyst nanoparticle nucleation (See Section 4.1.2). Carbon precursor molecules have not undergone pyrolysis at this stage (see section 5.1), so is not illustrated in this step. The second step represents catalyst nanoparticle nucleation, promoted by $\mathrm{S}$ with catalyst nanoparticle structures starting off as Fe and $\mathrm{Fe}+\mathrm{L}_{\mathrm{Fe}}$ as shown in Figure 9. Catalyst nanoparticles increasing in temperature will be evolving towards $\mathrm{L}_{1}+\mathrm{L}_{2}$ structures capable of rapid CNT growth (described in Section 4.3.2) but diffusion losses of small catalyst nanoparticles and evaporation of the remaining particles will be competing with this process.

At the renucleation and CNT growth stage, the pathways differ depending on whether high (Figure 14(a)) or low (Figure 14(b)) S/Fe ratios are present, however for both routes the CNT growth is driven by acetylenelike pyrolytic carbon compounds (see Section 5.1.2). Sufficient dilution of the entire reaction system by carrier gas is required such that carbon molar concentration does not exceed 3\% (see Section 5.3). The presence of $\mathrm{H}$ also chemically suppresses soot formation (see Section 5.4).

Figure 14(a) illustrates how a high $\mathrm{S} /$ Fe ratio leads to catalyst nanoparticles of predominantly $\mathrm{L}_{2}$ composition (see Figure 8(b)(iii)), therefore the whole diameter of the catalyst nanoparticle is used for CNT growth, generally favoring MWCNT synthesis. Where the S/Fe ratio is high, results point towards $\mathrm{H}$ being utilised in the reaction to remove excess $\mathrm{S}$ from the catalyst into the gas phase (see Section 5.4).

Figure 14(b) illustrates how a low S/Fe ratio leads to catalyst nanoparticles of predominantly $\mathrm{L}_{1}$ with only a little $\mathrm{L}_{2}$ (see Figure $8(\mathrm{~b})(\mathrm{i})$ ). This restricts the sizes of the sites from which CNTs grow, favouring rapid growth of nanotubes of small diameter, therefore predominantly SWCNTs or DWCNTs, with the possibility of growing more than one CNT from each catalyst nanoparticle (see Section 4.3.1).

The final steps on both pathways represent the selfassembly of CNTs into bundles driven by van der Waals dispersive forces and the further assembly of bundles to create the continuous aerogel which allows continuous, direct spinning of the macroscopic CNT material.

In conclusion, drawing information from 32 papers providing sufficient quantitative data we have carried out a detailed meta analysis of the reaction inputs $(\mathrm{S}$, $\mathrm{Fe}, \mathrm{H}, \mathrm{C})$ required for the direct-spinning of CNTs. We have mapped these with product type (SWCNTs, DWCNTs, and MWCNTs) and against one another to identify and quantify the key parameters controlling 


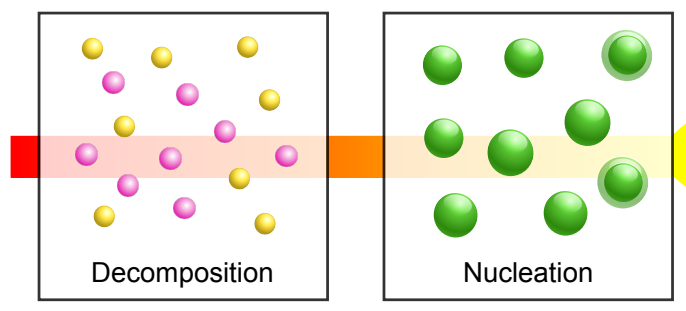

(b)

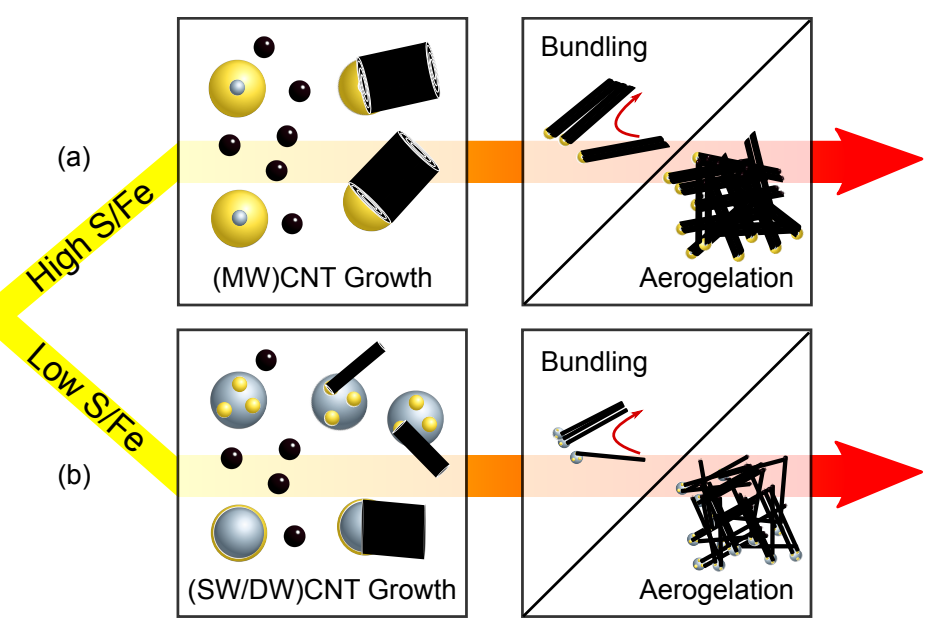

Figure 14: Schematic showing the impact of high (a) and low (b) sulfur to iron ratios on direct-spun CNT product synthesis. High S/Fe ratios favour MWCNT synthesis while low S/Fe ratios favour SW- or DWCNT synthesis due to the different catalyst nanoparticles formed. The pink, yellow and black circles represent decomposition of precursor sources releasing iron, sulfur and carbon, respectively.

the synthesis. Comparison of observed features and trends in these plots with research findings from across the broader literature spectrum have facilitated the development of new insights regarding factors controlling direct-spun synthesis.

\section{Challenges and opportunities}

We now identify possible opportunities and challenges for future research in this area. The knowledge gained since the process was originally conceived has allowed scale up to the pilot stage of commercialisation of direct-spun processes, but increased reaction densities are desired for further commercialisation. There remain many areas of the process yet to be fully understood despite this body of work. Process scale up can be achieved by two main approaches: i) a simple increase in the number or size of reactors, ii) process intensification via increasing the yield per unit product or per unit volume. To do so, research has to be carried out across a number of key areas.

As evidenced by this article, to date there is no quantitative theory for the formation of CNTs in the directspun process, either for nucleation or agglomeration. A main missing link is the ability to describe the steps in the chemical decomposition and nucleation process, as there are no quantitative inline measurements of the chemical species within the reactor. A major advancement would be the development of both non-intrusive and/or intrusive techniques for probing the chemical species in the reactor at conditions similar to those leading to the formation of precursor particles and onwards to CNT aerogels. There are no publications demonstrating the required optical access and chemical analysis capabilities for generating the necessary information. In part, there are rather specific challenges associated with probing inside these reactors, most importantly the diffusion of particles onto optically accessible surfaces, which hamper optical access, and the need for high temperatures and hydrogen atmospheres, which creates difficulties for sealing and sampling. A re-engineered reactor with the right temperature-time histories, but optical and sampling access would enable in situ or ex situ probing of the chemical environment, thus shedding direct light into the steps leading to the building blocks in the direct-spun process. Optical probing of the reactor would enable laser-based diagnostics, such as absorption, fluorescence and Raman spectroscopy, that could provide chemical and particle information critical in understanding the nucleation, growth and aerogelation of CNTs. These experimental studies would enable a computational model of the reactor dynamics to explain critical questions relating to the nature of particle formation, CNT growth and aerogelation.

The few reported quantitative results on product yield rely on manual fibre collection and determination of total weight, this is a relatively crude and time consuming technique. Emerging technologies using the unique properties of untreated CNT aerogels may be developed to design equipment utilising these properties to develop automated extraction techniques.

Given the self-selected nature of the reporting of results on aerogel formation, at present we do not know what happens beyond the bounds of the currently mapped parameter space. It is unclear whether current bounds of compositions and temperatures are truly limits to direct spinning, or simply a result of the historical development of the dataset. There is currently no general and robust method for measuring the lengths of bundled CNTs in situ, so one cannot interrogate the effect of operating conditions on the lengths of the constituent CNTs. This presents an opportunity for the development of experimental techniques; understanding the factors controlling the mean CNT length and the spectrum of length distribution in a sample may offer new ways of controlling the macroscopic material properties.

A step change in CNT production is still needed for broad-scale commercialisation, and fundamental in- 
sights into the reactor kinetics and dynamics are necessary to aid this development. Key questions remain related to the nature of intensified production, including whether higher synthesis densities can be achieved in laminar reactors and whether CNTs can grow and form aerogels within turbulent reactors. Novel reactor designs should be considered that go beyond singlepass tube furnaces to improve reactor density and manipulate aerogel formation. In-reactor and downstream aerogel manipulation is needed to better align product with enhanced properties, as well as process the aerogel downstream of the reactor. New discoveries into the chemical kinetics, particle dynamics and aerogel structure will be critical in improving the quantity, quality and efficiency of CNT production. These fundamental discoveries are needed by the scientific and engineering communities to harness the potential of this unique self-assembled CNT material for wide-spread utilisation across a broad range of applications.

\section{Acknowledgements and supporting informa- tion}

Lee Weller and Fiona Smail are both funded under EPSRC UK Award EP/M015211/1 within the ANAM Initiative. We thank Maxim Kuvshinov, Brian Graves and Liron Issman (University of Cambridge, Engineering Department) for reading and commenting on the manuscript. We thank Joe Stallard for providing the data files for creating Figures 1 and 2. We thank all corresponding authors associated with the publications in this article for supplying the relevant data where required.

The dataset associated with this article is available at the following DOI (10.17863/CAM.31712) or from the corresponding author on request.

\section{Appendix A : Experimental conditions}

This Appendix shows the calculations applied to the data found in each publication used in the parameterspace mapping exercise for the direct-spun FC-CVD process. Sections 9.1 to 9.5 cover calculations leading to residence times, process yields, vapour pressures, molar and mass flow rates and total mass concentrations, respectively. The authors highlight where particular calculations can suffer limitations to their accuracy (process yields 9.2) and any publications where values calculated by the original authors used a nonstandard method (vapour pressure section 9.3 and Table 1). The Appendix ends with a Table (Table 2) showing how all the data extracted from an example publication has been treated for inclusion in the mapping exercise.

\subsection{Bulk residence time}

The bulk residence time, $\tau_{\text {res }}$, is defined as [265]

$$
\tau_{\text {res }}=\frac{L \pi(D / 2)^{2}}{\dot{Q}} \frac{T_{0}}{T_{\mathrm{s}}},
$$

where the ratio of reactor volume ( $L$ and $D$ are the length and diameter dimensions of the tubular reactor in $\mathrm{m}$, respectively) to the total volumetric flow rate, $\dot{Q}$, is corrected for temperature $\left(T_{0}\right.$ and $T_{\mathrm{s}}$ are the reference temperature and set-point temperature of the furnace in $\mathrm{K}$, respectively).

There are individual residence times that could be calculated for different sections of the reactor, using fluid dynamic calculations. This requires specific knowledge of each author's temperature profile. Therefore in this publication we have chosen to calculate just the bulk residence time for each reactor.

\subsection{Carbon efficiency and process yield}

The carbon efficiency, $\eta_{\mathrm{c}}(\%)$, is defined as the percentage of the total harvested aerogel moles, $\dot{n}_{\text {out }}$, relative to the total supplied carbon moles, $\dot{n}_{\text {in }}$, in a given time interval.

The process yield, $\eta_{\mathrm{p}}(\%)$, is defined as the percentage of the total harvested aerogel moles, $\dot{n}_{\text {out }}$, relative to the total supplied moles, $\sum \dot{n}_{\text {in }}$, in a given time interval.

The authors acknowledge that in all cases the total harvested aerogel includes not only the mass of CNTs, but also a large quantity (typically up to $15 \%$ from TGA measurements) of extraneous materials (such as soot-like polyaromatic particles, graphitic impurities, and carbon-encapsulated iron) which often leads to an overestimation of the yield.

\subsection{Vapor pressure and partial pressures}

The vapour pressure (in bar), $P_{v}$, for the molecules of interest is given by the Antoine equation

$$
\log P_{v}=A-\frac{B}{C+T}
$$

where $A, B$ and $C$ are component-specific constants and $T$ is the absolute temperature (in $\mathrm{K}$ ). Table 1 shows the corresponding parameters used to calculate the typical vapour pressures one expects for the molecules of interest in the direct-spun process.

Note that one author group, accounting for $\approx 10 \%$ of the included data points, chose to use the Langmuir equation for evaporation [25, 160, 165] converting the vapour pressure (equation 3 ) to an evaporation rate. The use of a vaporisation constant $(\alpha)$ within the equation, with dependence on the dimensions of the sublimation pack and carrier gas flow rate, make this difficult to apply to other authors' work. Therefore, to correlate data from this publication we have chosen to base the mass rate of sublimed precursors solely on Equation 3 and partial pressures. The partial pressure quantity is equal to the calculated vapour pressure, $P_{v}$, divided by the atmospheric pressure, $P_{0}$.

\subsection{Molar and mass flow rate of molecules}

The molar flow rate, $\dot{n}_{\text {in }}$, of a given species is the product of the partial pressure and total volumetric flow rate with respect to the volume $\left(0.0224 \mathrm{~m}^{3}\right)$ of one mole of an ideal gas at standard pressure and gas 
Table 1: Antoine equation parameters and range of temperatures for the molecules of interest.

\begin{tabular}{lccccccc}
\hline \hline Molecule & Formula & $T_{\min }[\mathrm{K}]$ & $T_{\max }[\mathrm{K}]$ & $A$ & $B$ & $C$ & Reference \\
\hline Ferrocene & $\mathrm{C}_{10} \mathrm{H}_{10} \mathrm{Fe}$ & 288.16 & 452.09 & 6.43321 & 2982.168 & -38.258 & {$[260]$} \\
Thiophene & $\mathrm{C}_{4} \mathrm{H}_{4} \mathrm{~S}$ & 312.21 & 392.94 & 4.07358 & 1239.578 & -52.585 & {$[261]$} \\
Carbon Disulfide & $\mathrm{CS}_{2}$ & 276.74 & 353.08 & 4.06683 & 1168.620 & -31.616 & {$[262]$} \\
Sulfur & $\mathrm{S}$ & 373.15 & 823.15 & 3.82027 & 2285.382 & -118.149 & {$[263]$} \\
Selenophene & $\mathrm{C}_{4} \mathrm{H}_{4} \mathrm{Se}$ & 234.00 & 387.50 & 3.75976 & 1331.417 & -33.354 & {$[264]$} \\
\hline \hline
\end{tabular}

Table 2: Example experimental conditions for Hoecker et al. [161].

\begin{tabular}{|c|c|c|c|c|c|c|c|c|c|}
\hline$\overline{L L(\mathrm{~m})}$ & $\overline{D(\mathrm{~m})}$ & $\overline{T_{0}\left({ }^{\circ} \mathrm{C}\right)}$ & \multicolumn{2}{|c|}{$T_{\mathrm{s}}\left({ }^{\circ} \mathrm{C}\right)$} & $\overline{\tau_{\text {res }}(\mathrm{s})}$ & \multicolumn{2}{|c|}{$\overline{\dot{m}_{\text {out }}\left(\mathrm{mg} \min ^{-1}\right)}$} & $\overline{\eta_{\mathrm{c}}(\%)}$ & $\overline{\eta_{\mathrm{p}}(\%)}$ \\
\hline 0.7 & 0.04 & 25 & \multicolumn{2}{|c|}{1250} & 14.0 & & 2 & 6.48 & 2.21 \\
\hline Molecule & Formula & $\mathrm{C}$ & $\mathrm{H}$ & $\mathrm{Fe}$ & $\mathrm{S}$ & $\mathrm{O}$ & $M_{\mathrm{m}}\left(\mathrm{g} \mathrm{mol}^{-1}\right)$ & $\rho\left(\mathrm{kg} \mathrm{m}^{-3}\right)$ & $T\left({ }^{\circ} \mathrm{C}\right)$ \\
\hline Ferrocene & $\left(\mathrm{C}_{5} \mathrm{H}_{5}\right)_{2} \mathrm{Fe}$ & 10 & 10 & 1 & 0 & 0 & 186.0 & 1110 & 70 \\
\hline Thiophene & $\mathrm{C}_{4} \mathrm{H}_{4} \mathrm{~S}$ & 4 & 4 & 0 & 1 & 0 & 84.1 & 1050 & 0 \\
\hline Methane & $\mathrm{CH}_{4}$ & 1 & 4 & 0 & 0 & 0 & 16.0 & 0.656 & 20 \\
\hline Hydrogen & $\mathrm{H}_{2}$ & 0 & 2 & 0 & 0 & 0 & 2.0 & 0.08988 & 20 \\
\hline Molecule & $P_{v}(\mathrm{~Pa})$ & $P_{v} / P_{0}$ & \multicolumn{3}{|c|}{$\dot{V}_{\text {in }}\left(1 \mathrm{~min}^{-1}\right)$} & \multicolumn{2}{|c|}{$\dot{n}_{\text {in }}\left(\times 10^{-8} \mathrm{~mol} \mathrm{~s}^{-1}\right)$} & \multicolumn{2}{|c|}{$\dot{m}_{\mathrm{in}}\left(\mathrm{mg} \mathrm{min} \mathrm{min}^{-1}\right)$} \\
\hline Ferrocene & 45 & 0.0004 & \multirow{2}{*}{\multicolumn{3}{|c|}{$\begin{array}{c}0.07 \\
0.012\end{array}$}} & & 1.8 & \multicolumn{2}{|c|}{0.21} \\
\hline Thiophene & 2842 & 0.0280 & & & & & 25.1 & \multicolumn{2}{|c|}{1.27} \\
\hline Methane & 101325 & 1 & \multicolumn{3}{|c|}{0.06} & & 4163.5 & 40.0 & \\
\hline Hydrogen & 101325 & 1 & \multicolumn{3}{|c|}{$0.5(+0.082)$} & & 40385.8 & \multicolumn{2}{|c|}{48.85} \\
\hline Atom & \multicolumn{2}{|c|}{$\dot{m}_{\mathrm{in}}\left(\mathrm{mg} \min ^{-1}\right)$} & \multicolumn{3}{|c|}{$\mathrm{Y}$} & $\dot{n}_{\text {in }}$ & $\left(\times 10^{-8} \mathrm{~mol} \mathrm{~s}^{-1}\right)$ & \multicolumn{2}{|c|}{$\rho_{\text {in }}\left(\times 10^{4} \mathrm{mg} \mathrm{m}^{-3}\right)$} \\
\hline $\mathrm{C}$ & \multicolumn{2}{|c|}{30.86} & \multicolumn{3}{|c|}{0.3414} & & 4282.1 & \multicolumn{2}{|c|}{4.807} \\
\hline $\mathrm{H}$ & \multirow{2}{*}{\multicolumn{2}{|c|}{$\begin{array}{c}58.99 \\
0.06\end{array}$}} & \multirow{2}{*}{\multicolumn{3}{|c|}{$\begin{array}{l}0.6526 \\
0.0007\end{array}$}} & & 97544.3 & \multicolumn{2}{|c|}{9.188} \\
\hline $\mathrm{Fe}$ & & & & & & & 1.8 & \multicolumn{2}{|c|}{0.010} \\
\hline $\mathrm{S}$ & \multicolumn{2}{|c|}{0.48} & \multicolumn{3}{|c|}{0.0053} & & 25.1 & 0.07 & \\
\hline $\mathrm{O}$ & \multicolumn{2}{|c|}{0.00} & \multicolumn{3}{|c|}{0.0000} & & 0.0 & \multicolumn{2}{|c|}{0.000} \\
\hline
\end{tabular}

*standard conditions @ $25^{\circ} \mathrm{C}$ and 1.01325 bar

temperature (in K). The molar flow rate is corrected to the temperature it is supplied at, by introducing a multiplication factor $T_{0} / T$

$$
\dot{n}_{\text {in }}=\frac{P_{v}}{P_{0}} \frac{T_{0}}{T} \frac{\dot{V}_{\text {in }}}{0.0224} .
$$

The mass flow rate, $\dot{m}_{\mathrm{in}}$, is given by the product of the molar flow rate and the molecular mass, $M_{\mathrm{m}}$, of the corresponding species

$$
\dot{m}_{\text {in }}=\dot{n}_{\text {in }} M_{\mathrm{m}} .
$$

\subsection{Atomic mass fraction, total mass and mass con- centration}

The atomic mass fraction, $Y$, is defined as the ratio of atomic (carbon, hydrogen, iron, sulfur and oxygen) mass rates, $\dot{m}_{\mathrm{in}}$, to total atomic mass rate, which is given by the summation of each atomic mass rate.

$$
\dot{m}_{\mathrm{in}}=\sum_{\mathrm{m}} \# \frac{M_{\mathrm{a}}}{M_{\mathrm{m}}} \dot{m}_{\mathrm{in}} .
$$

The molar atomic flow rate, $\dot{n}_{\text {in }}$, is defined as the ratio of atomic mass rate to atomic mass of each atom. The atomic mass concentration, $\rho_{\text {in }}$, is defined as the atomic mass rate divided by the total volumetric flow rate within the reactor.

\section{Appendix $\mathrm{B}: \mathrm{Fe}-\mathrm{S}$ and $\mathrm{Fe}-\mathrm{C}$ binary phase diagrams}

This appendix includes the binary $\mathrm{Fe}-\mathrm{S}$ and $\mathrm{Fe}-\mathrm{C}$ phase diagrams used in the construction of the ternary phase diagrams in sections 4.3.1 and 4.3.2.

Figure 15 shows the equilibrium binary phase diagrams for $\mathrm{Fe}-\mathrm{S}$ and $\mathrm{Fe}-\mathrm{C}$ in the temperature range $600-1600{ }^{\circ} \mathrm{C}$ at atmospheric pressure. Phase diagrams describe systems in thermodynamic equilibrium, however the nanoscale nature of the catalyst particles affects their physical properties, in particular, the depression of their melting points below bulk material values [168]. For this reason we chose to consider the phase diagrams well above $\left(1400{ }^{\circ} \mathrm{C}\right)$ the minimum 


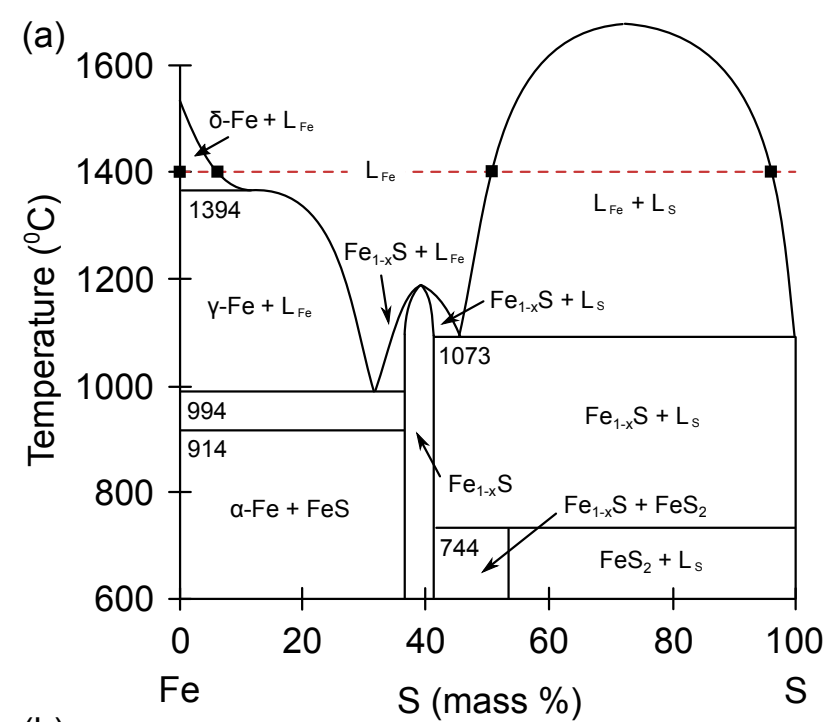

(b)

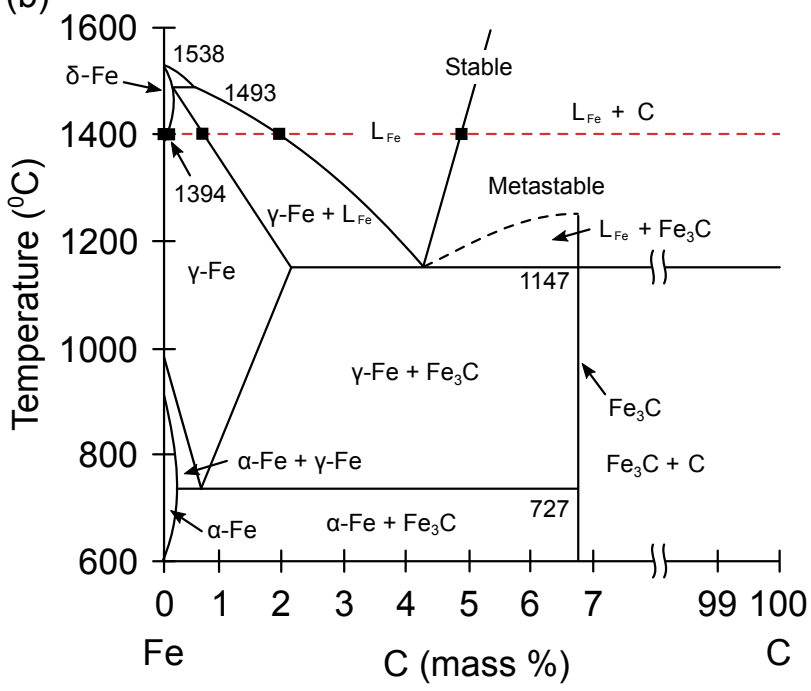

Figure 15: Bulk binary phase diagrams for (a) Fe-S [266, 267] and (b) $\mathrm{Fe}-\mathrm{C}$ [268] in the temperature range $600-1600{ }^{\circ} \mathrm{C}$.

temperature $\left(1050{ }^{\circ} \mathrm{C}\right)$ required for direct-spun process as being a representative first step in discussing the effects of the $\mathrm{S} / \mathrm{Fe}$ ratio on catalyst nanoparticle composition.

Figure 15 (a) shows the Fe-S binary phase diagram for bulk mixtures. Considering the (dashed red) isothermal line at $1400{ }^{\circ} \mathrm{C}$ on Figure 15 (a), a system with $0 \% \mathrm{~S}$ consists of BCC (Body Centred Cubic) $\delta$-ferrite. Addition of $\mathrm{S}$ creates an equilibrium of solid BCC $\delta$-ferrite + liquid Fe $\left(\mathrm{L}_{\mathrm{Fe}}\right)$ until 8 mass $\% \mathrm{~S}$, where a fully liquid $\mathrm{Fe}$ phase appears. Liquid $\mathrm{Fe}$ and liquid $\mathrm{S}$ $\left(\mathrm{L}_{\mathrm{S}}\right)$ phases coexist between about 50 mass $\% \mathrm{~S}$ through to approximately 97 mass\% S, after which fully liquid $\mathrm{S}$ exists.

Figure 15 (b) shows the corresponding $\mathrm{Fe}-\mathrm{C}$ binary phase diagram for bulk mixtures. Similarly to the Fe$\mathrm{S}$ binary phase diagram at $1400{ }^{\circ} \mathrm{C}$ (dashed red line) pure iron is found as BCC $\delta$-ferrite phase. With the increased carbon mass\% we move into the FCC (Face Centred Cubic) $\gamma$-austenite phase until the $\gamma$-austenite + liquid $\left(\mathrm{L}_{\mathrm{Fe}}\right)$ phase appears at approximately 0.8 mass\% C. The fully liquid $\left(\mathrm{L}_{\mathrm{Fe}}\right)$ phase appears at ap- proximately 2 mass \% C and remains until the liquid iron + solid $\mathrm{C}$ phase appears from an approximately 5 mass \% C up to $100 \%$ C. 
[1] Y. I. Jhon, C. Kim, M. Seo, W. J. Cho, S. Lee, Y. M. Jhon, Tensile characterization of singlewalled carbon nanotubes with helical structural defects, Scientific reports 6 (2016) 20324.

[2] H.-i. Kim, M. Wang, S. K. Lee, J. Kang, J.D. Nam, L. Ci, J. Suhr, Tensile properties of millimeter-long multi-walled carbon nanotubes, Scientific Reports 7 (1) (2017) 9512.

[3] A. Lekawa-Raus, J. Patmore, L. Kurzepa, J. Bulmer, K. Koziol, Electrical properties of carbon nanotube based fibers and their future use in electrical wiring, Advanced Functional Materials 24 (24) (2014) 3661-3682.

[4] M. Fujii, X. Zhang, H. Xie, H. Ago, K. Takahashi, T. Ikuta, H. Abe, T. Shimizu, Measuring the thermal conductivity of a single carbon nanotube, Physical review letters 95 (6) (2005) 065502 .

[5] A. S. Brady-Estévez, M. H. Schnoor, C. D. Vecitis, N. B. Saleh, M. Elimelech, Multiwalled carbon nanotube filter: improving viral removal at low pressure, Langmuir 26 (18) (2010) 1497514982.

[6] Y. Liu, J. Xie, C. N. Ong, C. D. Vecitis, Z. Zhou, Electrochemical wastewater treatment with carbon nanotube filters coupled with in situ generated h 2 o 2, Environmental Science: Water Research \& Technology 1 (6) (2015) 769-778.

[7] Y. Liu, H. Liu, Z. Zhou, T. Wang, C. N. Ong, C. D. Vecitis, Degradation of the common aqueous antibiotic tetracycline using a carbon nanotube electrochemical filter, Environmental science \& technology 49 (13) (2015) 7974-7980.

[8] K. Sears, L. Dumée, J. Schütz, M. She, C. Huynh, S. Hawkins, M. Duke, S. Gray, Recent developments in carbon nanotube membranes for water purification and gas separation, Materials 3 (1) (2010) 127-149.

[9] C.-F. de Lannoy, D. Jassby, K. Gloe, A. D. Gordon, M. R. Wiesner, Aquatic biofouling prevention by electrically charged nanocomposite polymer thin film membranes, Environmental science \& technology 47 (6) (2013) 2760-2768.

[10] Q. Wu, C. Zhang, R. Liang, B. Wang, Fire retardancy of a buckypaper membrane, Carbon 46 (8) (2008) 1164-1165.

[11] W. Knapp, D. Schleussner, Carbon buckypaper field emission investigations, Vacuum 69 (1) (2002) 333-338.

[12] J. Y. Oh, S. J. Yang, J. Y. Park, T. Kim, K. Lee, Y. S. Kim, H. N. Han, C. R. Park, Easy preparation of self-assembled high-density buckypaper with enhanced mechanical properties, Nano letters 15 (1) (2014) 190-197.
[13] Z. Li, J. Xu, J. P. O'Byrne, L. Chen, K. Wang, M. A. Morris, J. D. Holmes, Freestanding bucky paper with high strength from multi-wall carbon nanotubes, Materials Chemistry and Physics 135 (2-3) (2012) 921-927.

[14] P. Gonnet, Z. Liang, E. S. Choi, R. S. Kadambala, C. Zhang, J. S. Brooks, B. Wang, L. Kramer, Thermal conductivity of magnetically aligned carbon nanotube buckypapers and nanocomposites, Current Applied Physics 6 (1) (2006) 119-122.

[15] B. Vigolo, A. Pénicaud, C. Coulon, C. Sauder, R. Pailler, C. Journet, P. Bernier, P. Poulin, Macroscopic fibers and ribbons of oriented carbon nanotubes, Science 290 (5495) (2000) 13311334 .

[16] L. M. Ericson, H. Fan, H. Peng, V. A. Davis, W. Zhou, J. Sulpizio, Y. Wang, R. Booker, J. Vavro, C. Guthy, et al., Macroscopic, neat, single-walled carbon nanotube fibers, Science 305 (5689) (2004) 1447-1450.

[17] M. Zhang, K. R. Atkinson, R. H. Baughman, Multifunctional carbon nanotube yarns by downsizing an ancient technology, Science 306 (5700) (2004) 1358-1361.

[18] Y.-L. Li, I. A. Kinloch, A. H. Windle, Direct spinning of carbon nanotube fibers from chemical vapor deposition synthesis, Science 304 (5668) (2004) 276-278.

[19] H. Cheng, F. Li, G. Su, H. Pan, L. He, X. Sun, M. Dresselhaus, Large-scale and low-cost synthesis of single-walled carbon nanotubes by the catalytic pyrolysis of hydrocarbons, Applied Physics Letters 72 (25) (1998) 3282-3284.

[20] H. Cheng, F. Li, X. Sun, S. Brown, M. Pimenta, A. Marucci, G. Dresselhaus, M. Dresselhaus, Bulk morphology and diameter distribution of single-walled carbon nanotubes synthesized by catalytic decomposition of hydrocarbons, Chemical Physics Letters 289 (5-6) (1998) 602-610.

[21] L. Ci, Y. Li, B. Wei, J. Liang, C. Xu, D. Wu, Preparation of carbon nanofibers by the floating catalyst method, Carbon 38 (14) (2000) 19331937.

[22] H. Zhu, C. Xu, D. Wu, B. Wei, R. Vajtai, P. Ajayan, Direct synthesis of long single-walled carbon nanotube strands, Science 296 (5569) (2002) 884-886.

[23] D. Conroy, A. Moisala, S. Cardoso, A. Windle, J. Davidson, Carbon nanotube reactor: Ferrocene decomposition, iron particle growth, nanotube aggregation and scale-up, Chemical Engineering Science 65 (10) (2010) 2965-2977. 
[24] X.-H. Zhong, Y.-L. Li, J.-M. Feng, Y.-R. Kang, S.-S. Han, Fabrication of a multifunctional carbon nanotube "cotton" yarn by the direct chemical vapor deposition spinning process, Nanoscale 4 (18) (2012) 5614-5618.

[25] S.-H. Lee, J. Park, H.-R. Kim, J. Lee, K.-H. Lee, Synthesis of high-quality carbon nanotube fibers by controlling the effects of sulfur on the catalyst agglomeration during the direct spinning process, RSC Advances 5 (52) (2015) 41894-41900.

[26] J.-M. Feng, R. Wang, Y.-L. Li, X.-H. Zhong, L. Cui, Q.-J. Guo, F. Hou, One-step fabrication of high quality double-walled carbon nanotube thin films by a chemical vapor deposition process, Carbon 48 (13) (2010) 3817-3824.

[27] Y.-Y. Fan, A. Kaufmann, A. Mukasyan, A. Varma, Single-and multi-wall carbon nanotubes produced using the floating catalyst method: Synthesis, purification and hydrogen up-take, Carbon 44 (11) (2006) 2160-2170.

[28] Y.-L. Li, L.-H. Zhang, X.-H. Zhong, A. H. Windle, Synthesis of high purity single-walled carbon nanotubes from ethanol by catalytic gas flow cvd reactions, Nanotechnology 18 (22) (2007) 225604.

[29] J. Wei, B. Jiang, D. Wu, B. Wei, Large-scale synthesis of long double-walled carbon nanotubes, The Journal of Physical Chemistry B 108 (26) (2004) 8844-8847.

[30] X.-H. Zhong, Y.-L. Li, Y.-K. Liu, X.-H. Qiao, Y. Feng, J. Liang, J. Jin, L. Zhu, F. Hou, J.Y. Li, Continuous multilayered carbon nanotube yarns, Advanced materials 22 (6) (2010) 692-696.

[31] R. M. Sundaram, K. K. Koziol, A. H. Windle, Continuous direct spinning of fibers of singlewalled carbon nanotubes with metallic chirality, Advanced Materials 23 (43) (2011) 5064-5068.

[32] J. Wang, X. Luo, T. Wu, Y. Chen, High-strength carbon nanotube fibre-like ribbon with high ductility and high electrical conductivity, Nature communications 5 .

[33] T. Gspann, F. Smail, A. Windle, Spinning of carbon nanotube fibres using the floating catalyst high temperature route: purity issues and the critical role of sulphur, Faraday Discuss. 173 (2014) 47-65.

[34] W. Xu, Y. Chen, H. Zhan, J. N. Wang, Highstrength carbon nanotube film from improving alignment and densification, Nano letters 16 (2) (2016) 946-952.

[35] T. Q. Tran, R. J. Headrick, E. A. Bengio, S. Myo Myint, H. Khoshnevis, V. Jamali, H. M. Duong, M. Pasquali, Purification and dissolution of carbon nanotube fibers spun from the floating catalyst method, ACS applied materials \& interfaces 9 (42) (2017) 37112-37119.
[36] J. S. Bulmer, T. S. Gspann, J. S. Barnard, J. A. Elliott, Chirality-independent characteristic crystal length in carbon nanotube textiles measured by raman spectroscopy, Carbon 115 (2017) 672-680.

[37] P.-X. Hou, C. Liu, H.-M. Cheng, Purification of carbon nanotubes, carbon 46 (15) (2008) 20032025 .

[38] J. Stallard, W. Tan, F. Smail, T. Gspann, A. Boies, N. Fleck, The mechanical and electrical properties of direct-spun carbon nanotube mats, Extreme Mechanics Letters 21 (2018) 65-75.

[39] J. J. Vilatela, A. H. Windle, A multifunctional yarn made of carbon nanotubes, J. Eng. Fiber. Fabr 7 (2012) 23-28.

[40] Y. Yue, K. Liu, M. Li, X. Hu, Thermal manipulation of carbon nanotube fiber by mechanical stretching, Carbon 77 (2014) 973-979.

[41] P. Liu, Z. Fan, A. Mikhalchan, T. Q. Tran, D. Jewell, H. M. Duong, A. M. Marconnet, Continuous carbon nanotube-based fibers and films for applications requiring enhanced heat dissipation, ACS applied materials \& interfaces 8 (27) (2016) 17461-17471.

[42] T. S. Gspann, S. M. Juckes, J. F. Niven, M. B. Johnson, J. A. Elliott, M. A. White, A. H. Windle, High thermal conductivities of carbon nanotube films and micro-fibres and their dependence on morphology, Carbon 114 (2017) 160168.

[43] K. K. Koziol, D. Janas, E. Brown, L. Hao, Thermal properties of continuously spun carbon nanotube fibres, Physica E: Low-dimensional Systems and Nanostructures 88 (2017) 104-108.

[44] Tortech Nano Fibers Ltd. URL http://tortechnano.com/ tortech-nano-fibers

[45] Nanocomp Technologies Inc (2016). URL http://www. nanocomptech.com

[46] H. Chen, S. Zeng, M. Chen, Y. Zhang, Q. Li, Fabrication and functionalization of carbon nanotube films for high-performance flexible supercapacitors, Carbon 92 (2015) 271-296.

[47] A. Lekawa-Raus, T. Gizewski, J. Patmore, L. Kurzepa, K. K. Koziol, Electrical transport in carbon nanotube fibres, Scripta Materialia 131 (2017) 112-118.

[48] L. Yu, C. Shearer, J. Shapter, Recent development of carbon nanotube transparent conductive films, Chemical reviews 116 (22) (2016) 1341313453. 
[49] X. Zhang, X. Yu, J. Zhao, Q. Li, Bio-inspired design and fabrication of super-strong and multifunctional carbon nanotube composites, in: Carbon Nanotubes-Current Progress of their Polymer Composites, InTech, 2016.

[50] H. M. Duong, F. Gong, P. Liu, T. Q. Tran, Advanced fabrication and properties of aligned carbon nanotube composites: Experiments and modeling, in: Carbon NanotubesCurrent Progress of their Polymer Composites, InTech, 2016.

[51] M. D. Yadav, K. Dasgupta, A. W. Patwardhan, J. B. Joshi, High performance fibers from carbon nanotubes: Synthesis, characterization, and applications in composites a review, Industrial \& Engineering Chemistry Research 56 (44) (2017) 12407-12437.

[52] R. Beigmoradi, A. Samimi, D. Mohebbi-Kalhori, Engineering of oriented carbon nanotubes in composite materials, Beilstein Journal of Nanotechnology 9 (2018) 415.

[53] D. Janas, K. K. Koziol, Carbon nanotube fibers and films: synthesis, applications and perspectives of the direct-spinning method, Nanoscale 8 (47) (2016) 19475-19490.

[54] J. Foroughi, T. Mitew, P. Ogunbona, R. Raad, F. Safaei, Smart fabrics and networked clothing: Recent developments in cnt-based fibers and their continual refinement, IEEE Consumer Electronics Magazine 5 (4) (2016) 105-111.

[55] J. Di, X. Zhang, Z. Yong, Y. Zhang, D. Li, R. Li, Q. Li, Carbon-nanotube fibers for wearable devices and smart textiles, Advanced materials 28 (47) (2016) 10529-10538.

[56] S. Shahidi, B. Moazzenchi, Carbon nanotube and its applications in textile industry-a review, The Journal of The Textile Institute (2018) 1-14.

[57] Y. Jung, Y. S. Cho, J. W. Lee, J. Y. Oh, C. R. Park, How can we make carbon nanotube yarn stronger?, Composites Science and Technology.

[58] Y. Li, K. Ji, Y. Duan, G. Meng, Z. Dai, Effect of hydrogen concentration on the growth of carbon nanotube arrays for gecko-inspired adhesive applications, Coatings 7 (12) (2017) 221.

[59] G. Hou, D. Chauhan, V. Ng, C. Xu, Z. Yin, M. Paine, R. Su, V. Shanov, D. Mast, M. Schulz, et al., Gas phase pyrolysis synthesis of carbon nanotubes at high temperature, Materials \& Design 132 (2017) 112-118.

[60] J. Elliott, T. Gspann, J. Terrones, A. Windle, The measurement of properties in carbon nanotube yarns, WSEAS Transactions on Applied and Theoretical Mechanics 12 (February) (2017) 33-40.
[61] C. Hoecker, F. Smail, M. Pick, A. Boies, The influence of carbon source and catalyst nanoparticles on cvd synthesis of cnt aerogel, Chemical Engineering Journal 314 (2017) 388-395.

[62] J. Di, X. Wang, Y. Xing, Y. Zhang, X. Zhang, W. Lu, Q. Li, Y. T. Zhu, Dry-processable carbon nanotubes for functional devices and composites, Small 10 (22) (2014) 4606-4625.

[63] H. Misak, S. Mall, Cryogenic tensile strength and fatigue life of carbon nanotube multi-yarn, Journal of nanoscience and nanotechnology 16 (3) (2016) 3021-3025.

[64] M. J. Schulz, G. Hou, V. Ng, M. Rabiee, M. Cahay, S. Chaudhary, D. Lindley, D. Chauhan, M. Paine, D. Vijayakumar, C. Xu, Z. Yin, K. Haworth, Y. Liu, M. Sundaram, W. Li, D. Mast, V. N. Shanov, Science to Commercialization of Carbon Nanotube Sheet and Yarn, WSEAS Transactions on Applied and Theoretical Mechanics 12 (2017) 41-50.

[65] M. W. Schauer, M. A. White, Tailoring industrial scale cnt production to specialty markets, MRS Online Proceedings Library Archive 1752 (2015) 103-109.

[66] O.-K. Park, W. Y. Kim, S. M. Kim, N.-H. You, Y. Jeong, H. S. Lee, B.-C. Ku, Effect of oxygen plasma treatment on the mechanical properties of carbon nanotube fibers, Materials Letters 156 (2015) 17-20.

[67] A. Mikhalchan, Z. Fan, T. Q. Tran, P. Liu, V. B. Tan, T.-E. Tay, H. M. Duong, Continuous and scalable fabrication and multifunctional properties of carbon nanotube aerogels from the floating catalyst method, Carbon 102 (2016) 409-418.

[68] D. Janas, K. K. Koziol, The influence of metal nanoparticles on electrical properties of carbon nanotubes, Applied Surface Science 376 (2016) $74-78$.

[69] H. Xu, X. Tong, Y. Zhang, Q. Li, W. Lu, Mechanical and electrical properties of laminated composites containing continuous carbon nanotube film interleaves, Composites Science and Technology 127 (2016) 113-118.

[70] T. Wu, J. N. Wang, Carbon nanotube springs with high tensile strength and energy density, RSC Advances 6 (44) (2016) 38187-38191.

[71] J. Yu, W. Lu, S. Pei, K. Gong, L. Wang, L. Meng, Y. Huang, J. P. Smith, K. S. Booksh, Q. Li, et al., Omnidirectionally stretchable high-performance supercapacitor based on isotropic buckled carbon nanotube films, ACS nano 10 (5) (2016) 52045211. 
[72] X. Cheng, J. Zhang, J. Ren, N. Liu, P. Chen, Y. Zhang, J. Deng, Y. Wang, H. Peng, Design of a hierarchical ternary hybrid for a fiber-shaped asymmetric supercapacitor with high volumetric energy density, The Journal of Physical Chemistry C 120 (18) (2016) 9685-9691.

[73] T. Q. Tran, Z. Fan, P. Liu, S. M. Myint, H. M. Duong, Super-strong and highly conductive carbon nanotube ribbons from posttreatment methods, Carbon 99 (2016) 407-415.

[74] T. Q. Tran, Z. Fan, A. Mikhalchan, P. Liu, H. M. Duong, Post-treatments for multifunctional property enhancement of carbon nanotube fibers from the floating catalyst method, ACS applied materials \& interfaces 8 (12) (2016) 79487956 .

[75] M. L. Wu, Y. Chen, L. Zhang, H. Zhan, L. Qiang, J. N. Wang, High-performance carbon nanotube/polymer composite fiber from layerby-layer deposition, ACS applied materials \& interfaces 8 (12) (2016) 8137-8144.

[76] X. G. Luo, X. X. Huang, X. X. Wang, X. H. Zhong, X. X. Meng, J. N. Wang, Continuous preparation of carbon nanotube film and its applications in fuel and solar cells, ACS applied materials \& interfaces 8 (12) (2016) 7818-7825.

[77] H. E. Misak, J. L. Rutledge, E. D. Swenson, S. Mall, Thermal transport properties of dry spun carbon nanotube sheets, Journal of Nanomaterials 2016 (2016) 79.

[78] J.-W. Kim, G. Sauti, R. J. Cano, R. A. Wincheski, J. G. Ratcliffe, M. Czabaj, N. W. Gardner, E. J. Siochi, Assessment of carbon nanotube yarns as reinforcement for composite overwrapped pressure vessels, Composites Part A: Applied Science and Manufacturing 84 (2016) 256-265.

[79] A. Mikhalchan, T. Gspann, A. Windle, Aligned carbon nanotube-epoxy composites: the effect of nanotube organization on strength, stiffness, and toughness, Journal of Materials Science 51 (22) (2016) 10005-10025.

[80] Y. Chen, L. Zhang, H. Zhan, J. N. Wang, New processing method to fabricate high-performance carbon-nanotube/polyvinyl alcohol composite films, Carbon 110 (2016) 490-496.

[81] S. R. Kanel, H. Misak, D. Nepal, S. Mall, S. W. Brittle, I. Sizemore, D. M. Kempisty, M. N. Goltz, The use of carbon nanotube yarn as a filter medium to treat nitroaromatic-contaminated water, New Carbon Materials 31 (4) (2016) 415423.

[82] P. Liu, Y. F. Tan, D. C. Hu, D. Jewell, H. M. Duong, Multi-property enhancement of aligned carbon nanotube thin films from floating catalyst method, Materials \& Design 108 (2016) 754-760.

[83] P.-M. Hannula, A. Peltonen, J. Aromaa, D. Janas, M. Lundström, B. P. Wilson, K. Koziol, O. Forsén, Carbon nanotube-copper composites by electrodeposition on carbon nanotube fibers, Carbon 107 (2016) 281-287.

[84] A. Hopkins, A. Labatete-Goeppinger, H. Kim, H. Katzman, Space survivability of carbon nanotube yarn material in low earth orbit, Carbon 107 (2016) 77-86.

[85] J. P. Abdou, K. J. Reynolds, M. R. Pfau, J. van Staden, G. A. Braggin, N. Tajaddod, M. Minus, V. Reguero, J. J. Vilatela, S. Zhang, Interfacial crystallization of isotactic polypropylene surrounding macroscopic carbon nanotube and graphene fibers, Polymer 91 (2016) 136-145.

[86] E. Senokos, V. Reguero, J. Palma, J. Vilatela, R. Marcilla, Macroscopic fibres of cnts as electrodes for multifunctional electric double layer capacitors: from quantum capacitance to device performance, Nanoscale 8 (6) (2016) 3620-3628.

[87] G. Hou, G. Wang, Y. Deng, J. Zhang, J. P. Nshimiyimana, X. Chi, X. Hu, W. Chu, H. Dong, Z. Zhang, et al., Effective enhancement of the mechanical properties of macroscopic singlewalled carbon nanotube fibers by pressure treatment, RSC Advances 6 (99) (2016) 97012-97017.

[88] Y. Wang, G. Colas, T. Filleter, Improvements in the mechanical properties of carbon nanotube fibers through graphene oxide interlocking, Carbon 98 (2016) 291-299.

[89] Y. Chen, X. X. Wang, B. Li, X. X. Huang, J. N. Wang, Porous platinum aggregates deposited on a carbon nanotube film with high catalytic activity and durability, ChemElectroChem 3 (11) (2016) 1908-1914.

[90] W. Li, F. Xu, Z. Wang, J. Wu, W. Liu, Y. Qiu, Effect of thermal treatments on structures and mechanical properties of aerogel-spun carbon nanotube fibers, Materials Letters 183 (2016) $117-121$.

[91] J. Lee, T. Kim, Y. Jung, K. Jung, J. Park, D.M. Lee, H. S. Jeong, J. Y. Hwang, C. R. Park, K.-H. Lee, et al., High-strength carbon nanotube/carbon composite fibers via chemical vapor infiltration, Nanoscale 8 (45) (2016) 1897218979.

[92] J. C. Fernández-Toribio, A. Íñiguez-Rábago, J. Vilà, C. González, Á. Ridruejo, J. J. Vilatela, A composite fabrication sensor based on electrochemical doping of carbon nanotube yarns, Advanced Functional Materials 26 (39) (2016) 71397147 . 
[93] J. Zou, X. Zhang, J. Zhao, C. Lei, Y. Zhao, Y. Zhu, Q. Li, Strengthening and toughening effects by strapping carbon nanotube cross-links with polymer molecules, Composites Science and Technology 135 (2016) 123-127.

[94] K. Krukiewicz, J. S. Bulmer, K. K. Koziol, J. K. Zak, Charging and discharging of the electrochemically swelled, aligned carbon nanotube fibers, Electrochemistry Communications 64 (2016) 30-34.

[95] S. Yehezkel, M. Auinat, N. Sezin, D. Starosvetsky, Y. Ein-Eli, Bundled and densified carbon nanotubes (cnt) fabrics as flexible ultra-light weight li-ion battery anode current collectors, Journal of Power Sources 312 (2016) 109-115.

[96] Z. Zhang, Y. Gu, S. Wang, Q. Li, M. Li, Z. Zhang, Enhanced dielectric and mechanical properties in chlorine-doped continuous cnt sheet reinforced sandwich polyvinylidene fluoride film, Carbon 107 (2016) 405-414.

[97] M. M. Hossain, M. A. Islam, H. Shima, M. Hasan, M. Lee, Alignment of carbon nanotubes in carbon nanotube fibers through nanoparticles: A route for controlling mechanical and electrical properties, ACS applied materials \& interfaces 9 (6) (2017) 5530-5542.

[98] R. M. Sundaram, A. H. Windle, One-step purification of direct-spun cnt fibers by postproduction sonication, Materials \& Design 126 (2017) 85-90.

[99] E. Senokos, V. Reguero, L. Cabana, J. Palma, R. Marcilla, J. J. Vilatela, Large-area, all-solid, and flexible electric double layer capacitors based on cnt fiber electrodes and polymer electrolytes, Advanced Materials Technologies 2 (7).

[100] Y. Shang, Y. Wang, S. Li, C. Hua, M. Zou, A. Cao, High-strength carbon nanotube fibers by twist-induced self-strengthening, Carbon 119 (2017) 47-55.

[101] J. Park, S.-H. Lee, J. Lee, D.-M. Lee, H. Yu, H. S. Jeong, S. M. Kim, K.-H. Lee, Accurate measurement of specific tensile strength of carbon nanotube fibers with hierarchical structures by vibroscopic method, RSC Advances 7 (14) (2017) 8575-8580.

[102] O.-K. Park, H. Choi, H. Jeong, Y. Jung, J. Yu, J. K. Lee, J. Y. Hwang, S. M. Kim, Y. Jeong, C. R. Park, et al., High-modulus and strength carbon nanotube fibers using molecular crosslinking, Carbon 118 (2017) 413-421.

[103] S. Y. Kim, E. Jee, J. S. Kim, D. H. Kim, Conformable and ionic textiles using sheath-core carbon nanotube microyarns for highly sensitive and reliable pressure sensors, RSC Advances 7 (38) (2017) 23820-23826.
[104] Y.-O. Im, S.-H. Lee, T. Kim, J. Park, J. Lee, K.-H. Lee, Utilization of carboxylic functional groups generated during purification of carbon nanotube fiber for its strength improvement, Applied Surface Science 392 (2017) 342-349.

[105] D. Chauhan, G. Hou, V. Ng, S. Chaudhary, M. Paine, K. Moinuddin, M. Rabiee, M. Cahay, N. Lalley, V. Shanov, et al., Multifunctional smart composites with integrated carbon nanotube yarn and sheet, in: A Tribute Conference Honoring Daniel Inman, Vol. 10172, International Society for Optics and Photonics, 2017, p. 1017205.

[106] Q. Zhang, K. Li, Q. Fan, X. Xia, N. Zhang, Z. Xiao, W. Zhou, F. Yang, Y. Wang, H. Liu, et al., Performance improvement of continuous carbon nanotube fibers by acid treatment, Chinese Physics B 26 (2) (2017) 028802.

[107] X. Xu, Y. Zhang, J. Jiang, H. Wang, X. Zhao, Q. Li, W. Lu, In-situ curing of glass fiber reinforced polymer composites via resistive heating of carbon nanotube films, Composites Science and Technology 149 (2017) 20-27.

[108] J. Pan, M. Li, S. Wang, Y. Gu, Q. Li, Z. Zhang, Hybrid effect of carbon nanotube film and ultrathin carbon fiber prepreg composites, Journal of Reinforced Plastics and Composites 36 (6) (2017) 452-463.

[109] P.-M. Hannula, J. Aromaa, B. P. Wilson, D. Janas, K. Koziol, O. Forsén, M. Lundström, Observations of copper deposition on functionalized carbon nanotube films, Electrochimica Acta 232 (2017) 495-504.

[110] J. Zou, X. Zhang, C. Xu, J. Zhao, Y. T. Zhu, Q. Li, Soldering carbon nanotube fibers by targeted electrothermal-induced carbon deposition, Carbon 121 (2017) 242-247.

[111] W. Zhou, Q. Fan, Q. Zhang, L. Cai, K. Li, X. Gu, F. Yang, N. Zhang, Y. Wang, H. Liu, et al., Highperformance and compact-designed flexible thermoelectric modules enabled by a reticulate carbon nanotube architecture, Nature communications 8 (2017) 14886.

[112] C. J. An, Y. H. Kang, H. Song, Y. Jeong, S. Y. Cho, High-performance flexible thermoelectric generator by control of electronic structure of directly spun carbon nanotube webs with various molecular dopants, Journal of Materials Chemistry A 5 (30) (2017) 15631-15639.

[113] B. Han, E. Guo, X. Xue, Z. Zhao, L. Luo, H. Qu, T. Niu, Y. Xu, H. Hou, Fabrication and densification of high performance carbon nanotube/copper composite fibers, Carbon 123 (2017) 593-604. 
[114] X. Zhang, L. Yang, H. Liu, M. Zu, A novel highcontent cnt-reinforced sic matrix composite-fiber by precursor infiltration and pyrolysis process, RSC Advances 7 (38) (2017) 23334-23341.

[115] J. Choi, Y. Jung, S. J. Yang, J. Y. Oh, J. Oh, K. Jo, J. G. Son, S. E. Moon, C. R. Park, H. Kim, Flexible and robust thermoelectric generators based on all-carbon nanotube yarn without metal electrodes, ACS nano 11 (8) (2017) 7608-7614.

[116] J. S. Bulmer, T. S. Gspann, F. Orozco, M. Sparkes, H. Koerner, A. Bernardo, A. Niemiec, J. Robinson, K. K. Koziol, J. A. Elliott, et al., Photonic sorting of aligned, crystalline carbon nanotube textiles, Scientific reports 7 (1) (2017) 12977.

[117] S. Zeng, H. Chen, H. Wang, X. Tong, M. Chen, J. Di, Q. Li, Crosslinked carbon nanotube aerogel films decorated with cobalt oxides for flexible rechargeable zn-air batteries, Small 13 (29).

[118] S. Zhang, J. G. Park, N. Nguyen, C. Jolowsky, A. Hao, R. Liang, Ultra-high conductivity and metallic conduction mechanism of scale-up continuous carbon nanotube sheets by mechanical stretching and stable chemical doping, Carbon 125 (2017) 649-658.

[119] A. Moya, N. Kemnade, M. Osorio, A. Cherevan, D. Granados, D. Eder, J. Vilatela, Large area photoelectrodes based on hybrids of cnt fibres and ald-grown tio 2, Journal of Materials Chemistry A 5 (47) (2017) 24695-24706.

[120] S. Yehezkel, M. Auinat, N. Sezin, D. Starosvetsky, Y. Ein-Eli, Distinct copper electrodeposited carbon nanotubes (cnt) tissues as anode current collectors in li-ion battery, Electrochimica Acta 229 (2017) 404-414.

[121] S. Lee, H. Song, J. Y. Hwang, Y. Jeong, Directlyprelithiated carbon nanotube film for highperformance flexible lithium-ion battery electrodes, Fibers and Polymers 18 (12) (2017) 23342341 .

[122] D. Iglesias, E. Senokos, B. Aleman, L. Cabana, C. Navío, R. Marcilla, M. Prato, J. J. Vilatela, S. Marchesan, Gas-phase functionalization of macroscopic carbon nanotube fiber assemblies: reaction control, electrochemical properties, and use for flexible supercapacitors, ACS applied materials \& interfaces.

[123] H. Khoshnevis, S. M. Mint, E. Yedinak, T. Q. Tran, A. Zadhoush, M. Youssefi, M. Pasquali, H. M. Duong, Super high-rate fabrication of high-purity carbon nanotube aerogels from floating catalyst method for oil spill cleaning, Chemical Physics Letters.
[124] X. Yang, M. Yang, H. Zhang, J. Zhao, X. Zhang, Q. Li, Electro-purification of carbon nanotube networks without damaging the assembly structure and crystallinity, Applied Surface Science 442 (2018) 232-238.

[125] T. Li, M. Li, Y. Gu, S. Wang, Q. Li, Z. Zhang, Mechanical enhancement effect of the interlayer hybrid cnt film/carbon fiber/epoxy composite, Composites Science and Technology.

[126] P. Liu, Y. Li, Y. Xu, L. Bao, L. Wang, J. Pan, Z. Zhang, X. Sun, H. Peng, Stretchable and energy-efficient heating carbon nanotube fiber by designing a hierarchically helical structure, Small 14 (4) (2018) 1702926.

[127] K. Jin, S. Zhang, S. Zhou, J. Qiao, Y. Song, J. Di, D. Zhang, Q. Li, Self-plied and twist-stable carbon nanotube yarn artificial muscles driven by organic solvent adsorption, Nanoscale.

[128] E. Senokos, Y. Ou, J. J. Torres, F. Sket, C. González, R. Marcilla, J. J. Vilatela, Energy storage in structural composites by introducing cnt fiber/polymer electrolyte interleaves, Scientific reports 8 (1) (2018) 3407.

[129] H. Le, T. Xuan, B. Alemán, J. J. Vilatela, M. Bechelany, M. Cretin, enhanced electrofenton mineralization of acid orange 7 using a carbon nanotube fiber-based cathode, Frontiers in Materials 5 (2018) 9.

[130] A. Mikhalchan, M. Ridha, T. Tay, Carbon nanotube fibres for cfrp-hybrids with enhanced inplane fracture behaviour, Materials \& Design 143 (2018) 112-119.

[131] Q. Liu, M. Li, Y. Gu, S. Wang, Y. Zhang, Q. Li, L. Gao, Z. Zhang, Interlocked cnt networks with high damping and storage modulus, Carbon 86 (2015) 46-53.

[132] B. Alemán, M. M. Bernal, B. Mas, E. M. Pérez, V. Reguero, G. Xu, Y. Cui, J. J. Vilatela, Inherent predominance of high chiral angle metallic carbon nanotubes in continuous fibers grown from a molten catalyst, Nanoscale 8 (7) (2016) 4236-4244.

[133] J. Severino, J.-M. Yang, L. Carlson, R. Hicks, Progression of alignment in stretched cnt sheets determined by wide angle x-ray scattering, Carbon 100 (2016) 309-317.

[134] C. Li, S. Xu, Y. Yue, B. Yang, X. Wang, Thermal characterization of carbon nanotube fiber by time-domain differential raman, Carbon 103 (2016) 101-108.

[135] J. Zhu, Electrical conductivity of carbon nanotube fibers synthesized by chemical vapor deposition, in: Energy Science and Applied Technology ESAT 2016: Proceedings of the International 
Conference on Energy Science and Applied Technology (ESAT 2016), Wuhan, China, June 25-26, 2016, CRC Press, 2016, p. 135.

[136] Y. Shao, F. Xu, W. Li, K. Zhang, C. Zhang, R. Li, Y. Qiu, Interfacial strength and debonding mechanism between aerogel-spun carbon nanotube yarn and polyphenylene sulfide, Composites Part A: Applied Science and Manufacturing 88 (2016) 98-105.

[137] G. Hou, V. Ng, Y. Song, L. Zhang, C. Xu, V. Shanov, D. Mast, M. Schulz, Y. Liu, Numerical and experimental investigation of carbon nanotube sock formation, MRS Advances 2 (1) (2017) 21-26.

[138] W. Zhou, Q. Fan, Q. Zhang, K. Li, L. Cai, X. Gu, F. Yang, N. Zhang, Z. Xiao, H. Chen, et al., Ultrahigh-power-factor carbon nanotubes and an ingenious strategy for thermoelectric performance evaluation, Small 12 (25) (2016) 34073414 .

[139] X. Liu, F. Xu, K. Zhang, B. Wei, Z. Gao, Y. Qiu, Characterization of enhanced interfacial bonding between epoxy and plasma functionalized carbon nanotube films, Composites Science and Technology 145 (2017) 114-121.

[140] B. Alemán, R. Ranchal, V. Reguero, B. Mas, J. Vilatela, Carbon nanotube fibers with martensite and austenite fe residual catalyst: room temperature ferromagnetism and implications for cvd growth, Journal of Materials Chemistry C 5 (22) (2017) 5544-5550.

[141] C. Luo, F. Li, D. Li, Q. Fu, C. Pan, Bioinspired single-walled carbon nanotubes as a spider silk structure for ultrahigh mechanical property, ACS applied materials \& interfaces 8 (45) (2016) 31256-31263.

[142] G. Hou, V. Ng, C. Xu, L. Zhang, G. Zhang, V. Shanov, D. Mast, W. Kim, M. Schulz, Y. Liu, Multiscale modeling of carbon nanotube bundle agglomeration inside a gas phase pyrolysis reactor, MRS Advances 2 (48) (2017) 2621-2626.

[143] H. Yue, V. Reguero, E. Senokos, A. MonrealBernal, B. Mas, J. Fernández-Blázquez, R. Marcilla, J. Vilatela, Fractal carbon nanotube fibers with mesoporous crystalline structure, Carbon 122 (2017) 47-53.

[144] J. W. Singleton, H. E. Misak, S. Mall, Relationships between tensile behavior, physical parameters and manufacturing parameters of carbon nanotube sheet, Materials \& Design 116 (2017) 199-206.

[145] S. Gbordzoe, S. Yarmolenko, Y.-Y. Hsieh, P. K. Adusei, N. T. Alvarez, S. Fialkova, V. Shanov, Three-dimensional texture analysis of aligned carbon nanotube structures, Carbon 121 (2017) 591-601.

[146] B. Han, X. Xue, Y. Xu, Z. Zhao, E. Guo, C. Liu, L. Luo, H. Hou, Preparation of carbon nanotube film with high alignment and elevated density, Carbon 122 (2017) 496-503.

[147] G. R. Cobb, A. K. Singh, S. Mall, In-situ characterization of microstructural changes in a carbon nanotube sheet under sustained load, Materials \& Design 134 (2017) 494-501.

[148] M. Zhang, M. Li, S. Wang, Y. Wang, Y. Zhang, Y. Gu, Q. Li, Z. Zhang, The loading-rate dependent tensile behavior of cnt film and its bismaleimide composite film, Materials \& Design 117 (2017) 37-46.

[149] D.-Z. Chen, J. Yu, W. Lu, Y. Zhao, Y. Yan, T.W. Chou, Temperature effects on electrochemical performance of carbon nanotube film based flexible all-solid-state supercapacitors, Electrochimica Acta 233 (2017) 181-189.

[150] J. C. Fernández-Toribio, B. Alemán, Á. Ridruejo, J. J. Vilatela, Tensile properties of carbon nanotube fibres described by the fibrillar crystallite model, Carbon 133 (2018) 44-52.

[151] A. Mikhalchan, A. M. Banas, K. Banas, A. M. Borkowska, M. Nowakowski, M. B. Breese, W. M. Kwiatek, C. Paluszkiewicz, T. E. Tay, Revealing chemical heterogeneity of cnt fiber nanocomposites via nanoscale chemical imaging, Chemistry of Materials 30 (6) (2018) 1856-1864.

[152] Y. Wang, S. Wang, M. Li, Y. Gu, Z. Zhang, Piezoresistive response of carbon nanotube composite film under laterally compressive strain, Sensors and Actuators A: Physical 273 (2018) 140-146.

[153] H. Cho, H. Lee, E. Oh, S.-H. Lee, J. Park, H. J. Park, S.-B. Yoon, C.-H. Lee, G.-H. Kwak, W. J. Lee, et al., Hierarchical structure of carbon nanotube fibers, and the change of structure during densification by wet stretching, Carbon 136 (2018) 409-416.

[154] X. Zhang, L. Yang, H. Liu, High-temperature conduction behavior of carbon nanotube fiber from $25^{\circ} \mathrm{c}$ to $1100^{\circ} \mathrm{c}$, Applied Physics Letters 112 (16) (2018) 164103.

[155] V. Mordkovich, A. Karaeva, M. Khaskov, I. Solomonik, E. Mitberg, B. Kulnitskiy, I. Perezhogin, Water concentration influence on catalytic growth of carbon nanotubes in a suspended bed reactor, MRS Online Proceedings Library Archive 1407.

[156] A. Karaeva, M. Khaskov, E. Mitberg, B. Kulnitskiy, I. Perezhogin, L. Ivanov, V. Denisov, A. Kirichenko, V. Mordkovich, Longer carbon 
nanotubes by controlled catalytic growth in the presence of water vapor, Fullerenes, Nanotubes and Carbon Nanostructures 20 (4-7) (2012) 411418.

[157] Y. Jung, J. Song, W. Huh, D. Cho, Y. Jeong, Controlling the crystalline quality of carbon nanotubes with processing parameters from chemical vapor deposition synthesis, Chemical engineering journal 228 (2013) 1050-1056.

[158] Q. Liu, M. Li, Y. Gu, Y. Zhang, S. Wang, Q. Li, Z. Zhang, Highly aligned dense carbon nanotube sheets induced by multiple stretching and pressing, Nanoscale 6 (8) (2014) 4338-4344.

[159] G. Hou, R. Su, A. Wang, V. Ng, W. Li, Y. Song, L. Zhang, M. Sundaram, V. Shanov, D. Mast, et al., The effect of a convection vortex on sock formation in the floating catalyst method for carbon nanotube synthesis, Carbon 102 (2016) 513519 .

[160] S.-H. Lee, J. Park, H.-R. Kim, T. Lee, J. Lee, Y.-O. Im, C.-H. Lee, H. Cho, H. Lee, C.-H. Jun, et al., Synthesis of carbon nanotube fibers using the direct spinning process based on design of experiment (doe), Carbon 100 (2016) 647-655.

[161] C. Hoecker, F. Smail, M. Bajada, M. Pick, A. Boies, Catalyst nanoparticle growth dynamics and their influence on product morphology in a cvd process for continuous carbon nanotube synthesis, Carbon 96 (2016) 116-124.

[162] B. Mas, B. Alemán, I. Dopico, I. MartinBragado, T. Naranjo, E. M. Pérez, J. J. Vilatela, Group 16 elements control the synthesis of continuous fibers of carbon nanotubes, Carbon 101 (2016) 458-464.

[163] J. Barnard, C. Paukner, K. Koziol, The role of carbon precursor on carbon nanotube chirality in floating catalyst chemical vapour deposition, Nanoscale 8 (39) (2016) 17262-17270.

[164] Y. Zhang, S. Han, Carbon nanotube fibers prepared by activating deactivated iron particles in floating catalyst chemical vapor deposition tail gas, Materials Science 23 (3) (2017) 260-265.

[165] S.-H. Lee, H.-R. Kim, T. Lee, H. Lee, J. Lee, J. Lee, J. Park, K.-H. Lee, Synthesis of carbon nanotube fibers from carbon precursors with low decomposition temperatures using a direct spinning process, Carbon 124 (2017) 219-227.

[166] C. Hoecker, F. Smail, M. Pick, L. Weller, A. Boies, The dependence of cnt aerogel synthesis on sulphur-driven nucleation processes and a critical catalyst particle mass concentration, in preparation.
[167] V. Mordkovich, N. Kazennov, V. Ermolaev, E. Zhukova, A. Karaeva, Scaled-up process for producing longer carbon nanotubes and carbon cotton by macro-spools, Diamond and Related Materials 83 (2018) 15-20.

[168] M. Motta, I. Kinloch, A. Moisala, V. Premnath, M. Pick, A. Windle, The parameter space for the direct spinning of fibres and films of carbon nanotubes, Physica E: Low-dimensional Systems and Nanostructures 37 (1) (2007) 40-43.

[169] X. Zhong, R. Wang, W. Yangyang, L. Yali, Carbon nanotube and graphene multiple-thread yarns, Nanoscale 5 (3) (2013) 1183-1187.

[170] V. Reguero, B. Alemán, B. Mas, J. J. Vilatela, Controlling carbon nanotube type in macroscopic fibers synthesized by the direct spinning process, Chemistry of Materials 26 (11) (2014) 3550-3557.

[171] B. Alemán, V. Reguero, B. Mas, J. J. Vilatela, Strong carbon nanotube fibers by drawing inspiration from polymer fiber spinning, ACS nano 9 (7) (2015) 7392-7398.

[172] R. Das, S. Bee Abd Hamid, E. Ali, S. Ramakrishna, W. Yongzhi, et al., Carbon nanotubes characterization by $\mathrm{x}$-ray powder diffraction-a review, Current Nanoscience 11 (1) (2015) 2335 .

[173] A. Abu-Bakar, K. Moinuddin, Effects of variation in heating rate, sample mass and nitrogen flow on chemical kinetics for pyrolysis, in: 18th Australasian fluid mechanics conference Launceston, Australia, 2012, pp. 3-7.

[174] A. Windle, Understanding the direct spinning of CNT fibres in terms of the thermodynamic and kinetic landscape : a personal view., in preparation, 2018.

[175] T. P. Herbell, A. J. Eckel, D. R. Hull, A. K. Misra, Effect of hydrogen on the strength and microstructure of selected ceramics.

[176] T. P. Herbell, D. R. Hull, A. Garg, Hot hydrogen exposure degradation of the strength of mullite, Journal of the American Ceramic Society 81 (4) (1998) 910-916.

[177] P. S. Gentile, et al., Investigation of aluminosilicate refractory for solid oxide fuel cell applications, Ph.D. thesis, Montana State UniversityBozeman, College of Engineering (2010).

[178] O. Noury, T. Stöckli, M. Croci, A. C. J.-M. Bonard, Growth of carbon nanotubes on cylindrical wires by thermal chemical vapor deposition, Chemical physics letters 346 (5) (2001) 349-355.

[179] P. K. Tripathi, S. Durbach, N. J. Coville, Synthesis of multi-walled carbon nanotubes from plastic waste using a stainless-steel cvd reactor as catalyst, Nanomaterials 7 (10) (2017) 284. 
[180] M. Čaplovičová, L. Čaplovič, D. Búc, P. Vinduška, J. Janík, Carbon nanostructures grown on fe-cr-al alloy, Journal of Electrical Engineering 61 (6) (2010) 373-377.

[181] A. Rahaman, N. Patra, K. K. Kar, Self catalyzing behavior of kanthal wire for coating of carbon nanotubes, Fullerenes, Nanotubes, and Carbon Nonstructures 16 (1) (2008) 78-87.

[182] D. J. Jin, H. S. Uhm, G. Cho, Influence of the gas-flow reynolds number on a plasma column in a glass tube, Physics of Plasmas 20 (8) (2013) 083513 .

[183] Q. Liu, W. Ren, Z.-G. Chen, D.-W. Wang, B. Liu, B. Yu, F. Li, H. Cong, H.-M. Cheng, Diameter-selective growth of single-walled carbon nanotubes with high quality by floating catalyst method, ACS nano 2 (8) (2008) 1722-1728.

[184] Y. Ma, A. B. Dichiara, D. He, L. Zimmer, J. Bai, Control of product nature and morphology by adjusting the hydrogen content in a continuous chemical vapor deposition process for carbon nanotube synthesis, Carbon 107 (2016) 171-179.

[185] R. Silsby, E. Sawyer, The dealkylation of alkyl aromatic hydrocarbons i. the kinetics and mechanism of toluene decomposition in the presence of hydrogen, Journal of Applied Chemistry 6 (8) (1956) 347-356.

[186] C. Zhang, L. Weller, S. Hochgreb, A thermodynamic equilibrium study for floating catalyst cvd synthesis of carbon nanotubes, in preparation.

[187] V. Jourdain, C. Bichara, Current understanding of the growth of carbon nanotubes in catalytic chemical vapour deposition, Carbon 58 (2013) 239.

[188] K. A. Shah, B. A. Tali, Synthesis of carbon nanotubes by catalytic chemical vapour deposition: A review on carbon sources, catalysts and substrates, Materials Science in Semiconductor Processing 41 (2016) 67-82.

[189] Y. Yan, J. Miao, Z. Yang, F.-X. Xiao, H. B. Yang, B. Liu, Y. Yang, Carbon nanotube catalysts: recent advances in synthesis, characterization and applications, Chemical Society Reviews 44 (10) (2015) 3295-3346.

[190] R. Sen, A. Govindaraj, C. Rao, Carbon nanotubes by the metallocene route, Chemical Physics Letters 267 (3-4) (1997) 276-280.

[191] M. Mayne, N. Grobert, M. Terrones, R. Kamalakaran, H. Kroto, High yield synthesis of carbon nanotube arrays by pyrolysis of benzene/metallocene aerosols, in: The American Carbon Society Carbon Conference, 2001. URL http://acs.omnibooksonline.com
[192] U. Weissker, S. Hampel, A. Leonhardt, B. Büchner, Carbon nanotubes filled with ferromagnetic materials, Materials 3 (8) (2010) 4387-4427.

[193] L. Dyagileva, V. Mar'In, E. Tsyganova, G. Razuvaev, Reactivity of the first transition row metallocenes in thermal decomposition reaction, Journal of Organometallic Chemistry 175 (1) (1979) $63-72$.

[194] K. Elihn, K. Larsson, A theoretical study of the thermal fragmentation of ferrocene, Thin Solid Films 458 (1) (2004) 325-329.

[195] G. Dormans, Omcvd of transition metals and their silicides using metallocenes and (di) silane or silicon tetra-bromide, Journal of crystal growth 108 (3-4) (1991) 806-816.

[196] S. Girshick, C.-P. Chiu, Homogeneous nucleation of particles from the vapor phase in thermal plasma synthesis, Plasma Chemistry and Plasma Processing 9 (3) (1989) 355-369.

[197] D. E. Jensen, Condensation modelling for highly supersaturated vapours: application to iron, Journal of the Chemical Society, Faraday Transactions 2: Molecular and Chemical Physics 76 (1980) 1494-1515.

[198] K. F. Sheldon, Smoke, dust, and haze: Fundamentals of aerosol dynamics (2000).

[199] C. Paukner, K. K. Koziol, Ultra-pure single wall carbon nanotube fibres continuously spun without promoter, Scientific reports 4 .

[200] Z. Ristovski, E. Jayaratne, M. Lim, G. A. Ayoko, L. Morawska, Influence of diesel fuel sulfur on nanoparticle emissions from city buses, Environmental science \& technology 40 (4) (2006) 13141320 .

[201] H. Ma, H. Jung, D. B. Kittelson, Investigation of diesel nanoparticle nucleation mechanisms, Aerosol Science and Technology 42 (5) (2008) 335-342.

[202] P. Karjalainen, T. Rönkkö, L. Pirjola, J. Heikkilä, M. Happonen, F. Arnold, D. Rothe, P. Bielaczyc, J. Keskinen, Sulfur driven nucleation mode formation in diesel exhaust under transient driving conditions, Environmental science \& technology 48 (4) (2014) 2336-2343.

[203] J. Lee, K. Morita, Effect of carbon and sulphur on the surface tension of molten iron, Steel research 73 (9) (2002) 367-372.

[204] H. Ur Rahman Memon, A. Williams, P. T. Williams, Shock tube pyrolysis of thiophene, International journal of energy research 27 (3) (2003) 225-239. 
[205] M. Motta, A. Moisala, I. Kinloch, A. Windle, The role of sulphur in the synthesis of carbon nanotubes by chemical vapour deposition at high temperatures, Journal of nanoscience and nanotechnology 8 (5) (2008) 2442-2449.

[206] C. Wu, V. Sahajwalla, Dissolution rates of coals and graphite in fe-cs melts in direct ironmaking: Influence of melt carbon and sulfur on carbon dissolution, Metallurgical and materials Transactions B 31 (2) (2000) 243-251.

[207] K. Gao, V. Sahajwalla, H. Sun, C. Wheatley, R. Dry, Influence of sulfur content and temperature on the carbon boil and co generation in fe-cs drops, ISIJ international 40 (4) (2000) 301-308.

[208] H. Sun, K. Gao, V. Sahajwalla, K. Mori, R. D. Pehlke, Kinetics of gas oxidation of liquid fe-cs alloys and carbon boil phenomenon, ISIJ international 39 (11) (1999) 1125-1133.

[209] T. Ramanarayanan, The interaction of carbon and sulfur with iron-base alloys in predominantly carburizing environments, Materials Science and Engineering 87 (1987) 113-118.

[210] J. Zhang, C. M. Megaridis, Iron/soot interaction in a laminar ethylene nonpremixed flame, in: Symposium (International) on Combustion, Vol. 25, Elsevier, 1994, pp. 593-600.

[211] T. Hirasawa, C.-J. Sung, Z. Yang, A. Joshi, H. Wang, Effect of ferrocene addition on sooting limits in laminar premixed ethylene-oxygenargon flames, Combustion and Flame 139 (4) (2004) 288-299.

[212] D. R. Lide, et al., CRC handbook of chemistry and physics, CRC Boca Raton, 2012.

[213] F. Ding, A. Rosén, K. Bolton, Size dependence of the coalescence and melting of iron clusters: A molecular-dynamics study, Physical Review B 70 (7) (2004) 075416.

[214] F. Benissad, P. Gadelle, M. Coulon, L. Bonnetain, Formation de fibres de carbone a partir du methane: I croissance catalytique et epaississement pyrolytique, Carbon 26 (1) (1988) 6169.

[215] F. Tafwidli, Y.-B. Kang, Thermodynamic modeling of fe- ${ }^{-}-\mathrm{s}$ ternary system, ISIJ International 57 (5) (2017) 782-790.

[216] H. Yin, M. Suzuki, T. Emi, Interfacial properties of dilute fe-os melts on alumina substrates, ISIJ international 38 (3) (1998) 229-238.

[217] W. Ren, F. Li, H.-M. Cheng, Evidence for, and an understanding of, the initial nucleation of carbon nanotubes produced by a floating catalyst method, The Journal of Physical Chemistry B 110 (34) (2006) 16941-16946.
[218] J. Wei, H. Zhu, Y. Jia, Q. Shu, C. Li, K. Wang, B. Wei, Y. Zhu, Z. Wang, J. Luo, et al., The effect of sulfur on the number of layers in a carbon nanotube, Carbon 45 (11) (2007) 2152-2158.

[219] N. Matsumoto, A. Oshima, S. Ishizawa, G. Chen, K. Hata, D. N. Futaba, One millimeter per minute growth rates for single wall carbon nanotube forests enabled by porous metal substrates, RSC Advances 8 (14) (2018) 7810-7817.

[220] G. Chen, R. C. Davis, H. Kimura, S. Sakurai, M. Yumura, D. N. Futaba, K. Hata, The relationship between the growth rate and the lifetime in carbon nanotube synthesis, Nanoscale 7 (19) (2015) 8873-8878.

[221] L. Zheng, M. O'connell, S. Doorn, X. Liao, Y. Zhao, E. Akhadov, M. Hoffbauer, B. Roop, Q. Jia, R. Dye, et al., Ultralong single-wall carbon nanotubes, Nature materials 3 (10) (2004) 673.

[222] A. A. Puretzky, D. B. Geohegan, S. Jesse, I. N. Ivanov, G. Eres, In situ measurements and modeling of carbon nanotube array growth kinetics during chemical vapor deposition, Applied Physics A 81 (2) (2005) 223-240.

[223] S. Suzuki, S. Mori, Promoted growth of carbon nanotubes by sulfur addition in chemical vapor deposition shown via arrhenius law, Diamond and Related Materials 89 (2018) 74-83.

[224] V. I. Artyukhov, E. S. Penev, B. I. Yakobson, Why nanotubes grow chiral, Nature Communications 5 (2014) 4892.

[225] E. S. Penev, K. V. Bets, N. Gupta, B. I. Yakobson, Transient kinetic selectivity in nanotubes growth on solid co-w catalyst, Nano letters 18 (8) (2018) 5288-5293.

[226] B. Yu, C. Liu, P.-X. Hou, Y. Tian, S. Li, B. Liu, F. Li, E. I. Kauppinen, H.-M. Cheng, Bulk synthesis of large diameter semiconducting single-walled carbon nanotubes by oxygenassisted floating catalyst chemical vapor deposition, Journal of the American Chemical Society 133 (14) (2011) 5232-5235.

[227] K. Hata, D. N. Futaba, K. Mizuno, T. Namai, M. Yumura, S. Iijima, Water-assisted highly efficient synthesis of impurity-free single-walled carbon nanotubes, Science 306 (5700) (2004) 13621364 .

[228] D. N. Futaba, K. Hata, T. Yamada, K. Mizuno, M. Yumura, S. Iijima, Kinetics of water-assisted single-walled carbon nanotube synthesis revealed by a time-evolution analysis, Physical review letters 95 (5) (2005) 056104. 
[229] T. Yamauchi, K. Nagamatsu, Y. Karayama, M. Naitoh, S. Nishigaki, H. Okado, Influence of oxygen on the growth of carbon nanotubes by the sic surface decomposition method, Applied Surface Science 256 (4) (2009) 930-933.

[230] Y.-C. Chou, H.-C. Wu, C.-K. Hsieh, From graphene to carbon nanotube: The oxygen effect on the synthesis of carbon nanomaterials on nickel foil during cvd process, Japanese Journal of Applied Physics 55 (1S) (2015) 01AE12.

[231] G. Zhang, D. Mann, L. Zhang, A. Javey, Y. Li, E. Yenilmez, Q. Wang, J. P. McVittie, Y. Nishi, J. Gibbons, et al., Ultra-high-yield growth of vertical single-walled carbon nanotubes: Hidden roles of hydrogen and oxygen, Proceedings of the National Academy of Sciences of the United States of America 102 (45) (2005) 16141-16145.

[232] M. Motta, Y.-L. Li, I. Kinloch, A. Windle, Mechanical properties of continuously spun fibers of carbon nanotubes, Nano letters 5 (8) (2005) 1529-1533.

[233] M. A. Oehlschlaeger, D. F. Davidson, R. K. Hanson, Thermal decomposition of toluene: Overall rate and branching ratio, Proceedings of the Combustion Institute 31 (1) (2007) 211-219.

[234] G. E. Davico, V. M. Bierbaum, C. H. DePuy, G. B. Ellison, R. R. Squires, The ch bond energy of benzene, Journal of the American Chemical Society 117 (9) (1995) 2590-2599.

[235] J. Zheng, T. Yu, D. G. Truhlar, Multi-structural thermodynamics of $\mathrm{c}-\mathrm{h}$ bond dissociation in hexane and isohexane yielding seven isomeric hexyl radicals, Physical Chemistry Chemical Physics 13 (43) (2011) 19318-19324.

[236] G. Ingram, S. Rizvi, The pyrolytic identification of organic molecules: Iii. a mechanistic approach, Microchemical Journal 19 (3) (1974) 253-271.

[237] Y.-R. Luo, Comprehensive handbook of chemical bond energies, CRC press, 2007.

[238] R. M. Sundaram, A. H. Windle, Effect of carbon precursors on the structure and properties of continuously spun carbon nanotube fibers, Science of Advanced Materials 7 (4) (2015) 643-653.

[239] B. Capelin, G. Ingram, J. Kokolis, The pyrolytic identification of organic molecules: Ii. a quantitative evaluation, Microchemical Journal 19 (3) (1974) 229-252.

[240] J. Park, R. Zhu, M. Lin, Thermal decomposition of ethanol. i. ab initio molecular orbital/riceramsperger-kassel-marcus prediction of rate constant and product branching ratios, The Journal of chemical physics 117 (7) (2002) 32243231 .
[241] H. Sugime, S. Noda, S. Maruyama, Y. Yamaguchi, Multiple "optimum" conditions for $\mathrm{CO}^{-}$ mo catalyzed growth of vertically aligned singlewalled carbon nanotube forests, Carbon 47 (1) (2009) 234-241.

[242] R. Xiang, B. Hou, E. Einarsson, P. Zhao, S. Harish, K. Morimoto, Y. Miyauchi, S. Chiashi, Z. Tang, S. Maruyama, Carbon atoms in ethanol do not contribute equally to formation of singlewalled carbon nanotubes, ACS nano 7 (4) (2013) 3095-3103.

[243] G. Ingram, S. Rizvi, The pyrolytic identification of organic molecules: Iv. the pyrolytic behavior of the isomeric butanols, Microchemical Journal 20 (3) (1975) 324-352.

[244] G. Eres, A. A. Kinkhabwala, H. Cui, D. B. Geohegan, A. A. Puretzky, D. H. Lowndes, Molecular beam-controlled nucleation and growth of vertically aligned single-wall carbon nanotube arrays, The Journal of Physical Chemistry B 109 (35) (2005) 16684-16694.

[245] G. Zhong, S. Hofmann, F. Yan, H. Telg, J. Warner, D. Eder, C. Thomsen, W. Milne, J. Robertson, Acetylene: a key growth precursor for single-walled carbon nanotube forests, The Journal of Physical Chemistry C 113 (40) (2009) 17321-17325.

[246] K. Kuwana, T. Li, K. Saito, Gas-phase reactions during cvd synthesis of carbon nanotubes: Insights via numerical experiments, Chemical engineering science 61 (20) (2006) 6718-6726.

[247] G. G. Tibbetts, Carbon fibers produced by pyrolysis of natural gas in stainless steel tubes, Applied physics letters 42 (8) (1983) 666-668.

[248] J. Kong, H. T. Soh, A. M. Cassell, C. F. Quate, H. Dai, Synthesis of individual single-walled carbon nanotubes on patterned silicon wafers, Nature 395 (6705) (1998) 878.

[249] C.-J. Chen, M. Back, R. Back, Mechanism of the thermal decomposition of methane, ACS Publications, 1976.

[250] A. Holmen, O. Rokstad, A. Solbakken, Hightemperature pyrolysis of hydrocarbons. 1. methane to acetylene, Industrial \& Engineering Chemistry Process Design and Development 15 (3) (1976) 439-444.

[251] A. Emelianov, A. Eremin, V. Golub, E. Gurentsov, V. Fortov, Energy gain at pyrolysis and combustion of acetylene.

[252] S. K. Pillai, S. S. Ray, M. Moodley, Purification of multi-walled carbon nanotubes, Journal of nanoscience and nanotechnology 8 (12) (2008) 6187-6207. 
[253] P. Liu, D. C. Hu, T. Q. Tran, D. Jewell, H. M. Duong, Electrical property enhancement of carbon nanotube fibers from post treatments, Colloids and Surfaces A: Physicochemical and Engineering Aspects 509 (2016) 384-389.

[254] G. G. Tibbetts, C. A. Bernardo, D. W. Gorkiewicz, R. L. AliG, Role of sulfur in the production of carbon fibers in the vapor phase, Carbon 32 (4) (1994) 569-576.

[255] C.-H. Kiang, M. Dresselhaus, R. Beyers, D. Bethune, Vapor-phase self-assembly of carbon nanomaterials, Chemical physics letters 259 (1-2) (1996) 41-47.

[256] C.-H. Kiang, W. A. I. Goddard, R. Beyers, J. R. Salem, D. S. Bethune, Catalytic synthesis of single-layer carbon nanotubes with a wide range of diameters, The Journal of Physical Chemistry 98 (26) (1994) 6612-6618.

[257] T. Hoffmann, C. D. O’Dowd, J. H. Seinfeld, Iodine oxide homogeneous nucleation: An explanation for coastal new particle production, Geophysical Research Letters 28 (10) (2001) 19491952.

[258] M. Maalekian, The effects of alloying elements on steels (i).

[259] D.-H. Kim, M.-K. Paek, T.-J. Kim, S.-Y. Won, J.-J. Pak, Carbon solubility in liquid iron containing v, mo and ni, Materials Transactions 55 (3) (2014) 610-615.

[260] M. Fulem, K. Ržička, C. Červinka, M. A. Rocha, L. M. Santos, R. F. Berg, Recommended vapor pressure and thermophysical data for ferrocene, The Journal of Chemical Thermodynamics 57 (2013) 530-540.

[261] G. Waddington, J. Knowlton, D. Scott, G. Oliver, S. Todd, W. Hubbard, J. Smith, H. M. Huffman, Thermodynamic properties of thiophene, Journal of the American Chemical Society 71 (3) (1949) 797-808.

[262] G. Waddington, J. Smith, K. Williamson, D. Scott, Carbon disulfide as a reference substance for vapor-flow calorimetry; the chemical thermodynamic properties, The Journal of Physical Chemistry 66 (6) (1962) 1074-1077.

[263] J. G. Speight, et al., Lange's handbook of chemistry, Vol. 1, McGraw-Hill New York, 2005.

[264] D. R. Stull, Vapor pressure of pure substances. organic and inorganic compounds, Industrial \& Engineering Chemistry 39 (4) (1947) 517-540.

[265] L. Ci, J. Wei, B. Wei, J. Liang, C. Xu, D. Wu, Carbon nanofibers and single-walled carbon nanotubes prepared by the floating catalyst method, Carbon 39 (3) (2001) 329-335.
[266] D. Dilner, H. Mao, M. Selleby, Thermodynamic assessment of the $\mathrm{mn}-\mathrm{s}$ and fe-mn-s systems, Calphad 48 (2015) 95-105.

[267] P. Walder, A. Pelton, Thermodynamic modeling of the fe-s system, Journal of phase equilibria and diffusion 26 (1) (2005) 23-38.

[268] W. D. Callister, D. G. Rethwisch, Materials science and engineering, Vol. 5, John Wiley \& Sons NY, 2011. 